\title{
Nigeria: Poverty Reduction Strategy Paper- National Economic Empowerment and Development Strategy
}

Poverty Reduction Strategy Papers (PRSPs) are prepared by member countries in broad consultation with stakeholders and development partners, including the staffs of the World Bank and the IMF. Updated every three years with annual progress reports, they describe the country's macroeconomic, structural, and social policies in support of growth and poverty reduction, as well as associated external financing needs and major sources of financing. This country document for Nigeria is being made available on the IMF website by agreement with the member country as a service to users of the IMF website.

To assist the IMF in evaluating the publication policy, reader comments are invited and may be sent by e-mail to publicationpolicy@imf.org.

Copies of this report are available to the public from

International Monetary Fund • Publication Services

$70019^{\text {th }}$ Street, N.W. • Washington, D.C. 20431

Telephone: (202) 623-7430 • Telefax: (202) 623-7201

E-mail: publications@imf.org •Internet: http://www.imf.org

Price: $\$ 15.00$ a copy

\section{International Monetary Fund Washington, D.C.}





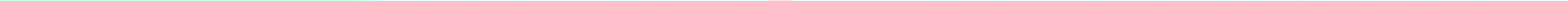




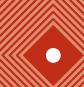

c.

$(-)$
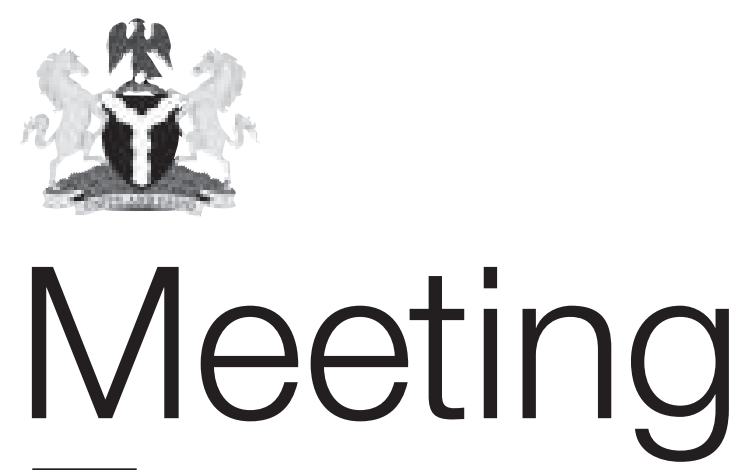
Everyone's Needs

National Economic Empowerment and Development Strategy

Nigerian National Planning Commission Abuja 2004 
C2004 Nigerian National Planning Commission Abuja, Nigeria

All rights reserved.

Editing and production by Communications Development Incorporated. Design by Grundy \& Northedge. Photographs by Chris Martin, Real World Photography.

ISBN 0-9741108-4-1 


\section{Foreword}

The National Economic Empowerment and Development Strategy (NEEDS) is the response to the development challenges of Nigeria. In 1999, most people grossly underestimated the extent of social, political, and economic decay of the country. Since 1999, we have succeeded in stabilizing the polity, consolidated the democratic governance structure, and made modest progress in the social and economic spheres. Over the next few years (2003-07), NEEDS will consolidate the achievements of the previous four years and lay a solid foundation for sustainable poverty reduction, employment generation, wealth creation, and value reorientation.

Nigeria has all it takes (human and material resources) to become the strongest economy in Africa - and one of the leading economies in the world in the longer term. The goal of NEEDS is to mobilize the resources of Nigeria to make a fundamental break with the failures of the past and bequeath a united and prosperous nation to generations to come.

I am particularly happy that if there is anything like a home-grown reform programme, NEEDS is it. For the first time, we embarked on an extensive consultative and participatory process, involving major stakeholders in the design of NEEDS. It is this national ownership, together with the results already visible, that will ensure the sustainability of the NEEDS beyond 2007. As we all know, it is only bad plans that do not allow for periodic amendments. NEEDS is a living document, and aspects of it may be modified in the light of implementation experiences. Nigerians have agreed, however, that the major thrusts of NEEDS are what Nigeria needs to move forward.

The reform programme is rightly ambitious. For one thing, we need focused goals and ambition to make progress. The programme reflects the impatience of Nigerians to see things change dramatically and also the fact that Nigeria has immense potential waiting to be unleashed, talents to be tapped. Having lost some decades, we are in haste to cover lost ground, catch up with our contemporaries, and become the largest and strongest economy in Africa. We are, however, mindful of the need to sequence the reforms to minimize the costs and preventable pitfalls while maximizing the benefits.

While we look forward to a better future under NEEDS, we are not unmindful of the long and difficult journey ahead. The economic and development agenda under NEEDS must of necessity be complemented by other reformsespecially in the electoral and political governance architecture that is consistent with deepening and sustaining democracy. The 
political class, legislature, and judiciary need to also think about and act on reforms so that we all can build a more sustainable future.

Some state governments have already designed and are implementing their own State Economic Empowerment and Development Strategy (SEEDS). Other states need to complete their own SEEDS as necessary complements to NEEDS. As the saying goes, if you fail to plan, you plan to fail. Medium-term planning also needs to be mainstreamed at the local government levels, and more effective accountability and transparency need to be instituted at the lower levels of government. For sustainable poverty reduction in Nigeria, the states and local governments also need serious reforms.

Finally, let me commend NEEDS to all Nigerians and to all stakeholders in the Nigerian economy. It is your plan: seize it with both hands. It should be our collective responsibility to ensure effective implementation and monitoring. Chapter 11 on implementation details the roles and responsibilities of everyone in ensuring effective implementation. Everyone has a role to play. If everyone plays it well, Nigeria will surely be great again-and soon. In my dreams I see a new Nigeria in the hands of God. As I traverse all parts of Nigeria, I feel a new Nigeria emerging. Let us therefore join hands and make Nigeria even better.

Olusegun Obasanjo, GCFR President, Federal Republic of Nigeria 


\section{Table of Contents}

Foreword iii
Preface vii
Overview viii

\section{Part One}

Vision and Macroeconomic Framework 1

Chapter 1

Statement of Vision, Values, and Principles 2

Chapter 2

The Development Challenges Facing Nigeria 7

Chapter 3

The Macroeconomic Framework 14

\section{Part Two}

Empowering People 26

Chapter 4

The Social Charter: Investing in the Nigerian People

\section{Part Three}

Promoting Private Enterprise $\quad 50$

Chapter 5

Creating a Competitive Private Sector 52

Chapter 6

Sectoral Strategies 67

Chapter 7

Regional Integration and Trade Policies

\section{Part Four}

Changing the Way the Government Does Its Work 84

Chapter 8

Creating a More Efficient and Responsive Public Sector 86

Chapter 9

Improving Security and the Administration of Justice 95

Chapter 10

Tackling Corruption and Promoting Transparency and Accountability

Chapter 11

Implementation and Financing 103

\section{Boxes \\ 1 The Kuru Declaration viii \\ 2 We Are Already Making Progress xii \\ 3 Maintaining the Environment xix \\ 1.1 Nigeria at a Glance 3}


1.2 The Kuru Declaration 5

2.1 Nigeria's Economy Is Improving 8

4.1 Measuring the Quality of Life: Comments by President Olusegun Obasanjo 29

5.1 Institutional and Administrative Reforms to Reduce the Cost of Doing Business 56

11.1 Allocation of the Federal Government Capital Budget to Priority Sectors 113

\section{Tables}

1 Targeted Instruments for Protecting Vulnerable Groups $\quad$ xvii

2 Selected Targets Under NEEDS, 2003-07 xxiv

2.1 Implications of Alternative Growth Scenarios for Key Development Indicators, 2000, 2015, 2030

3.1 Selected Macroeconomic Projections, 2003-07 15

4.1 Incidence of Poverty in Nigeria, Selected Years 31

4.3 Risks, At-Risk Groups, and Formal Responses 48

4.4 Targeted Instruments for Protecting Vulnerable Groups 49

8.1 Monetized Fringe Benefits for Federal Civil Servants 92

11.1 New Legislation Needed to Implement NEEDS 111

11.2 Aggregate Investment Projections, 2003-07 112

\section{Figures}

1 NEEDS at a Glance $x$

2 How NEEDS Will Be Implemented xxii

11.1 Institutional Framework for Implementing NEEDS 105

Abbreviations 118 


\section{Preface}

This is the first volume of the National Economic Empowerment and Development Strategy (NEEDS) working document. After two months of nationwide consultations and debates on the earlier draft document, it was substantially revised, as comments and contributions received from stakeholders and government officials were incorporated. The volume specifies the broad strategic thrusts, targets, and instruments of NEEDS, charting the overall direction of change, the destination, and how to get there. Volume II, the Implementation Guide, includes matrices of objectives, specific targets, implementation timelines, responsible agencies, and similar detail for each reform element described in this volume.

Work is still ongoing on some technical aspects of the strategy, especially on costing the programme; developing nationally coordinated sectoral strategies for agriculture, the environment, health, education, water, and infrastructure; and streamlining and rationalizing implementation agencies and the coordination framework. The federal ministries responsible for these issues will collaborate with the National Planning Commission, with the respective state government ministries, and with relevant stakeholders to develop the national sectoral strategies and project plans. National sectoral councils will play a critical role in this process. The output of these sector-wide strategies will feed into the revisions of the NEEDS document.

NEEDS provides a framework for a nationally coordinated programme of action by the federal, state, and local governments. Most of what is articulated here refers to actions by the federal government. However, with state and local governments controlling half of consolidated public sector spending, effective coordination among the tiers of government in the federation is key for success. Without state and local governments, federal programmes alone would amount to attempting to clap with one hand.

The importance of coordination was recognized very early in the development of NEEDS. Through the statutory organs for intergovernmental coordination (the National Economic Council, the National Council for Development Planning, and the Joint Planning Board), state governments not only endorsed the thrusts of NEEDS but also committed to developing State Economic Empowerment and Development Strategies (SEEDS).

The states also agreed on a minimum set of priorities that each state government must reflect in its SEEDS, namely, agriculture, small and medium-size enterprises, rehabilitation and maintenance of infrastructure (especially roads), and public finance reforms and transparency. The National Planning Commission is collaborating with donor agencies to provide technical assistance to the states in developing their SEEDS as a necessary complement to NEEDS. Using the Guidance Manual it prepared, the National Planning Council is organizing training workshops for the states in the six geopolitical zones of the country on preparing, monitoring, and evaluating state plans.

In addition, work will soon begin on a full Medium-Term Expenditure Framework and a clearly articulated Project Plan for the medium term. A policy matrix (indicating the status of each policy measure) is also being prepared.

The 2004 budget proposals already reflect some of the major thrusts of NEEDS. The sectors that are key to poverty reduction-health, education, electricity, roads, and water-received the highest priority in resource allocation, receiving about 60 percent of the total capital budget. 


\section{Overview}

NEEDS is Nigeria's

plan for prosperity

\section{What Is NEEDS?}

NEEDS—-the National Economic Empowerment and Development Strategy -is Nigeria's plan for prosperity. It is the people's way of letting the government know what kind of Nigeria they wish to live in, now and in the future. It is the government's way of letting the people know how it plans to overcome the deep and pervasive obstacles to progress that the government and the people have identified. It is also a way of letting the international community know where Nigeria stands-in the region and in the world-and how it wishes to be supported.

What is the vision for Nigeria? What kind of Nigeria do we want for ourselves, for our children, and for the rest of the world? These questions were our starting point in creating a plan for prosperity. In the three years it took to develop NEEDS, a dedicated team travelled the country, holding meetings and workshops to identify what the Nigerian people want for the future, what problems they face, and what can be done to overcome them.

NEEDS is the people's plan. It is up to regular Nigerians as well as the government to see that it is implemented.

\section{A Vision of Tomorrow's Nigeria}

The NEEDS vision is based on the Constitution; the Kuru Declaration (box 1); previous initiatives, such as Vision 2010; and the widespread consultation and participation throughout Nigeria that was part of the NEEDS process. The programme's core values draw on the Vision 2010 report, which recognized the importance of respect for elders, honesty and accountability, cooperation, industry, discipline, self-confidence, and moral courage.

Before the restoration of democracy, Nigeria suffered setbacks that tarnished its reputation. A primary aim of NEEDS is to create a new Nigerian citizen who values hard work and who realizes that one cannot have something for nothing. Achieving this aim may be the strongest action Nigeria can take to build a better future for its people.

\section{Box 1 The Kuru Declaration}

The 2001 Kuru Declaration embodies the vision we have for Nigeria: to build a truly great African democratic country, politically united, integrated and stable, economically prosperous, socially organized, with equal opportunity for all, and responsibility from all, to become the catalyst of (African) Renaissance, and making adequate all-embracing contributions, subregionally, regionally, and globally. 
Although Nigeria is rich in natural and human resources, 7 of every 10 Nigerians live on less than $\$ 1$ a day. NEEDS wishes to make poverty a thing of the past in Nigeria. It aims to create a Nigeria that Nigerians can be proud to belong to and grateful to inhabit, a Nigeria that rewards hard work, protects its people and their property, and offers its children better prospects than those they may be tempted to seek in Europe or the United States. All citizens, regardless of gender, race, religion, or politics, should feel that they have a stake in Nigeria's future and that their loyalty and diligence will be rewarded. The NEEDS vision is also one in which Nigeria fulfils its potential to become Africa's largest economy and a major player in the global economy.

\section{How Can NEEDS Help Realize This Vision?}

NEEDS focuses on four key strategies: reorienting values, reducing poverty, creating wealth, and generating employment. It is based on the notion that these goals can be achieved only by creating an environment in which business can thrive, government is redirected to providing basic services, and people are empowered to take advantage of the new livelihood opportunities the plan will stimulate (figure 1).

NEEDS sets out far-reaching public reforms that will make clear that corruption and graft will be punished. The National Orientation Agency and its state-level counterparts will be strengthened to lead a campaign to re-instil the virtues of honesty, hard work, selfless service, moral rectitude, and patriotism. The campaign will draw on resources from a variety of government agencies, nongovernmental organizations (NGOs), and community-based organizations, including schools colleges, universities, and private sector, religious, social, cultural, and traditional organizations.

NEEDS is about the Nigerian people. Their welfare, health, employment, education, political power, physical security, and empowerment are of paramount importance in realizing this vision of the future. To reduce poverty and inequality, the plan proposes acting on several fronts:

- Offering farmers improved irrigation, machinery, and crop varieties will help boost agricultural productivity and tackle poverty head on, since half of Nigeria's poor people work in agriculture.

Supporting small and medium-size enterprises will help create jobs. Together with the state economic empowerment and development strategies (SEEDS), NEEDS seeks to implement an integrated rural development programme to stem the flow of migration from rural to urban areas.
NEEDS focuses on

four key strategies:

reorienting values,

reducing poverty,

creating wealth, and

generating

employment 


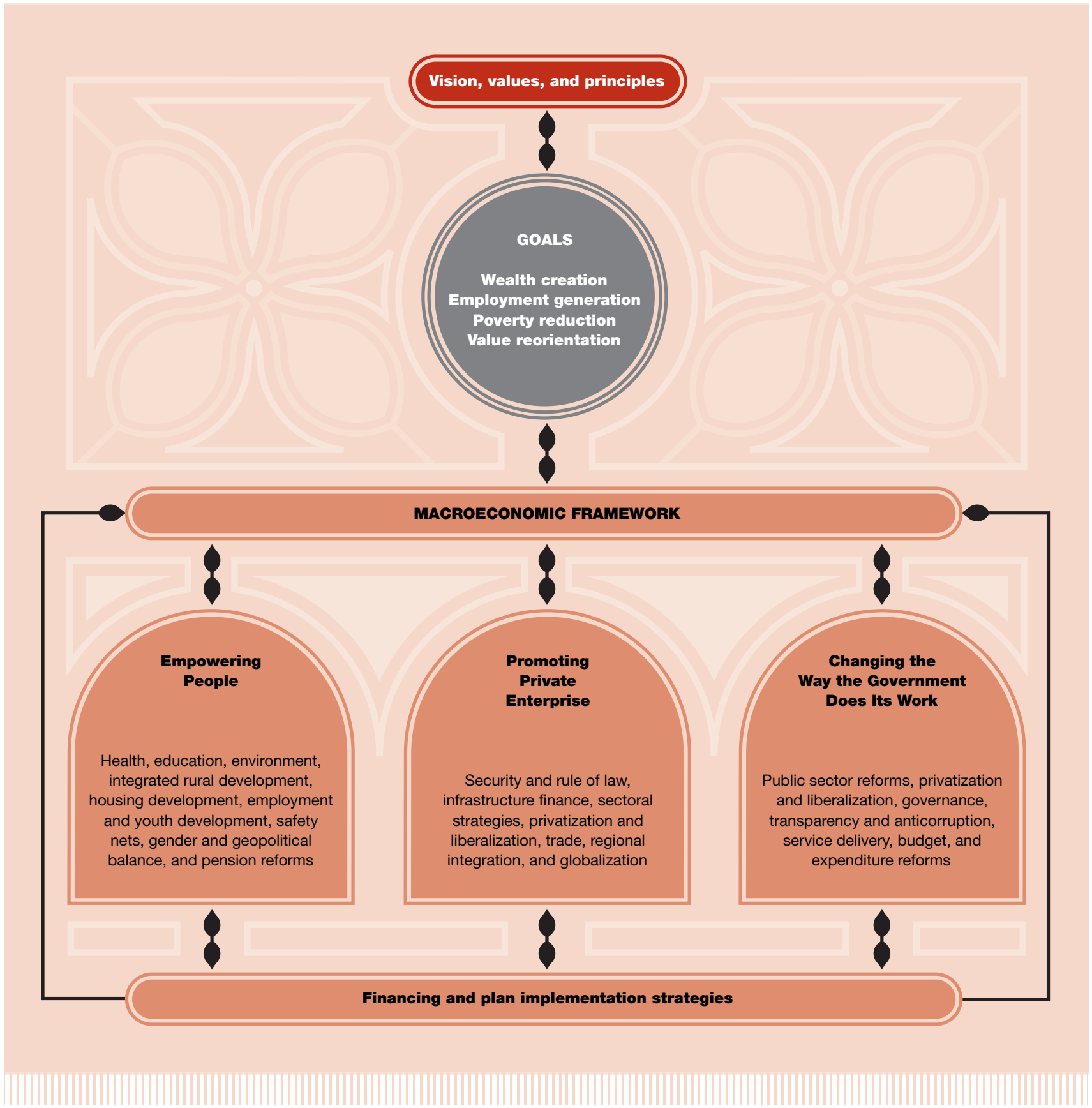


- Half of Nigeria's people are children, the bridge to a prosperous future. NEEDS recognizes the importance of children by making the improvement of the education system a top priority.

- HIV/AIDS is a major social and health problem. It also threatens the country's productivity and economy. The plan is to improve the system of health care delivery, with emphasis on HIV/AIDS and other preventable diseases, such as malaria, tuberculosis, and reproductive health-related illnesses.

- NEEDS calls for replacing the pension scheme, which is in crisis, with a contributory scheme. It proposes special programmes targeting people who have the weakest political voice and who are most vulnerable to the ravages of poverty. Laws and programmes will be implemented to empower women, children, the disabled, and the elderly.

NEEDS emphasizes the critical importance of improving infrastructure. More-and more reliable-electricity and a new and better maintained network of roads will encourage businesses to expand.

NEEDS gives special support to agriculture, industry, small and medium-scale enterprises, and oil and gas. Under the plan, the government will seek long-term capital for investment. Trade policy, so critical to Nigeria's stake in the regional economy, will be modified to unburden business of the red tape and complex procedures that hinder it from flourishing. NEEDS envisages forging stronger links between educational institutions and industry to stimulate rapid industrial growth and efficient exploitation of resources.

Empowering people. By allowing the private sector to thrive, NEEDS creates opportunities for employment and wealth creation. It empowers people to take advantage of these opportunities by creating a system of incentives that reward hard work and punish corruption, by investing in education, and by providing special programmes for the most vulnerable members of society.

Promoting private enterprise. The private sector will be the engine of economic growth under NEEDS. It will be the executor, investor, and manager of businesses. The government will play the role of enabler, facilitator, and regulator, helping the private sector grow, create jobs, and generate wealth. Deregulation and liberalization will diminish governmental control and attract private sector investment.

Changing the way the government does its work. NEEDS aims to restructure the government to make it smaller, stronger, better skilled, and more efficient at delivering essential services. It seeks to transform the government from a haven of corruption to an institution that spurs development and serves the people.

The number of government jobs will decline, and the cost of running the government will fall dramatically, as in-kind benefits for civil servants, such as subsidized housing, transport, and utilities, are monetized. Reforms and regulations will be implemented to ensure greater transparency and accountability, and corrupt practices will be outlawed. Government activities and budgeting will be informed by a framework that connects policy with government income and expenditure.

\section{Our Future, Our Plan}

NEEDS is a development plan like no other ever seen in Nigeria. It identifies the major problems we face today and suggests how we can begin

\section{NEEDS aims to}

restructure the

government to make it

smaller, stronger,

better skilled, and

more efficient at

delivering essential

services 


\section{Box 2 We Are Already Making Progress}

NEEDS builds on the progress made between 1999 and 2003. It used the information and insights generated during the two-year effort to prepare the Interim Poverty Reduction Strategy Paper and the wide consultative and participatory processes associated with it.

The government has already delivered significant benefits.

International relations

- Nigeria has reintegrated with the regional and international community.

NEEDS differs from

earlier development

plans in three important

ways

- It is the people's plan

for prosperity

- It coordinates action

at the federal and

state levels

- It is a feasible plan

- Electricity generation in Nigeria has doubled since 1999.
- The number of telephone lines rose from just 400,000 in 1999 to about 3 million in 2003.

Economic development

- Government support to agriculture has boosted productivity. According to the UN Food and Agriculture Organization, Nigerian agriculture grew an unprecedented 7 percent in 2003.

- Industrial capacity more than doubled, from 29 percent in 1999 to 60 percent in 2003.

- Income grew at an average rate of 3.6 percent between 1999 and 2003-a significant increase over the 2.8 percent rate of growth during the 1990s.

- Unemployment fell from 18 percent in 1999 to 10.8 percent in 2003, and 3.5 million new jobs were created.

- Foreign direct investment in the nonoil sector grew at an average annual rate of 3.6 percent between 1999 and 2003.

Security

- The police force doubled in size between 1999 and 2003. Infrastructure development

The government is committed to consolidating and expanding these achievements under NEEDS.

through commercial enterprises and communitybased organizations. Using this framework, it can check the progress it is making against the targets set out in NEEDS.

\section{How Is This Plan Different?}

NEEDS differs from earlier development plans in three important ways. First, it really is the people's plan for prosperity. Our government wrote the plan, using the information it collected from the Nigerian people.

Past development plans have been made without sound knowledge of the causes of poverty. Before drafting this plan, for the first time the government investigated how ordinary 
Nigerians live. The process began in 2001, when people from all walks of life and all parts of Nigeria were given the chance to tell the government about their needs and ambitions. Information collected from farmers, labourers, factory owners, teachers and university professors, communitybased organizations, charities, and other stakeholders was used to draft an Interim Poverty Reduction Strategy Paper.

NEEDS builds on the information gathered for that strategy paper. We continued to consult with stakeholders in preparing the first draft of NEEDS. The government circulated the draft plan in April 2004, asking the people who took part in earlier consultations for their comments. This process gives us confidence that the final version of NEEDS reflects the true feelings of the Nigerian people about where the country stands today and how it should develop and grow over the next three years.

Second, NEEDS coordinates action at the federal and state levels. It connects problems on the ground with programmes at the federal and state levels. Each state drafts it own SEEDS, which identifies priority programmes for key areas of development.

This coordination is critically important when it comes to financing development programmes. For the first time in Nigeria, government and key beneficiaries will work at the national level to develop sector-wide strategies for key sectors, including agriculture, solid minerals, and small and medium-scale enterprises. The federal government will be able to budget accurately for development programmes at the national and state levels.

Finally, NEEDS is a feasible plan. The fact that Nigerians have spent so much time and effort giving their views allowed the drafting committee to write a plan based on a thorough understanding of what life is like for people at all levels of society. The targets for progress are realistic, not "pie in the sky" objectives that will never be achieved. The targets are achievable, because they were set after taking into account the extent of the problems, the skills and funds needed to address them, and the amount of funding and expertise that can be mobilized over the next three years.

\section{What Prevents Progress?}

Despite great natural wealth, Nigeria is poor and social development is limited. If present trends continue, the country is not likely to meet the Millennium Development Goals.

Three main problems hamper progress:

- Not all our people enjoy the same chance of prosperity.

- Past governments in Nigeria, instead of focusing on delivering essential public services, assumed control of major sources of national income. In the process, corruption thrived in public service and gained a strong foothold in society.

- The environment in Nigeria is hostile to private enterprise, not one that helps businesses generate jobs and create wealth.

\section{Poverty and Inequality}

The plan for prosperity must address a startling paradox: more than two-thirds of the Nigerian people are poor, despite living in a country with vast potential wealth. Although revenues from crude oil have been increasing over the past decades, our people have been falling deeper into poverty. In 1980 an estimated 27 percent of Nigerians lived in poverty. By 1990, 70 percent of the population had income of less than $\$ 1$ a day-
The plan for prosperity

must address a

startling paradox:

more than two-thirds

of the Nigerian people

are poor, despite living

in a country with vast

potential wealth 
Perhaps the greatest

hindrance to progress

has been the boom-

and-bust mode of

economic

management,

encouraged by the

dominance of oil in

the economy and the figure has risen since then. Poverty levels vary across the country, with the highest

proportion of poor people in the northwest and the lowest in the southeast.

Why are so many of our people poor? Poverty is dynamic and has many dimensions. People may move in and out of poverty as a result of natural disasters or health problems, lack access to credit, or the lack of natural resources. Poor people are more likely to live in rural areas, be less educated, and have larger families than the rest of the population.

Poverty has many causes, all of which reinforce one another. One source of poverty is the lack of basic services, such as clean water, education, and health care. Another is lack of assets, such as land, tools, credit, and supportive networks of friends and family. A third is lack of income, including food, shelter, clothing, and empowerment (political power, confidence, dignity). Some of these factors directly affect poverty. Others contribute indirectly, by producing inequality_-by stifling the political power of certain sectors of the population, for example, or denying them their dignity or human rights. All of these factors are affected by the environment in which people live. Discrimination on the grounds of gender, race, disability, age, or ill health increase vulnerability to poverty. So do natural or human-caused shocks-market collapses, conflicts, droughts, or floods.

The many strands of poverty intertwine and can pull people into a downward spiral. Because tackling one factor may not be enough to lift a family out of poverty, an effective povertyreduction strategy must attack poverty on all fronts at the same time. Poverty is not the same as inequality, but solving the problems of inequality can help lift people out of poverty. One of the key ways in which NEEDS is different from previous development plans is that it relies on a holistic view of the social and economic challenges facing Nigeria and offers a multipronged approach to tackling them.

\section{Weak and Inappropriate Public Sector}

Nigeria's legacy of mismanagement and corrupt governance has encouraged many people to seek ways of sharing the national cake instead of helping bake it. By 1999 corruption was practically institutionalized. Government was widely regarded as a provider of large contracts, distributed by officers in power to people wealthy enough to buy their influence. This was particularly so in the case of the oil industry. Over time, the judiciary became intimidated, as the rich and powerful manipulated laws and regulations to their advantage. Instead of engaging in productive activities that would help our economy grow, people chose instead to peddle their influence and position. The legitimacy and stability of the state suffered, as people began to devise ways to survive that lay outside the law.

\section{Poor Economic Management}

Perhaps the greatest hindrance to progress has been the boom-and-bust mode of economic management, encouraged by the dominance of oil in the economy. Past governments allowed oil income to influence spending: when income was high, spending was high, while dips in oil prices were treated as temporary. Together with poor coordination between federal and state governments in budgeting and expenditure, this practice led to spiralling debt. Today all tiers of government spend far more than they earn: the deficit for the past five years alone amounts to more than $\sharp 1$ trillion. With external and domestic debt of 70 percent of GDP, current revenue is largely eaten up just by debt service. 
Nigeria has one of the weakest economies in the world, and it has lost decades of development as a result of slow economic growth. Despite oil export earnings of about $\$ 300$ billion since the mid-1970s, average income in 2000 was 20 percent lower than in 1975. Despite the mounting debt burden, past governments did not control public expenditure. Policies were not coordinated within federal departments or between federal and state governments. As a result, the national plan and budget have little relevance today as a guide to funding and implementing development programmes.

\section{Hostile Environment for Private Sector Growth}

Overdependence on oil and traditional sectors, such as agriculture and services, is partly due to the hostile business environment. Businesses wishing to operate in Nigeria face many constraints, including poor infrastructure, particularly road networks and electricity supply; inadequate physical security; corruption; weak enforcement of contracts, and the high cost of finance. These factors have deterred foreign entrepreneurs from investing in Nigeria and induced many Nigerians to take their money and skills abroad.

\section{How Will NEEDS Change Things?}

The success of NEEDS rests on three pillars: empowering our people, creating a legal and financial environment that enables us to make the most of our natural resources and flair for business, and reforming our laws and the way our government works. Remove or weaken any of these three pillars and NEEDS will topple, just like a threelegged stool will fall if any of its legs is removed.

\section{Empowering People}

Meeting the needs of our people and nation is the primary aim of the plan for prosperity. NEEDS insists that every Nigerian has the right to adequate water and sanitation, nutrition, clothing, shelter, basic education, and health care, as well as physical security and the means of making a living. NEEDS proposes a contract between the Nigerian people and their government in the form of a social charter, or bargain. This charter recognizes the people's rights to government services that provide basic needs for life. In return, the people agree to work hard and honestly to make NEEDS a success. In formalizing the contract between the people and the government, NEEDS empowers the people to challenge the government if it does not keep its side of the bargain.

NEEDS recognizes that poverty has many strands and must therefore be tackled from several different directions at once. It recognizes that the government must work not only to improve incomes but to tackle the many other social and political factors that contribute to poverty. These are very difficult to separate and are therefore often thought of as a bundle of factors that result in social exclusion. A poorly educated farmer is less likely to know how to keep his family healthy and less able to find alternative employment. As a result, he is more vulnerable to external shocks, such as drought or falling market prices. NEEDS empowers the poor by tackling social exclusion head on, paying particular attention to generating jobs to improve incomes, housing, health care, education, political power, and physical security.

To improve the lives of the Nigerian people, NEEDS includes plans for creating jobs, creating affordable housing, improving health care services, strengthening the skill base, protecting the vulnerable, and promoting peace and security.
NEEDS recognizes that

the government must

work not only to

improve incomes but

to tackle the many

other social and

political factors that

contribute to poverty

and social exclusion 
Nigeria's future

prosperity depends on

producing children

who are well prepared

to take their place in

tomorrow's society
Creating jobs. At 5.3 percent, the rate of urbanization in Nigeria is among the highest in the world. Since manufacturing is stagnant, there are few jobs for the growing urban population, and urban unemployment is currently estimated at 10.8 percent. The major focus of NEEDS is therefore economic empowerment. NEEDS policies will create about 7 million new jobs by 2007 by making it easier for private enterprises to thrive, by training people in skills relevant for the world of work, and by promoting integrated rural development in collaboration with the states (through their SEEDS programmes).

Creating affordable housing. Nigeria needs more houses that average Nigerians can afford. To address the problem, NEEDS will take several steps:

- Make it easier for developers to buy land on which to build affordable housing.

- Cut the cost of building houses by encouraging the use of local building materials.

- Train a new generation of architects in designing low-cost housing.

- Enable construction companies and local and state governments to assume responsibility for providing low-cost housing.

Improving health care services. NEEDS will fully review health care services in order to design a strong national health system that can deliver effective, good-quality, and affordable services to all Nigerians. The new policies will target priority diseases, such as malaria, tuberculosis, HIV/AIDS, and reproductive health-related illnesses. A stronger emphasis on health education will help make Nigerians more aware of their rights and obligations regarding health services as well as promote disease prevention.
NEEDS will also prioritize the creation of a National Health Insurance Scheme and a Blood Transfusion Service. It will support the establishment of a strong manufacturing base for essential drugs and reagents. Antenatal, postnatal, and family planning services and outlets will receive targeted support in order to reduce maternal and infant mortality.

Strengthening the skill base. Nigeria's future prosperity depends on producing children who are well prepared to take their place in tomorrow's society. The NEEDS strategy therefore seeks to implement the Universal Basic Education law in order to increase school enrolment and provide better schools and colleges and better-trained teachers and trainers. Specifically, NEEDS will ensure that more funds are spent on:

- Providing courses that build vocational and entrepreneurial skills

- Building technical schools and buying equipment

- Improving training and exposure to information and communication technology at all levels

- Making French compulsory from primary through secondary schools

- Providing special distance learning programmes for specific segments of the population, including nomadic peoples.

NEEDS will promote strict adherence to the University Autonomy Act, which permits universities to attract private-sector funding and institute new mechanisms to cover their operating costs. The courses taught at universities will be changed to reflect the priority demands of the economy. Science and technology, particularly information and communications technology, will be mainstreamed. Innovative approaches will be developed to ensure that lecturers have access to 
continuing professional development so that they remain at the cutting edge of their disciplines. Wages will be linked to performance, and students will be exposed to mobilization and reorientation campaigns that emphasize the critical importance of hard work, discipline, and selfless service.

Protecting the vulnerable. In addition to these comprehensive measures, special attention must be paid to particularly vulnerable groups. NEEDS provides a safety net that will prevent people from becoming poor or poorer. Special programmes will protect the rural and urban poor, people living with HIV/AIDS, women, widows and widowers, and victims of ethnic violence, crime, unemployment, or loss of income (table 1).

Promoting peace and security. To promote peace and security, a national action plan will:

- Reform the security sector.
- Reorient police officers to offer more people-friendly service.

- Establish an early warning and response system that will detect conflicts.

- Provide a fairer allocation of revenues and responsibilities between federal and state governments.

- Mainstream conflict prevention by establishing structures and processes that promote a peaceful culture.

\section{Promoting Private Enterprise}

If the private sector is to become Nigeria's engine of growth, its motor needs to be primed. The government has to make certain fundamental changes to create an environment in which business will thrive. In the language of economists, it has to create a macroeconomic framework - a kind of overarching, national housekeeping budget - that will ensure that Nigeria makes the most of what it earns as a

\section{Table $1 \quad$ Targeted Instruments for Protecting Vulnerable Groups}

\begin{tabular}{|c|c|}
\hline Group & Instruments and interventions \\
\hline Rural poor & $\begin{array}{l}\text { Access to credit and land; participation in decisionmaking; agricultural extension services; } \\
\text { improved seeds, farm inputs, and implements; strengthening of traditional thrift, savings, } \\
\text { and insurance schemes }\end{array}$ \\
\hline Urban poor & $\begin{array}{l}\text { Labour-intensive public works schemes; affordable housing, water, and sanitation; skill } \\
\text { acquisition and entrepreneurial development; access to credit; scholarships and adult } \\
\text { education }\end{array}$ \\
\hline Women & $\begin{array}{l}\text { Affirmative action (to increase women's representation to at least } 30 \text { percent) in all } \\
\text { programmes; education, including adult education; scholarships; access to credit and } \\
\text { land; maternal and child health }\end{array}$ \\
\hline Youth & $\begin{array}{l}\text { Education, entrepreneurial development, skill acquisition, access to credit, prevention and } \\
\text { control of HIV/AIDS and other sexually transmitted diseases }\end{array}$ \\
\hline Children & $\begin{array}{l}\text { Children's Parliament, juvenile justice administration, universal basic education, education } \\
\text { for girls, care of orphans and vulnerable children (children affected by HIV/AIDS), } \\
\text { prevention and treatment of childhood diseases }\end{array}$ \\
\hline Rural communities & Water, rural roads, electricity, schools, health facilities, communications \\
\hline
\end{tabular}

If the private sector is

to become Nigeria's

engine of growth, its

motor needs to be

primed 
Simply providing more

and more reliable

power could triple the

amount Nigerian

industries produce by

2007 nation, that it spends only what it can afford, and that all levels of government use the same budget.

NEEDS proposes that the government not spend more than it takes in, not pay for unbudgeted programmes or projects, not purchase goods or services that do not contribute to Nigeria's development. It also suggests increasing taxes to pay for basic services. Under NEEDS the government will try to stabilize the value of the naira and create a system to ensure that it has sufficient foreign exchange to buy the goods it needs from other countries.

Under NEEDS, the government will:

- Diversify the economy away from oil and solid minerals in order to increase economic stability and generate jobs.

- Privatize, deregulate, and liberalize publicly owned industries to promote competition, expand industries, generate employment, create wealth, and receive value for money.

- Develop infrastructure, particularly power generation, transport, and telecommunications infrastructure, to stimulate growth of the private sector.

NEEDS proposes the following strategies to stabilize and rationalize public spending, increase domestic savings and private investments, and address the issue of public debt:

- Adopt a medium-term expenditure framework to ensure predictable and sustainable public financing at all levels of government.

- Implement tax reforms to increase revenues.

- Enact a Fiscal Responsibility Pact to ensure the coordination of government expenditure across all tiers of government.

- Adopt an oil price-based fiscal rule and a fund for excess revenues from crude oil sales.
- Adopt a public expenditure rule that prohibits the deficit from exceeding 3 percent of GDP.

Many of Nigeria's laws and regulations stifle private enterprise. NEEDS seeks to simplify import and export procedures to make importing and exporting a less daunting prospect and to increase the turnover of businesses in the sector. The reform programme will also:

- Increase access to credit.

- Implement a coherent and consistent trade policy.

- Implement the comprehensive tax reform bill to eliminate multiple taxation and remove barriers to the growth of a vibrant private sector.

- Hold regular dialogue with private sector operators and participate in economic planning based on market principles.

- Grant land use rights and facilitate private sector development in the area of social and environmental responsibility (box 3).

- Empower indigenous small and mediumsize enterprises by imposing minimum quotas for local produce in tendering and procurement processes.

Improving infrastructure. Reforms in the transport sector aim to complete the 3,000kilometre network of roads and strengthen the Roads Maintenance Agency, which oversees the repair and rehabilitation of some 500 roads. The government aims to develop the country's sea ports to handle modern shipping activities, upgrade the railways, and achieve total radar coverage of Nigerian airspace.

Power alone accounts for 5 percent of new business start-up costs. Simply providing more and more reliable power could triple the amount Nigerian industries produce by 2007 . Under 


\section{Box 3 Maintaining the Environment}

Nigeria is endowed with a rich and diverse natural environment, but over the years it has reaped its riches with insufficient care for the livelihoods and well-being of future generations. NEEDS will address several areas of concern:

- Waste production and disposal. Development has proceeded with no regard for waste management or pollution control. Cities have inadequate systems for the safe disposal and treatment of waste. As rural emigration to urban areas grows, the problem worsens.

- Deforestation. Some 92,000 hectares-a quarter of our land-was once covered in forest. Today just half of our forests remain, and the potential for their future exploitation is extremely limited.

Deforestation has been followed by erosion and desertification in some areas.
- Conservation of unique habitats. Nigeria has twothirds of Central Africa's mangrove stands and wetlands. These are among the most important mangrove habitats in the world, but they are under threat from exploitation of timber, oil spills, gas flaring, and the impacts of increasing coastal urbanization.

- Pollution and other problems. Our environmental laws are inadequate and are not enforced. We do not know how much biodiversity has been lost as a result of oil and gas development.

NEEDS aims to turn this bleak picture around by establishing a regulatory agency to enforce environmental laws, monitor industry compliance, conduct environmental audits and impact assessments, and set standards. NEEDS seeks to develop a private-public sector partnership scheme to address the increasing problems of waste management.

enterprises. These enterprises will be developed in science and technology parks and technology incubation centres. They will focus on food processing, industrial chemicals, information and communication technologies, biotechnology, electronics and space technology, and energy, oil, and gas.

A major policy thrust of NEEDS is the idea that Nigeria should stop squandering its natural resources by selling them as crude products. The more these products can be processed within Nigeria, the more jobs they will create and the more export earnings they will generate. NEEDS sets ambitious targets for the sector: 7 percent annual growth, 70 percent capacity utilization, and 70 percent of investment made by the private sector by 2007. the industrial sector by relying more on local resources and less on imports. It will be guided by a local research and development strategy that seeks to promote science and technology-based small and medium-size
Improving agriculture. Agriculture is Nigeria's second-largest source of national wealth, after oil. NEEDS will promote the cultivation of improved,
Changing the way the

government works is

a colossal task, but

NEEDS will build on

processes that have

already begun to

make a difference 
higher yielding crop varieties and provide extra support to agricultural research and training. NEEDS aims to encourage business interests to provide credit and supply and distribute agricultural inputs, such as seeds, fertilizers, and machinery. Silo complexes will be refurbished to increase the capacity of the food reserve programme and move closer to food security.

Promoting other sectors. NEEDS will promote programmes that develop information and communication technology, tourism, and entertainment and financial services. Proposed trade policy reforms will aggressively promote exports and harmonize tariffs with regional trade organizations while protecting local industries. The plan also envisages developing a deep sea port, free trade zones, and a shipbuilding facility

framework and guidelines in order to boost coastal shipping, international trade, and regional integration.

\section{Changing the Way the Government Does Its Work}

NEEDS seeks to restore trust in government as a facilitator of development, an institution that creates or maintains an environment that enables Nigerians to implement livelihood strategies and achieve personal goals. The government has to stop trying to run businesses and redirect its effort to providing essential services. It must sell off the businesses currently under its control in order to free up labour and funds that it can use to improve basic services.

Changing the way the government works is a colossal task, but NEEDS will build on processes that have already begun to make a difference. The administration has already put several essential building blocks in place.

In privatization and liberalization, the government has auctioned licences and begun the process of attracting private investment in areas such as power generation and infrastructure development. To prevent nepotism, favouritism, and corruption, the government has transformed the process by which private companies bid for government contracts. It established the new Budget Monitoring and Price Intelligence Unit, which reviews, oversees, and certifies government contracts to ensure value for money. Commonly known as "due process," this mechanism has already saved the Treasury hundreds of millions of naira.

The government has also instituted massive anticorruption campaigns and established the Independent Corrupt Practices and Other Related Crimes Commission and the Economic and Financial Crimes Commission, which outlaw corrupt practices. The government is committed to the Extractive Industries Transparency Initiative, which encourages oil companies to fully disclose revenues and costs of operations. The government's televised auction of digital mobile licences was hailed as one of the most transparent licence auctions in the world.

Under NEEDS, the government will build on these efforts by:

- Strengthening and modernizing the anticorruption organizations it has established.

- Exposing unethical and illegal practices and punishing those who engage in them.

- Encouraging organizations to adopt and publish formal codes of ethics.

- Establishing formal training in ethics and fostering leadership by example.

- Enacting a Fiscal Responsibility Pact and a Right to Information Act. The Fiscal Responsibility Pact will require government agencies to publish annual audited accounts within six months of their financial year end and set up a revenue 
stabilization fund into which windfall revenues will be transferred. The Right to Information Act will promote openness and feedback.

To reform the bureaucracy, the government has begun cutting civil service benefits. The government has monetized benefits such as utilities, domestic assistance, and drivers and reduced the incentive for corruption by offering civil servants higher wages, bonuses, and improved working conditions.

NEEDS policies will ensure that all levels of government adopt an annual budget framework and guidelines. The guidelines will promote balanced budgets, implementation of priority programmes, budget discipline, cost effectiveness, and the generation of internal revenues and savings. A peer review mechanism will enable heads of government agencies to compare their performance and nurture a common culture of excellence. The Joint Planning Board, the Joint Tax Board, and the National Economic Council will work together to achieve a more effective system of economic management. The NEEDS period should be characterized by the punctual release of annual budgets. As participants in the plan for prosperity, the Nigerian people will be kept informed of how well these measures are performing by the press and by special reports.

\section{How Will NEEDS Be Implemented?}

NEEDS is a holistic plan that touches all aspects of the economic and political life of our country. To ensure a high level of coordination, the NEEDS Secretariat is located within the National Planning Commission, the hub of all governmental planning processes (figure 2). Coordination will be the responsibility of the National Council on
Development Planning, which will also provide a forum for dialogue between government and the business community. This dialogue will be intensified under NEEDS; the business community will participate more in statutory coordinating meetings, especially in the Independent Monitoring Committee at the National Council on Development Planning.

The framework for decisionmaking and implementing NEEDS will be regular meetings of the National Economic Council, the Economic Advisor and Planning Commissioners, the Joint Planning Board, the National Planning Commission Directors and Directors of Planning, the research and statistics departments of all line ministries, and representatives from the Ministry of Finance, the Nigeria Institute for Social and Economic Research, and the Federal Office of Statistics.

Putting NEEDS into operation will rely on the instruments of the plan and the budget, the medium-term expenditure framework, Presidential directives, legislation, and decisions of the Executive Council. The National Planning Commission will establish consultation meetings with the priority sectors of agriculture, industry, small and medium-size enterprises, solid minerals, culture, tourism and others that the President may specify.

\section{How Will We Pay for NEEDS?}

NEEDS will cost about \$4.5 billion through 2007, much of which will have to come from outside

Nigeria. Overseas development assistance-in the form of grants, loans, and technical assistance - is being sought. As the reforms begin to change the perceptions of Nigeria abroad, about $\$ 1.5$ billion in foreign direct investment can be expected in manufacturing, steel, construction, solid minerals, and large-
NEEDS will cost about

\section{$\$ 4.5$ billion through}

2007, much of which

will have to come

from outside Nigeria 


\section{Figure 2 How NEEDS Will Be Implemented}

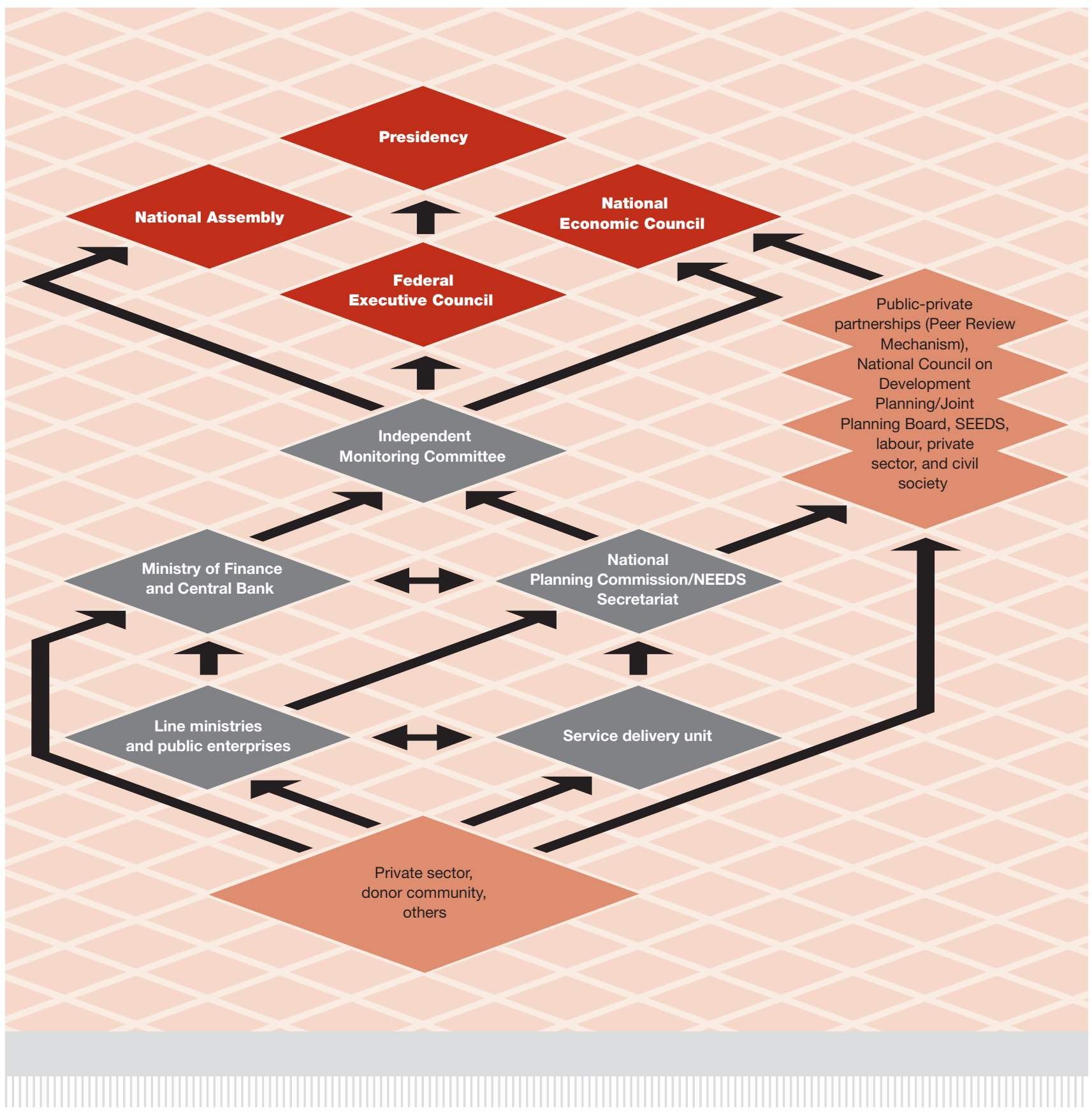


scale farming. At the same time, the government will increase its income by eliminating waste, selling assets, and reforming the tax laws.

\section{How Will We Know If NEEDS Is Working?}

A new organization, the Independent Monitoring Committee, made up of members of the government, the private sector, the media, and civil society, will periodically monitor and evaluate programmes implemented under SEEDS and NEEDS. The committee will report directly to the National Assembly for information and to the President, through the National Economic Council, for appropriate action. The Federal Office of Statistics will be responsible for providing the data necessary to monitor the progress of the plan.

In collaboration with the National Planning Commission, the Presidency will select 15-20 large projects for intensive monitoring. In addition, national consultative councils will be set up for agriculture, industry, health, and education.

Representatives of the federal government, the national legislature, the states, local government, business, labour organizations, civil society organizations, and international organizations will take part in an annual joint monitoring tour of all states to view progress and challenges. Their report will be presented to the National Economic Council for peer review and to the National Assembly for information.

The following information will be collected and analyzed as part of the monitoring and evaluation programme:

- Income per capita

- Changes in the cost of goods

- Amount and type of investment

- Income patterns across the population

- Development indices (infant mortality, primary school enrolment)

\section{The Success of NEEDS Depends on All of Us}

NEEDS is an excellent plan, but it is only a plan. However well thought out, plans remain merely thoughts on paper unless they are implemented. The President and his key advisors and ministers, governors and their key staff-all are fully committed to the reform programmes and to the massive changes that NEEDS calls on all Nigerians to make. All Nigerians have a stake in making NEEDS a success. The people of Nigeria must ensure that the government implements the reforms, and they must keep their side of the bargain by working hard to make NEEDS a success.
All Nigerians have a stake in making

NEEDS a success 


\section{Table 2 Selected Targets under NEEDS, 2003-07}

$2003 \quad 2004$

20052006

2007

\section{Macroeconomic}

Growth in real GDP (percent)

Growth in oil sector (percent)

Growth in nonoil sector (percent)

$\begin{array}{ccccc}10.2 & 5.0 & 6.0 & 6.0 & 7.0 \\ 23.0 & 0.0 & 0.0 & 0.0 & 0.0 \\ 3.3 & 7.3 & 8.5 & 8.3 & 9.5 \\ 5.0 & 5.0 & 5.0 & 5.0 & 5.0 \\ - & 1.0 & 2.0 & 2.0 & 2.0 \\ - & 4.8 & 4.8 & 4.8 & 4.8 \\ - & 2.0 & 2.0 & 2.0 & 2.0 \\ 15.0 & 10.0 & 9.5 & 9.5 & 9.0\end{array}$

Reduction in poverty incidence (percent)

Minimum number of new jobs (millions)

Growth in real private consumption (percent)

Growth in real private consumption, per capita (percent)

Inflation rate (percent)

$$
15.0
$$

$\begin{array}{cc}7.0 & 6 \\ - & 7 \\ 53.0 & \\ - & \end{array}$

$6.0 \quad 6.0$

Growth in agricultural sector (percent)

Growth in manufacturing sector (percent)

Manufacturing capacity utilization (percent)

6.0

6.0

6.0

Number of tourist visitors (percent)

Communication (teledensity)

$1: 40$

10.0

7.0

7.0

7.0

Solid minerals

Agricultural exports

Environment

Self-employment for at least 500,000 Nigerians

$$
\text { - } \quad \text { - } \quad \text { - } \quad-\quad \text { - } \quad \text { - } \quad \$ 3 \text { billion }
$$

Reduce all forms of environmental degradation by $30 \%$ of 2004

levels by 2007

\section{Fiscal}

Maximum public deficits (percent of GDP)

Maximum ways and means (percent of previous revenue) 12.5

Total expenditure (percent of GDP)

-

25.1

Recurrent expenditure (percent of total budget)

Capital expenditure (percent of total budget)

70.0

30.0

\section{External sector}

External reserves (\$ millions)

7,187

3.0

10.0

3.0

10.0

3.0

10.0

3.0

23.5

23.4

22.9

10.0

65.0

60.0

60.0

22.3

35.0

40.0

40.0

60.0

40.0

Growth in imports (percent)

Growth in exports (percent)

Earning from nonoil exports (percent of total exports)

Food (percent of total imports)

Unrequited transfers

$7,187 \quad 7,687$

\section{8,687}

9,687

10,687

- $\quad 15.0$

15.0
10.0

18.0

25.0

30.0

- $\quad 10.0 \quad 20$

$<5 \quad-$

-

-

25.0

30.0

14.5

At least $\$ 3$ billion a year from remittances

\section{Financial}

Growth in credit to private sector (percent)

30.0

30.0

30.0

30.0

30.0

\section{Education}

Adult literacy rate (percent)

$57.0-$

-

-

65.0




\section{Table 2 Selected Targets under NEEDS, 2003-07 (continued)}

$\begin{array}{lllll}2003 & 2004 & 2005 & 2006 & 2007\end{array}$

\section{Health}

HIV/AIDS prevalence rate (percent)

6.1

$\begin{array}{llll}- & - & - & 5.0\end{array}$

Immunization coverage (percent)

Access to safe water (percent)

6.1
39.0

64.1

53.0

Access to adequate sanitation (percent)

\section{Infrastructure}

Power generation (megawatts)

Roads (rehabilitation, maintenance and new roads) $\quad 3,000$

\section{Public sector reforms}

Public sector reform

Economic coordination and institutional reforms

Public-private sector partnership

Security and administration of justice

Judicial service reforms

Prison reforms

Eliminating corruption; improving transparency

and accountability

E-Governance

Strengthening of National Statistical System

\section{Millennium Development Goal Targets}

Literacy rate of girls

Primary school enrolment and completion

Maternal mortality

Infant mortality

- Review the nature

and relevance of

collected data

- Restructure and strengthen the institutional

capacity and

professionalization of

the statistical system

- Ensure production of timely,

reliable, and relevant statistics

Note: The GDP growth projections are very conservative. The growth potentials are huge - not only in terms of the abundant human and material resources, but also for the fact that Nigeria mimics a post-conflict economy with lots of idle resources. With the various targeted presidential initiatives on agriculture, the increased coordination with the states on key priority sectors-agriculture, small and medium-size enterprises, infrastructure and social sectors - the growth effects are expected to be substantial. However, the projections are kept low, with clear possibilities that they could be exceeded. 


\section{Part One}

Vision and Macroeconomic Framework

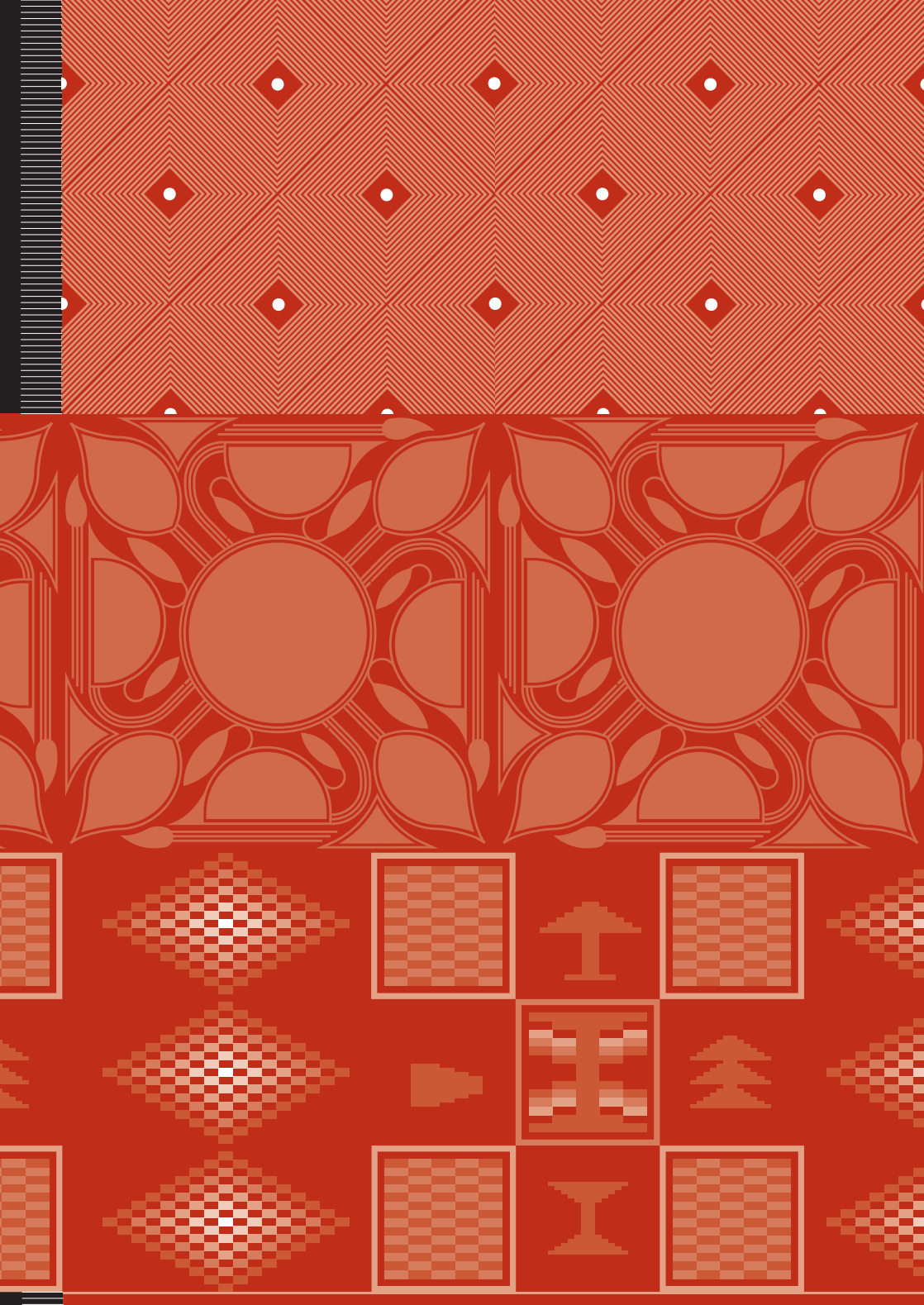

Chapter 1

Statement of Vision, Values, and Principles

Chapter 2

The Development Challenges Facing Nigeria

Chapter 3

The Macroeconomic Framework

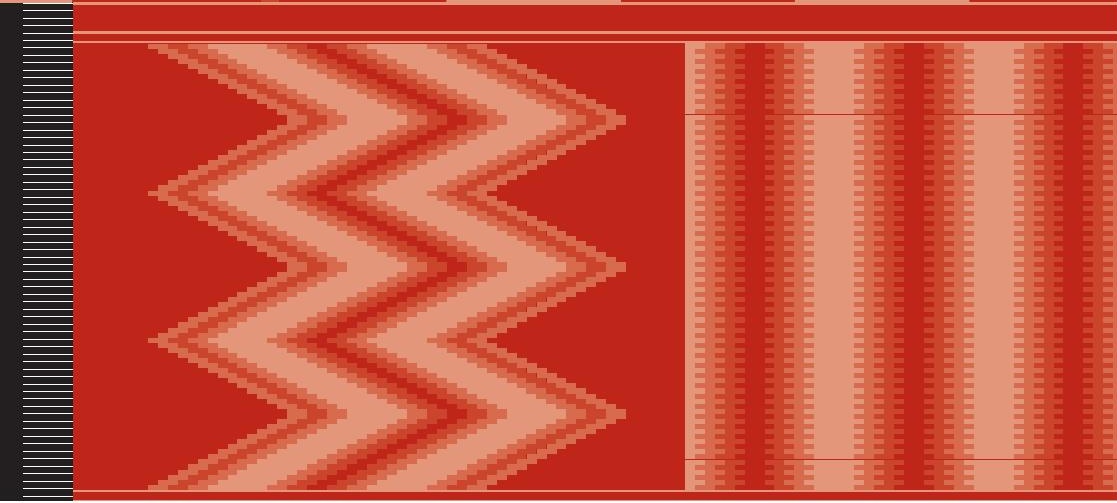




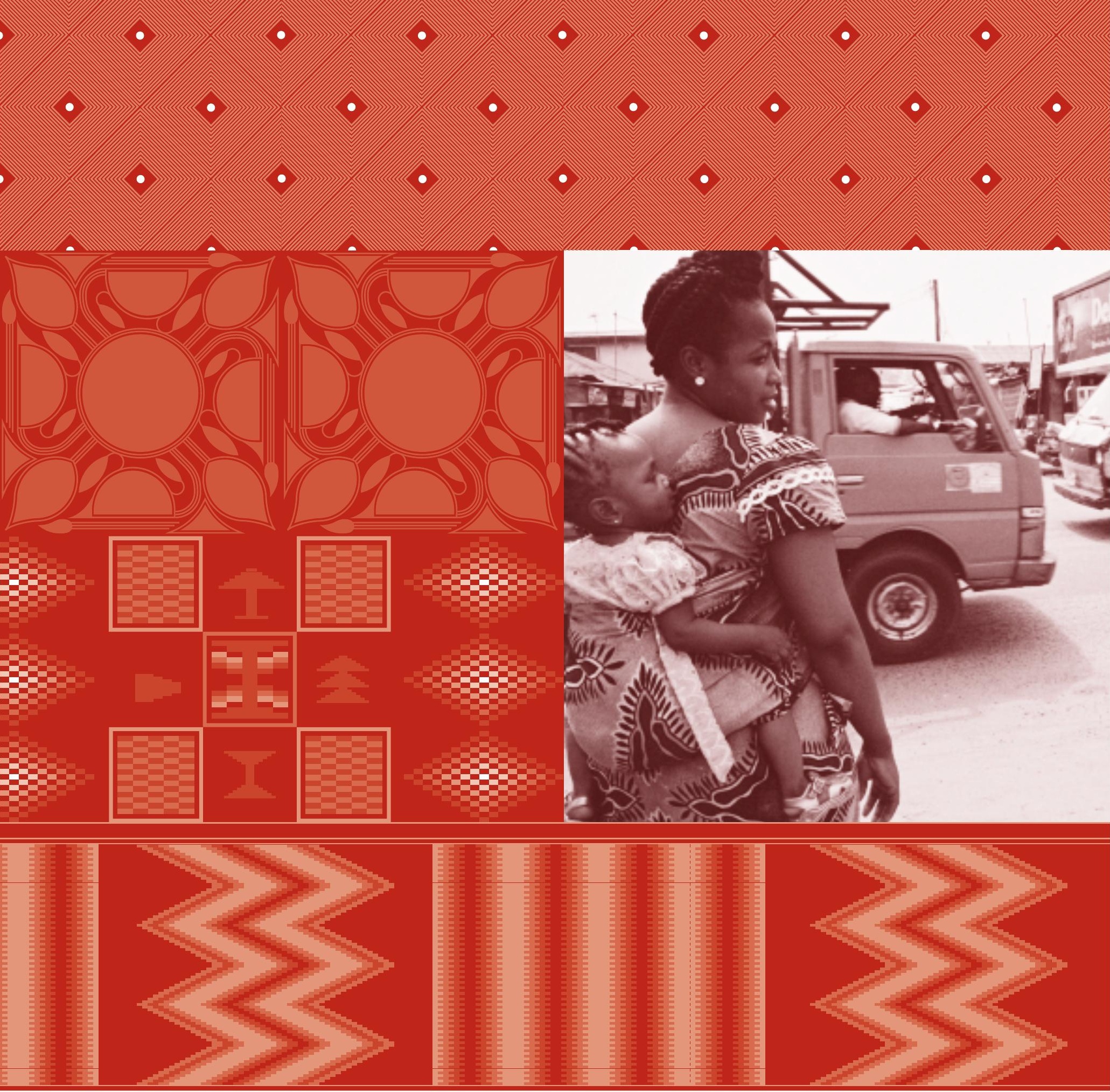




\section{Chapter Statement of Vision, Values, and Principles}

NEEDS is not just a

plan. It defines a

process of

development

anchored by a clear

vision, sound values,

and enduring

principles
NEEDS is not just a plan. It defines a process of development anchored by a clear vision, sound values, and enduring principles.

The vision for Nigeria's development derives from the country's history, endowments, experience, and aspirations. Development of this vision has drawn inspiration from the views of a cross-section of stakeholders and the aspirations of Nigerians as conveyed in provisions of the Constitution. The vision underscores the necessity and urgency of building a modern Nigeria that maximizes the potential of every citizen, of becoming the largest and strongest economy in Africa, and of becoming a force to be reckoned with in the world before the middle of the twenty-first century (box 1.1). Nigeria envisions a twenty-first century that is Africa's century, with Nigeria among the leading nations.

This vision was articulated in the 2001 Kuru Declaration, which states:

To build a truly great African democratic country, politically united, integrated and stable, economically prosperous, socially organized, with equal opportunity for all, and responsibility from all, to become the catalyst of (African) Renaissance, and making adequate all-embracing contributions, subregionally, regionally, and globally.
President Olusegun Obasanjo's government seeks to use NEEDS as a nationally coordinated framework of action, in close collaboration with state governments and other stakeholders, to consolidate the achievements of the past four years and build a solid foundation for the attainment of Nigeria's long-term vision. Over the medium term, NEEDS will lay the foundation and achieve significant progress in wealth creation, employment generation, and poverty reduction.

\section{Core Values}

NEEDS is anchored in the imperative to restore the fundamental values of Nigeria, which have been weakened over the years. As described in Vision 2010, "Nigeria is a multiethnic society, with a value system that derives from the diversity of its people, religion and cultures. The elements of this value system include respect for elders, honesty and accountability, cooperation, industry, discipline, self-confidence and moral courage." President Obasanjo captures the essence of the new value system as one that puts Nigeria, selfless service to country, and love of fellow citizen above all else. According to the President, "Always ask what is in it for Nigeria. I see a new Nigeria in the hands of the Lord. Our Mission is the creation of a New 


\section{Box 1.1 Nigeria at a Glance}

Nigeria had an estimated population of 125 million in 2001-nearly one-quarter of Sub-Saharan Africa's population. It is estimated that one in every six black people in the world is a Nigerian. The country has more than 200 ethnic groups, with three major tribes, the Igbo (East), the Hausa (North), and the Yoruba (West). More than 500 indigenous languages and dialects are spoken. Average life expectancy at birth is 54 years.

Nigeria spans an area of 924,000 square kilometres, bordered by the Gulf of Guinea, Cameroon, Benin, Niger, and Chad. The topography ranges from mangrove swampland along the coast to tropical rain forest and savannah to the north. The Sahara Desert encroaches upon the extreme northern part of the country, while gully erosion threatens the carrying capacity of lands in the south. Some 10 percent of the land is covered with forest, including large stands of mahogany, walnut, and obeche. Bountiful flora and fauna create a rich source of biodiversity that serves as a reservoir of the pharmaceutical industry and a sustainable source of genetic materials for improving the nation's food production potential. But rapid

deforestation has reduced Nigeria's forest by 50 percent in the past 15 years. The country's fishery resources are small, concentrated in the coastal area.

Agriculture is the dominant economic activity in terms of employment and linkages with the rest of the economy. Roughly 75 percent of Nigeria's land is arable, of which about 40 percent is cultivated. The United Nations Food and Agriculture Organization rates the productivity of Nigeria's farmland as low to mediumbut with medium to good productivity if properly managed. Despite two major rivers, the Niger and the Benue, agriculture is predominantly rain fed. Yams, cassava, rice, maize, sorghum, and millet constitute the main food crops. The principal export crops are cocoa and rubber, which together account for nearly 60 percent of nonoil merchandise exports.

Nigeria has estimated proven oil reserves of 32 billion barrels, mainly in the southeastern and southern coastal area, and is the sixth-largest producer in OPEC. At the current rate of production, these reserves are sufficient to last about 37 years. Proven natural gas reserves are estimated at 174 trillion cubic feet, with energy content slightly greater than the country's oil reserves. At current production levels, these reserves will last 110 years. Nearly 80 percent of the natural gas produced is currently being flared; most of the remaining 20 percent is used to generate electricity. It is expected that the export of gas will be substantial after 2004. Nigeria's rivers also constitute a substantial energy resource, providing the country with nearly half of its electricity.

Nigeria is blessed with abundant solid mineral deposits, including coal, tin ore, kaolin, gypsum, columbite, gold, gemstones, barites, graphite, marble, tantalite, uranium, salt, soda, and sulphur.

Nigeria has more than 60 universities and boasts an educated labour force. Various independent estimates put the unemployment and underemployment rate at more than 15 percent of the labour force, with a very high rate of unemployment among university graduates. The adult illiteracy rate is 49 percent. About 76 percent of children of primary school age attend school; the participation rate falls to 20 percent for children of secondary school age.

Capacity utilization in industry is about 50 percent. Independent estimates suggest that capital flight has been significant. If appropriate policies and enabling environment were in place to induce Nigerians to repatriate just the interest earnings on their assets, Nigeria could reap an estimated $\$ 2-\$ 3$ billion a year in return foreign direct investment-multiples of the current inflow of barely $\$ 1$ billion a year.

Nigeria has a large domestic market, which could serve as a springboard for entering export markets. These and many other national assets could pave the way for seizing the many development opportunities that come with cross-border cooperation and the globalization of industry, trade, and investment. With skillful management, such opportunities could be converted into higher per capita income, job creation, and reductions in poverty. 
NEEDS' focus is

wealth creation,

employment

generation, poverty

reduction, elimination

of corruption, and

values reorientation
Nigeria where all the negative values in our society are reversed and in their place are established enabling values of a caring, well-governed society where justice and equity reign."

These are the fundamental values upon which NEEDS rests. The strategy hopes to lay a solid foundation for a national rediscovery and strong values based on the following principles:

- Enterprise, competition, and efficiency at all levels

- Equity and care for the weak and vulnerable

- Moral rectitude, respect for traditional values, and pride in Nigeria's culture

- A value system for public service that results in efficient and effective service delivery to the citizens

- Discipline at all levels of leadership According to the 2001 Kuru Declaration (box 1.2), all public officials, elected and appointed, swear to abide by certain codes of values embodying Nigeria's development objectives and human capital needs. NEEDS recognizes that these values cannot take root and be sustained unless conscious efforts are made to mobilize the Nigerian people around them. Without paradigm shifts, fundamental changes in mindset, and acknowledgment that business as usual is not acceptable, especially by the elite, the change that NEEDS seeks to bring about will be difficult to attain and sustain.

Furthermore, the National Assembly is poised to enact the relevant legislation for effective implementation of NEEDS. Some of these are listed in chapter 11.

\section{Fundamental Principles}

Under the Fundamental Objectives and Directive Principles of State Policy, the 1999 Constitution of the Federal Republic of Nigeria mandates the following:

- The security and welfare of the people shall be the primary purpose of government.

- The state shall, within the context of the ideals and objectives for which provisions are made in this Constitution, harness the resources of the nation, promote national prosperity and an efficient, dynamic, and self-reliant economy and control of national economy in such a manner as to secure the maximum welfare, freedom, and happiness of every citizen on the basis of social justice and equality of status and opportunity.

- The state shall direct its policy towards ensuring

- The promotion of a planned and balanced economic development

- That the material resources of the nation are harnessed and distributed as well as possible to serve the common good

- That the economic system is not operated in such a manner as to permit the concentration of wealth or the means of production and exchange in the hands of a few individuals or a group.

- That suitable and adequate shelter, suitable and adequate food, a reasonable national minimum living wage, old age care and pensions, and unemployment, sick benefits, and welfare of the disabled are provided for all citizens.

- The government shall direct its policy towards ensuring that there are equal and adequate educational opportunities at all levels.

- The national ethic shall be discipline, integrity, dignity of labour, social justice, religious tolerance, self-reliance, and patriotism. 


\section{Box 1.2 The Kuru Declaration}

1 We adopt the New Orientation as an agenda for dealing with immediate and future issues of governance in Nigeria; removing impediments to efficiency and effective implementation and execution of programmes initiated by the federal government; expeditious actualization of government objectives and vision of national renewal and re-construction.

2 We rededicate ourselves and those who serve under us to the values of patriotism, honesty, hard work and diligence, merit and excellence, trustworthiness, personal discipline, tolerance and mutual respect, justice and fairness, love, care and compassion.

3 We pledge to eschew corruption, slothfulness, nepotism, indiscipline, bitterness, prejudice and other manifestations of anti-social behaviours.

4 We shall undertake a critical review of practices and procedures in every ministry and department of government, with the aim of introducing and inculcating modern management techniques and procedures in every department of government, so as to rapidly increase their productivity and service delivery to the public.

5 We shall foster a culture of efficiency in the management of funds and other resources, maintaining high standards of resource management and reducing waste at all times.

6 We shall effectively supervise all government departments and agencies, ensuring timely reports and returns and undertaking regular spot-checks.
7 We shall abide by the terms of the code of conduct which we all have signed, as expression of our commitment to the crusade against corruption, and work closely with all relevant agencies, such as the Independent Corrupt Practices and Other Related Offences Commission, the Code of Conduct Bureau, and the Public Complaints Commission.

8 We undertake to strengthen the partnership in working with the private sector, since this partnership translates to a better appreciation of the wealthcreating and job-creating capacity of this sector, and the need for government, through its various ministries and legislative processes, to create an enabling environment for the sector to function efficiently as the major driver of the economy.

9 We shall strive to strengthen and inculcate the culture of working closely and in consultation with the leadership of labour and civil society organizations.

10 We shall mobilize, involve and promote the interest of all stakeholders, namely, the society in general, since, in the ultimate, all decisions and actions of government are primarily concerned with promoting the security and general well-being of the people. There is also the need for a new attitude that has that concern permanently in focus, as the only goal, and that the economic well-being of all citizens in a truly democratic environment is of cardinal importance.

11 We shall design strategies and techniques of implementation for the New Orientation so as to ensure that the values being inculcated permeate all levels of management and staff.

NEEDS is based on these principles. It aims to achieve the directive principles of state policy. Its focus is the creation of wealth, the generation of employment, the reduction of poverty, the elimination of corruption, and the general reorientation of values. 
Three other principles underpin NEEDS. They commit the government to:

- Create an incentive structure that rewards and celebrates private enterprise, entrepreneurial spirit, and excellence.

- Establish new forms of partnership with all stakeholders in the economy-all branches of government, the public and private sectors, civil society and the international community - to promote prosperity.

- Create a public sector that delivers prompt and good-quality service. 


\section{Chapter The Development Challenges Facing Nigeria}

Since the transition to democracy in 1999 , Nigeria has laid a solid foundation for economic growth and development (box 2.1). NEEDS is a development strategy that consolidates the gains achieved over the past four years, unlocks Nigeria's dormant potential, and provides the base for sustained development. The strategy signals a break with past efforts to pursue several unsustainable strategies.

Nigeria's rich human and material resource endowments give it the potential to become Africa's largest economy and a major player in the global economy. But much of its potential has remained untapped, putting attainment of the Millennium Development Goals by 2015 in jeopardy.

\section{Development Challenges Remain Daunting}

Significant improvements have been recorded in many areas since 1999, but the development challenges remain daunting. NEEDS aims to address many of these challenges, including the following:

- Per capita GDP in Nigeria was among the lowest in the world during the 1980s and 1990s, costing it decades of development. Annual per capita GDP remained stagnant in the 1990s, and it grew just 0.8 percent between 1999 and 2003_far lower than the 4.2 percent per capita growth needed to significantly reduce poverty. Compared with other African and Asian countries, especially Indonesia, which is comparable to Nigeria in most respects, economic development in Nigeria has been disappointing. With GDP of about $\$ 45$ billion in 2001 and per capita income of about $\$ 300$ a year, Nigeria has become one of the poorest countries in the world. As of 2000 it had earned about $\$ 300$ billion from oil exports since the mid-1970s, but its per capita income was 20 percent lower than in 1975. Meanwhile, the country has become so heavily indebted - external and domestic debt amount to about 70 percent of GDP_that it has serious difficulty servicing debt. Regional and sectoral unevenness in growth performance is high. The real sector is still dominated by the primary production sectors. Agriculture, predominantly small farmers with low and declining productivity, accounts for 41 percent of the real sector, while crude oil accounts for 13 percent. The secondary sector, especially manufacturing, has been stagnating at about 5-7 percent of GDP, making Nigeria one of the least
Nigeria's rich human

and material resource endowments give it the potential to become Africa's largest economy and a major player in the global economy 


\section{Box 2.1 Nigeria's Economy Is Improving}

Confidence in Nigeria is high, the environment for doing business is improving, and both Nigerian and foreign businesses are reacting positively to recent developments in the country. The government has consolidated democracy and improved governance, and the economy has begun to turn around.

During the 1990s the economy stagnated, growing at an average annual rate of just 2.8 percent, leaving the per capita income growth rate at zero. By 1998 Nigeria was faced with both a failed state and a failed economy, and Nigerians were leaving the country in droves.

Today many of these trends have been reversed. Corruption and other economic and financial crimes are being vigorously fought. More than 200 Nigerians are currently being detained or tried for fraud, and illegally obtained assets worth more than $\$ 500$ million have been confiscated. The introduction of due process in government procurement has saved the government more than $\$ 600$ million. Aggregate annual GDP growth averaged about 5 percent between 1999 and 2003, and preliminary estimates of growth in 2003 stood at 10.23 percent, the highest rate of growth in three decades.

The superlative growth of 2003 was driven mainly by improvements in agriculture, which grew 7 percent, and the oil sector, which grew 23 percent. The minimum rediscount rate fell steadily, from 20.7 percent in 1999 to 15 percent in 2003. Other rates followed the same trend, with the prime lending rate falling from 22.5 percent to 19.6 percent and the rate on time deposits held more than a year falling from 15.3 percent to 12.3 percent. The annual depreciation of the exchange rate averaged 9.7 percent over the period, down from 29.4 percent for 1994-98 and 114 percent for 1986-93. The country's external reserves as of the end of March 2004 stood at about $\$ 10.2$ billion, about 10 months' import cover.

The liberalization of the service sector yielded significant results. In the first 40 years of Nigeria's independence, aggregate installed telecommunication lines stood at about 450,000. With the licensing of GSM and other wireless landline operators, this number grew nearly 1,000 percent, to more than 4 million lines in 2003. Growth in the hotel and tourism industry was also extraordinary. The total number of hotel beds nearly tripled, from 12,900 in 1999 to 37,528 in 2003. Room occupancy rate also increased, from 71 percent in 1999 to 82.5 percent in 2003. The number of visiting foreign nationals nearly tripled, from 1,392 to 3,897 , with annual growth rates in 2002 and 2003 averaging 30 percent.

Foreign direct investment in the nonoil sector also rose, from divestment in the 1990s to a few billion dollars in 1999-2003. Heineken built its largest plant in the world and upgraded its existing plants, investing about $€ 500$ million. The British American Tobacco is making large investments in Ibadan, and Solgas, a U.S. company, is investing in the Ajaokuta Steel Mill. A survey of 108 medium and large-scale firms operating in Nigeria showed that they invested more than $\$ 10$ billion during the period. Private investment in power and other infrastructure is also growing steadily, with a number of acquisitions and new investments already approved by the administration.

These developments have increased employment, causing the unemployment rate to fall from about 20 percent in 1999 to 10.8 percent in 2003. Male unemployment fell from 18 percent in 1999 to 10.6 percent in 2003, while female unemployment fell from 18.2 percent in 1999 to 11.2 percent in 2003 . There has also been a reversal of the decade-long decline in real take-home wages, with real wages rising about 30 percent between 1999 and 2003. The results of an ongoing household survey will provide more recent socioeconomic statistics. (The poor quality of socioeconomic data in Nigeria is being addressed by restructuring and strengthening the Federal Office of Statistics. Efforts are ongoing to refine the national accounts data using best-practice methodology. A household survey that will provide up-to-date statistics on basic socioeconomic conditions is also being conducted. The analysis in this report could be revised when new data become available.) 
industrialized countries in Africa. Services has been the fastest-growing sector since independence.

- Between 1975 and 2000 Nigeria's broad macroeconomic aggregates - growth, the terms of trade, the real exchange rate, government revenue and spending —were among the most volatile in the developing world. Over the past three decades, high macroeconomic volatility has become a key determinant-as well as a consequenceof poor economic management. The economy has been caught in a low growth trap, characterized by a low savingsinvestment equilibrium (at less than 20 percent). Industrialization and exports remain low. With an average annual investment rate of barely 16 percent of GDP, Nigeria is far below the minimum investment rate of about 30 percent of GDP required to unleash a poverty-reducing growth rate of at least 7-8 percent per year.

- In the more than 40 years since independence, Nigeria has never grown at 7 percent or more for more than three consecutive years. Because of perceptions of risks and the high costs of doing business, private agents keep the bulk of their assets abroad, and more than 2 million Nigerians (mostly highly educated) have emigrated to Europe and the United States. Most foreign direct investment into the country goes into the oil and extractive sectors. Only since 1999 has foreign direct investment in the nonoil sectors begun to rise significantly. Nigeria's economic structure remains highly undiversified. Oil exports account for 95 percent of total exports, while manufacturing accounts for less than 1 percent. Since the 1970 s
Nigeria has lost international market share even in its traditional (agricultural) exports.

- Macroeconomic policy has been highly circumscribed by inefficient, highly volatile, and unsustainable public sector spending and by unusually high volatility of major macroeconomic aggregates. Fiscal decentralization has proved a challenge to effective macroeconomic stabilization and efficient public finance management. There has been a lack of policy coherence between the states and the federal government and even among the various agencies of the federal government. The traditional instruments of economic management - the national plan and budgeting processes-have been rendered ineffective.

- Finances at all levels of government are in poor shape. Domestic debt increased more than 200 percent between 1999 and 2002 (to about $\$ 9$ billion). The external debt burden, which the government is barely able to service, represents about 50 percent of contractual service obligations. Government finance is also characterized by a pension crisis, arrears of salaries of civil servants, huge debts to government contractors and suppliers of goods and services, a boom and bust cycle of revenue and expenditure, misallocation and mismanagement of resources, and other problems. At the state government level, a major crisis is looming but goes largely unnoticed. Many states are accumulating debt at unsustainable levels, institutions are weak, and economic governance is poor.

- The very low productivity of the private sector and the lack of diversification of the economy are due mainly to the inhospitable
Nigeria's economic

structure remains

highly undiversified:

Oil exports account

for 95 percent of total

exports, while

manufacturing

accounts for less than

1 percent 
Despite efforts to

promote a private

sector-led market

economy, Nigeria still

faces the challenge of

transition from an

economy dominated

by the public sector business environment. The constraints to businesses include infrastructure deficiencies, poor security of lives and property, corruption and rent-seeking, low access to and the high cost of finance, weak institutions, poorly defined property rights and enforcement of contracts, and unstable macroeconomic policies, especially fiscal and trade policy. Although these conditions have begun to improve since 1999 , significant obstacles need to be addressed.

- Nigeria's urbanization rate-about 5.3 percent a year - is one of the fastest in the world. With a stagnant secondary sector, urban unemployment-and its attendant problems of slums, crime, and sociopolitical tensions-is high. In March 1999, 23.2 percent of the rural labour force and 12.4 percent of urban dwellers were without jobs. By March 2003 the rural unemployment rate had dropped to 12.3 percent and the urban rate to 7.4 percent, yielding a composite unemployment rate of 10.8 percent.

- Nigeria faces the challenge of meeting the Millennium Development Goals. Statistics from the 1996 survey indicate that poverty is deep and pervasive, with an estimated 70 percent of the population living in poverty. (Many analysts question the 1996 poverty statistics, especially the methodology used. The ongoing Living Standard Measurement Survey will give a more accurate picture of the actual level of poverty in Nigeria. See chapter 4 for a detailed analysis of the nature, dimensions, and causes of poverty in Nigeria, as well as a survey of the interventions the government has used to tackle it.) Poverty in Nigeria varies widely by region, sector, and gender. Other social indicators are also under stress: income inequality in
Nigeria is very high; unemployment is threatening social cohesion, security, and democracy; and the imminent HIV/AIDS epidemic is a potent time bomb waiting to explode, with potential dire consequences for productivity in the economy. Social exclusion and discrimination against women hamper their ability to fully contribute to the development of the economy.

- The educational system is dysfunctional, as graduates of many institutions cannot meet the needs of the country. Institutions are in decay, strikes and cultism are common, and corruption has become rampant. Youth militarism has now gone beyond the walls of schools to the heart of society.

- Despite efforts to promote a private sector-led, competitive market economy framework, Nigeria still faces the fundamental challenge of transition from statism and rent-seeking in an economy dominated by the public sector. The deep vested interests that profit from the system have proved resilient. They are strengthened by evidence of weak institutions. As a result, implementation failures in Nigeria are persistent.

\section{What Went Wrong?}

The problems NEEDS addresses reflect decades of corruption and mismanagement, especially under military rule. The old development models of import substitution industrialization and statism, in which government assumed the dominant role as producer and controller in the economy, created perverse incentives, inefficiencies, and waste. In an oil-producing economy (where rents from oil are easy sources of government revenue), a culture of rent-seeking 
quickly developed. The government became an instrument for instant acquisition of wealth, distorting the incentive to work and to create wealth in the private sector. With government as the major source of patronage and rent-seeking, the fight for public office became fierce.

These factors created an incentive framework that did not reward private enterprise, transparency, or accountability. Frequent regime changes and changes in policy were defining features in Nigeria in the past. Military dictatorships allowed weak institutions to endure. Inappropriate development frameworks, poor and frequently changing policies and programmes, lack of clear vision and commitment to development, and a citizenry that acquiesced to the culture of patronage are the major causes of Nigeria's failed past.

\section{Prospects for the Future}

The Nigerian economy faces enormous challenges - and a bleak future if fundamental steps are not taken to redress the legacies of the past. Among the many requirements for rejuvenating the economy is rapid and broad-based growth. Creating the conditions for such growth will require that Nigeria adopt fundamental new policies in order to break out of the low-growth poverty trap it finds itself in.

What are the implications of alternative growth scenarios for per capita income and poverty in the medium to long run (table 2.1)? Three scenarios are examined:

- In Scenario A Nigeria maintains the average growth performance recorded between 1999 and 2002 (about 3.5 percent) through 2030. Assuming that per capita income was $\$ 300$ in 2000 , it would increase by just $\$ 23$ by 2015 and by just $\$ 48$ in 2030. If current trends in the rest of the world continue, this rate of growth would leave Nigeria one of the poorest countries in the world. Under this scenario, poverty worsens, engulfing as much as 80 percent of the population by 2030 .

- In Scenario B growth rises to the average level of the late 1980s (5 percent). This level of growth is sufficient to prevent poverty from worsening, but it is not strong enough to reduce it. By 2030 the incidence of poverty remains at 70 percent, while per capita income increases to \$416 in 2015 and \$576 in 2030, still leaving the average Nigerian very poor.

\begin{tabular}{|c|c|c|c|c|c|}
\hline Table 2.1 & \multicolumn{5}{|c|}{$\begin{array}{l}\text { Implications of Alternative Growth Scenarios for Key Development } \\
\text { Indicators, } 2000,2015,2030\end{array}$} \\
\hline Scenario & Indicator & $\begin{array}{l}\text { Assumed } \\
\text { GDP growth }\end{array}$ & $\begin{array}{c}2000 \\
\text { (Actual) }\end{array}$ & 2015 & 2030 \\
\hline \multirow[t]{2}{*}{ A } & Per capita income & 3.6 & $\$ 300$ & $\$ 328$ & $\$ 352$ \\
\hline & Incidence of poverty & 3.6 & 70 percent & 75 percent & 80 percent \\
\hline \multirow[t]{2}{*}{$B$} & Per capita income & 5.0 & $\$ 300$ & $\$ 416$ & $\$ 576$ \\
\hline & Incidence of poverty & 5.0 & 70 percent & 70 percent & 70 percent \\
\hline \multirow[t]{2}{*}{ C } & Per capita income & 7.0 & $\$ 300$ & $\$ 556$ & $\$ 1,031$ \\
\hline & Incidence of poverty & 7.0 & 70 percent & 35 percent & 17 percent \\
\hline
\end{tabular}

\section{Creating the \\ conditions for rapid \\ and broad-based \\ growth will require \\ fundamental new}

policies to break out of

the low-growth poverty

trap 
- In Scenario C Nigeria fundamentally changes its strategy and achieves an average annual rate of growth of 7 percent. This rate of growth is adequate to meet the Millennium Development Goal of cutting the incidence of poverty by half by 2015 . Under this scenario, the percentage of people living below the poverty line could fall to less than 20 percent.

Of course, the impact of growth on poverty depends on the sources of growth. Even with rapid growth of 7 percent a year, the incidence of poverty may not decline significantly if growth is not pro-poor. The effects on poverty of growth led by agriculture, small and medium-size enterprises, and manufacturing would be very different from those of growth led by the mining and quarrying sector. A policy that targets the very poor states would have a greater effect on poverty reduction than one that does not.

Scenarios $A$ and $B$ reflect high population growth and urbanization. If the population continues to grow at 2.8 percent a year, there will be 182 million Nigerians by 2015, 87 million of them (48 percent) living in urban areas, and 275 million Nigerians by 2030, 182 million of them urban (66 percent). If the secondary sector, especially manufacturing and services, does not grow sufficiently to absorb the inflow of labour to urban areas or rural areas are not transformed enough to stem the rate of rural-urban migration, the rate of urban unemployment could soar.

All of the scenarios reflect increasing desertification, land use intensification, and rain-fed agriculture with low productivity. If current trends continue, agriculture will not be able to support the economy in terms of employment or income. The average age of the labour force in agriculture is about 48-60 years. The growing food import bill (about 10 percent of total imports) attests to the potential food security crisis. Nigeria's natural resource base is rapidly being depleted, and the process of diversification is proceeding very slowly. As a result of the declining educational system, an increasing proportion of graduates are unemployable. All these factors have grave implications for poverty and unemployment.

Nigeria's size and strategic importance in Africa (especially in West Africa) mean the stakes are very high. Nigeria is the source of stability in West Africa. It led multilateral peacekeeping forces in Liberia and Sierra Leone, and it continues to play a peacekeeping role in the subregion. On the economic front, Nigeria accounts for about 60 percent of West Africa's GDP. A vibrant and growing Nigerian economy will thus act as a strong growth pole for West and even Central Africa. Sub-Saharan Africa as a region cannot succeed in reducing poverty and it cannot reach the Millennium Development Goals by 2015 unless Nigeria, with one-fifth of the African population, develops successfully.

\section{The Potential for a New and Strong Beginning under NEEDS}

Nigeria has abundant human and material resources to initiate and sustain rapid and broadbased growth and development. It can also take advantage of opportunities offered by globalization (including prospects for leapfrogging) and by the preferential and differential trade arrangements and concessions under the Economic Community of West African States (ECOWAS) Treaty; the African Growth and Opportunity Act; and the Cotonou Agreement trade pact and impending economic partnership agreement between the European Union and the African, Caribbean, and Pacific countries. If appropriate incentives are in 
place, the brain drain of Nigerians could be turned into a brain gain-through increased remittances, technology transfer, and even return of capital flight (which could repatriate up to $\$ 2-\$ 5$ billion a year). In other words, there are ample opportunities to jump-start faster growth-if the right strategy can be crafted and implemented.

Some momentum for change has been building since the transition to democracy in 1999. This momentum can be accelerated and sustained. Since 1999 foreign direct investment in the nonoil sector has risen from almost zero to billions of dollars, capacity utilization in industry has doubled, unemployment rates are leveling off, and GDP growth has risen moderately. Increasing numbers of Nigerians in the diaspora are willing to return and contribute to the economy, and many of the donor agencies that boycotted Nigeria during the military era have returned. More fundamentally, the new political leadership at the federal and state levels as well as consensus among key stakeholders in the economy seems to be committed to a significant change.

Several factors suggest that NEEDS is a strategy that is likely to succeed. First, the current administration's policy thrust is consistent with the provisions of NEEDS. The 2004 budget signals a fundamental change in strategy. The liberalization of the downstream oil sector has begun, with the full elimination of subsidies, and the refineries will soon be privatized. The conversion of public servants' perquisites into cash to reduce government expenditure and waste associated with maintaining these facilities is on course. Actions to fight corruption and increase transparency have been taken, and commitment to the Extractive Industries Transparency Initiative has been reinvigorated. The piloting of public service reforms has begun, the privatization programme is on course, infrastructure rehabilitation and maintenance are proceeding, and an emphasis on agriculture led to an unprecedented bumper harvest in 2003. Furthermore, there is a broad national consensus around the reform agenda.

Second, effective mechanisms are being instituted for coordinating state and federal government programmes and jointly monitoring performance. The statutory organs for such coordination and monitoring (such as the National Economic Council, the National Council on Development Planning, and the Joint Planning Board) are being strengthened. The impact of the federal programme will be increased as the 36 states develop their own reform programmes (known as State Economic Empowerment and Development Strategies, or SEEDS) consistent with the broad thrusts of the federal reforms.

Third, the right people are in place to adopt and implement NEEDS. A critical mass of reformminded representatives are serving in the National Assembly, which is ready to enact the relevant legislations for effective implementation of NEEDS (see chapter 11). The President has constituted a very strong economic team to drive the process of reforms. There is a strong team spirit in government, which is critical for implementing and sustaining the reform effort.

Fourth, NEEDS will become the basis for government budgets and the eventual formulation of a medium-term expenditure framework. Implementation is a key element for success. The President is leading efforts at implementation, chairing a weekly, 90-minute meeting of the economic management team designed to monitor and coordinate implementation among key agencies and ministries. The agenda is focused and selective, and aspects of it will be implemented by the private sector, nongovernmental organizations (NGOs), and donor agencies.
There is a strong

team spirit in

government, which is

critical for

implementing and

sustaining the reform

effort 


\section{Chapter The Macroeconomic Framework}

\section{NEEDS proposes bold}

steps to achieve

macroeconomic

stability and support a

more efficient use of

resources to grow the

economy
Many factors inhibit growth in Nigeria, including:

- Inconsistent macroeconomic policy

- Instability and policy reversals

- Conflicts between different macroeconomic policy goals

- Public sector dominance in production and consumption

- Pervasive rent-seeking and corruption, facilitated by the fact that the government is the hub of economic activities

- Inadequate and decaying infrastructure

- High volatility of major macroeconomic aggregates

- Weak institutional capacity for economic policy management and coordination

- Unsustainability of public finance at all levels of government

- Lack of effective coordination across levels of government

- Large debt overhang

Many of these problems are institutional. Others reflect the fact that the means are inadequate to achieve the goals.

NEEDS aims to redress these imbalances, based on an overall macroeconomic framework. The analyses and projections presented in this chapter are based on the four basic macroeconomic accounts: the real sector, the fiscal account, the balance of payments accounts, and the monetary sector accounts (table 3.1). A workable programme requires that the four accounts be consistent, so that they ensure predictability and sustainability of the macroeconomy and spur rapid and broadly shared pro-poor growth.

\section{The Real Sector}

Overall, growth in Nigeria has been disappointing. Annual growth averaged less than 3 percent for most of the three decades following the discovery and exploitation of oil. This era, through 1999, was bedeviled by waste, a bloated public sector, high public expenditures, a distorted budgeting system, and a weak private sector. Changes occurred, but they were minor. Coming at a time when some of the world's fastest growing economies were growing by more than 10 percent a year, 3 percent real GDP growth was sad news, particularly given annual population growth of 2.8 percent. Efforts clearly needed to be stepped up to improve the performance of the economy.

With the return to democracy in May 1999, hopes were rekindled about prospects for jumpstarting the economy. Everyone underestimated the magnitude of the decay and hence the 


\section{Table 3.1 Selected Macroeconomic Projections, 2003-07}

\begin{tabular}{|c|c|c|c|c|c|}
\hline Indicator & $2003^{a}$ & 2004 & 2005 & 2006 & 2007 \\
\hline \multicolumn{6}{|l|}{ Real sector } \\
\hline Growth in real GDP (percent) & 10.2 & 5.0 & 6.0 & 6.0 & 7.0 \\
\hline Growth in oil sector (percent) & 23.0 & 0.0 & 0.0 & 0.0 & 0.0 \\
\hline Growth in nonoil sector (percent) & 3.3 & 7.3 & 8.5 & 8.3 & 9.5 \\
\hline \multicolumn{6}{|l|}{ Oil production, including condensates } \\
\hline (millions of barrels a day) & 2.2 & 2.2 & 2.2 & 2.2 & 2.2 \\
\hline Gross national savings (percent of GDP) & 12.4 & 14.1 & 17.2 & 23.9 & 29.0 \\
\hline Inflation rate (percent) & 11.0 & 10.0 & 9.5 & 9.5 & 9.0 \\
\hline
\end{tabular}

\section{Federal government finance (percent of GDP)}

\begin{tabular}{lrrrrr} 
Overall fiscal balance & -3.3 & -1.9 & -3.2 & -3.2 & -3.2 \\
\hline Primary balance & -1.4 & 0.1 & -1.7 & -1.5 & -1.4 \\
\hline Retained revenue & 9.7 & 9.7 & 7.8 & 7.6 & 7.3 \\
\hline Total expenditure & 25.0 & 23.5 & 23.4 & 22.9 & 22.3
\end{tabular}

\section{External sector}

\begin{tabular}{|c|c|c|c|c|c|}
\hline Overall balance (percent of GDP) & -7.7 & -10.8 & -9.2 & -4.4 & -1.3 \\
\hline Current account balance (percent of GDP) & 2.7 & -2.9 & -2.3 & -0.5 & 0.3 \\
\hline External reserves (\$ millions) & 7,187 & 7,687 & 8,687 & 9,687 & 10,687 \\
\hline
\end{tabular}

\section{Growth in money and credit (percent)}

\begin{tabular}{llllll} 
Net domestic credit & 28.3 & 24.5 & 24.6 & 22.5 & 21.8 \\
Net credit to government & 44.4 & 29.9 & 29.9 & 3.5 & 30.0 \\
Credit to private sector & 30.0 & 30.0 & 30.0 & 30.0 \\
Narrow money (M1) & 10.3 & 10.8 & 8.3 & 16.7 & 19.8 \\
\hline Broad money (M2) & 15.0 & 15.0 & 15.5 & 15.5
\end{tabular}

a. Provisional.

challenges that needed to be faced. Aggregate growth has been slow and the sectoral distribution of growth uneven. While some sectors, such as telecommunications, have enjoyed very rapid growth, others, such as mining, have contracted. Some of the sectors that recorded very high growth rates in 2001 slumped in 2002. Oil refining, for example, grew 191 percent in 2001 but declined about 8 percent in 2002. Indications are that average growth of about 21 percent in the electricity subsector in 2002 may be threatened.

This unstable growth - a hallmark of sectoral performance-presents an enormous challenge. Putting the economy back on the path of sustainable growth requires a systematic and consistent framework. NEEDS proposes bold steps to plug leakages in order to achieve macroeconomic stability and support a more efficient use of resources to grow the economy. 
NEEDS supports

systematically

reducing the role of

government in the

direct production of

goods and

strengthening its

facilitating and

regulatory functions

\section{Policy Thrusts}

NEEDS supports the following policy thrusts:

- Sustain a rapid, broad-based GDP growth rate outside of the oil sector that is consistent with poverty reduction, employment generation, and a sustainable environment.

- Diversify the production structure away from oil and mineral resources.

- Make the productive sector internationally competitive.

- Systematically reduce the role of government in the direct production of goods, and strengthen its facilitating and regulatory functions.

\section{Key Strategies}

NEEDS proposes achieving its goals in the following ways:

- Privatize, deregulate, and liberalize key sectors of the economy.

- Coordinate national sectoral development strategies for agriculture, industry (especially small and medium-size enterprises), and services (especially tourism).

- Develop infrastructure, especially electricity, transport, and water.

- Address the problems of financing the real sector, and mobilize long-term savings and investment.

- Create effective regulatory regimes that include environmental standards.

- Target programmes to promote private sector growth and development.

A major target of the current reform effort is the reduction of poverty. But the effects of some structural changes will be felt only after a lag. Medium-term growth performance is projected based on the assumption that given the reform efforts, almost every sector will perform better in the coming years. Stronger growth performance is expected as the private sector takes advantage of the different reform strategies and policies and as the government reduces its role in the economy and redresses the perverse incentive structure facing investors. Growth projections attach weights to different informal sector activities in order to capture the overall share of the sector in projected economic growth. Changes in agriculture will generally drive increases in growth.

Critical to growth performance is improvement in power and other infrastructure; a reduction in the cost of doing business; creation of a more conducive investment environment, including security of life and property; and training and development of the human resources needed to increase capacity and productivity. Human resource development is needed to reduce the reliance on expatriates and increase the contribution of the local labour force in foreign investment.

Strong growth is expected in the primary and secondary sectors, particularly agriculture, manufacturing, and solid minerals. The manufacturing sector is expected to grow at least 7 percent a year between 2004 and 2007, while agriculture is expected to grow about 6 percent. Growth in other sectors may not be as strong as growth in the primary sector. Aggregate output for the four years of NEEDS is projected to increase 5 percent in 2004, 6 percent in 2005, 6 percent in 2006, and 7 percent in 2007. Output in the oil and gas sector is expected to remain unchanged. The projected decline in oil production as Nigeria maintains its OPEC quota is expected to be offset by increases in gas production, leaving net output in the sector unchanged. Growth of the nonoil 
sector, the major target of the diversification effort, is expected to rise from 6.8 percent in 2003 to more than 9 percent in 2007.

Annual private consumption is expected to grow 4.8 percent in real terms. With projected population growth rate of 2.8 percent, this will mean a 2 percent growth in annual real per capita consumption. At the same time, public consumption expenditure is expected to steadily decline. Investible resources will be reallocated from the public sector to the private sector, and the investment pattern by both government and private investors will change. For example, with agriculture as a priority area in the medium term, the government will increase incentives for investment in the sector.

\section{Fiscal Operations and Policy: Budget, Tax Reforms, and Public Expenditure Management}

Fiscal policy is the most important instrument of macroeconomic management in Nigeria. Reforms at this level are therefore critical for overall macroeconomic consistency.

Despite plans to diversify the government's revenue base, Nigeria's fiscal and budget landscape has been dominated by oil income, which accounts for at least 70 percent of total government revenues. Swings in the international oil price and production create enormous volatility in government revenue. In periods of boom, government expenditures increase, while drops in oil prices are treated as temporary. The same pattern is repeated by the states and local governments.

Other problems include inefficient use of resources, waste and misplaced priorities in government expenditure, high fiscal deficits at all tiers of government, weak institutional structure, a fiscal federalism structure that places little or no premium on intertemporal fiscal solvency, and a weak institutional mechanism for regulating the actions of the different tiers of government and their agencies. These problems have led to a heavy debt burden, huge recurrent expenditure burdens at all tiers of government, inefficient public delivery of services, and distortions in the incentive structure for both the private and public sectors. Currently, all tiers of government spend far more than they earn: cumulative deficits over the past five years alone stand at more than $\$ 1$ trillion, excluding arrears of pensions and gratuities and debt to local contractors. With foreign debt of about $\$ 31$ billion in fiscal 2001 (in a $\$ 45$ billion economy), the government spends a huge proportion of current revenue in debtservicing and interest payments.

The budgeting process reached the point of near collapse before the democratic government came to power. The main problems have to do with lack of political will and commitment to abide by stipulated rules and budget guidelines. This has led to a high incidence of extrabudgetary expenditures and the breakdown of medium- to long-term plans to guide the budgeting process, with projects implemented haphazardly without proper evaluation and coordination. As a result, hundreds of projects lie uncompleted or abandoned; completing the projects would cost more than $\$ 100$ billion. Allocation to projects became ineffective and often arbitrary. Spread thinly over a large number projects, the allocations had little impact for the most part. A high level of recurrent expenditures and the lack of cooperation between tiers of government and line ministries with the coordinating agencies (such as the National Planning Commission and the Ministry of
Currently, all tiers of

government spend far

more than they earn:

cumulative deficits

over the past five

years alone stand at

more than $\$ 1$ trillion 
The success (or

failure) of the reform

programme hinges

largely on greater

fiscal coordination
Finance) undermine the budget process. The lack of a formal mechanism for dealing with budget surpluses or shortfalls has led to the issuance of warrants without cash backing.

\section{Policy Thrusts}

The key policy thrusts of NEEDS include the following:

- Create a predictable macroeconomic environment in which resources are used efficiently, predicated on a Medium-Term Expenditure Framework that ensures predictable and sustainable public finance at all levels of government.

- Adopt policies that are consistent with raising domestic savings and increasing private investments.

- Maintain a sustainable level of public debt.

\section{Key Strategies}

The key strategies and instrument include the following:

- Adopt a budget strategy that strengthens the planning process and project and programme evaluation, with early involvement of stakeholders.

- Adopt tax reforms aimed at raising revenues and diversifying the revenue base.

- Strengthen the Budget Office.

- Adopt a medium-term expenditure framework and a fiscal strategy paper consistent with the thrusts of NEEDS.

- Establish intergovernmental fiscal coordination based on a Fiscal Responsibility Act or similar initiative.

- Reform and strengthen the procurement process.

- Establish a fiscal rule based on the price of oil, and establish a stabilization fund for excess revenue from crude oil sales, with specific conditions for the fund's use.

- Establish a public expenditure rule that holds the deficit to no more than 3 percent of GDP.

Projections on the fiscal account are based on consolidated public sector revenue and expenditure profiles. The international price of oil is expected to decline over the period, but production and earnings in the gas subsector are expected to rise significantly, offsetting any negative oil price movements that may occur.

A basic assumption made in the fiscal account is that state and local governments balance their budgets. However, the federal government can borrow up to 12.5 percent of the previous year's retained revenue from the central bank to finance its deficits. This provision, which is consistent with the Central Bank Act, is expected to lapse in fiscal 2004.

Beginning in fiscal 2005, the projections in the fiscal account reflect the provisions of the West African Monetary Zone, which stipulates that no more than 10 percent of the previous year's retained revenue can be financed by the central bank. An oil price-based rule using projections of oil prices that are lower than the expected international price of oil over the timeframe is also adopted. Public sector (consolidated) deficits are constrained not to exceed 3 percent of GDP. While the reform plan has a long-term component, the framework is designed principally with a medium-term focus.

Given the proposed public sector reforms, overall recurrent expenditure as a proportion of total expenditure is expected to continue to fall. Currently, recurrent expenditure consumes about 70 percent of total revenues at both the federal and other levels of government. Given the planned increase in government efficiency, 
recurrent expenditure is expected to fall gradually over the reform period. State governments are assumed to maintain previous levels of recurrent expenditure (about 80 percent of total revenue) in 2004. The ratio of recurrent to capital expenditure is expected to improve to 70/30 in 2005 and to $60 / 40$ in 2006 and 2007.

All tiers of government in Nigeria suffer from the volatility of revenue and expenditure. State and local governments account for about 50 percent of consolidated public sector spending. This figure could increase with the proposed new revenue allocation formula. Over time it has been difficult to control the intertemporal distribution of expenditure of state and local governments using monetary and fiscal policies as the Constitution grants each state full autonomy over its fiscal actions. The success (or failure) of the reform programme hinges largely on greater fiscal coordination.

The Fiscal Responsibility Pact, expected to come into effect no later than 2005, will help achieve such coordination. Under the provisions of the bill, executive office holders are expected to structure their expenditures in line with the provisions of the capital and recurrent expenditure provisions of the reform programme. In addition, the central bank is currently discouraging bank lending to all tiers of government. According to the new rule, any bank is free to lend to any government agency, provided it provisions 50 percent of the loan value to the Central Bank of Nigeria if the loan is considered performing or 100 percent if the loan is considered nonperforming. The Securities and Exchange Commission is also revising the conditions for borrowing, lending, and floating bonds by all tiers of government to maintain consistency in the pattern of capital market access and usage by all tiers of government.
Coordination will be improved by the active use of the formal organs of government, including the National Council on Development Planning, the Joint Planning Board, and the National Economic Council.

While the key challenge is to rein in government spending and get all tiers of government to spend no more than they take in, spending must also be in line with predetermined priorities and reap value for money spent. Thus part of the strategy of the reform effort is to strengthen the due process mechanism and the institutions set up by the administration. Based on established sectoral priorities, the government will set expenditure ceilings through lump-sum allocations to public enterprises and government agencies, and it will monitor the performance of these agencies. The overall aim is to gradually but consistently reduce the government deficit from the current 5 percent to no more than 3 percent of GDP over the lifespan of NEEDS. Doing so will require a roll-back of recurrent expenditures by all three branches of government-executive, legislature, and judiciary-as well as by all tiers of government, primarily through efficiency gains.

The budgeting framework will adopt a mandatory calendar that ensures early involvement of the legislature and finalization of the budget at least three months before the beginning of a new budget year. In collaboration with the National Planning Commission, the Budget Office will produce and disseminate quarterly monitoring and evaluation reports to the general public. The budget process will also be reformed to reduce or eliminate arbitrariness. Essentially, the budget will be in line with the policies and priorities of NEEDS, subject to more detailing of programmes and projects by line ministries and state enterprises.
While the key

challenge is to rein in

government spending

and get all tiers of

government to spend

no more than they

take in, spending

must also be in line

with predetermined

priorities and reap

value for money spent 
Part of the new strategy will be to

introduce a more

collaborative

approach between the

executive and

legislative branches of

government in order

to enhance the

effectiveness of the

budget process
In the immediate term (2004 and 2005), the aim will be to introduce a more orderly and disciplined budget formulation process that tries to corral the numerous sources of extrabudgetary expenditures, a process that involves input upfront from both the executive and the legislative branches on priorities. The lack of ownership by the legislature of the priorities set forth by the government in previous budgets-as well as attempts to add priorities, regardless of the impact on the overall fiscal position-virtually derailed the budget process in 1999-2003. Part of the new strategy will be to introduce a more collaborative approach between the two branches of government in order to enhance the effectiveness of the budget process.

The bloated federal recurrent budget is unsustainable, as is the unwieldy capital account, a substantial part of which is made up of abandoned and underfunded projects. State governments also have bloated recurrent expenditures and little room for capital programmes. The challenge is to design appropriate strategies and action plans to redress the situation.

The public sector capital programme will be rationalized to give priority to health, education, agriculture, power supply, and the maintenance of infrastructure projects that have high linkage effects with other projects and those that will generate employment at minimal cost. A sunk cost approach will be introduced in determining whether to proceed with ongoing and abandoned projects. Rigorous project selection criteria will be imposed on new projects, including the need to ensure funding to completion. The cleaning up of the budget will produce a more concise capital programme in fiscal 2005.

Pruning waste. NEEDS will support new procurement procedures by strengthening the due process mechanism and developing a catalogue of commonly procured equipment, supplies, and services as a reference for ministries and agencies. Tender procedures will be enforced, and the scope of checks on value for money will be expanded.

Procedures for competitive bidding, contract review, and award of various levels of contracts have been introduced. The Budget Monitoring and Price Intelligence Unit was created in the Presidency to oversee the procurement reforms and push implementation of the due process review and contract certification process. The mechanism will be strengthened and upgraded into the Federal Procurement Commission. Accounting officers will ensure that excessive expenditures discovered by postauditing checks are recovered from those responsible. Every department will have internal and external auditors, who will be responsible for tracking expenditures and ensuring value for money.

Increasing revenue generation and supporting tax reforms. The reforms also aim at strengthening the machinery for tax collection, tracking all government revenues paid into different bank accounts as well as recovering debts, misappropriated and looted funds, and payments for work not executed. State and local governments are expected to gear up their efforts to generate revenue rather than depend on statutory allocation from the federation account or borrowing on the capital market.

In the short to medium term, the strategy will address six issues:

- The structure of the tax system

- Revenue generation

- Efficiency of collection

- Tracking and response to comparative and international standards

- Investment promotion

- Coordination of tax administration 
The structure of the tax system overwhelmingly favours indirect taxes. Although these taxes are generally regressive, the high rate of evasion of direct taxes-attributed mainly to poor data on people and sources of income (the result of a large informal sector) - makes indirect taxes attractive. This structure will continue over the NEEDS period. The main sources of nonoil revenue include customs tariffs, value-added tax, and sales taxes. Governments at all levels will continue to explore the possibilities of collecting user charges on infrastructure and some social services.

The government is collecting far less in income tax (individual and corporate, including withholding taxes) than it should. The tax collection machinery will therefore be revamped, restructured, and strengthened for more effective collection.

A new phenomenon is the loss of revenues arising from the system of remittance of tax revenues paid through banks to the appropriate authority. Significant revenue is being lost through diversion and inadequate monitoring of the process. Such leakages will be plugged, and defaulting banks will be delisted and subject to substantial penalties.

In addressing the level and structure of taxes, attention will be paid to competitiveness.

Taxation and fiscal policy will be pro-poor and used as an instrument for reducing high income disparities, as well as providing incentives for investment and productivity growth. Direct taxes on lower income groups will be reduced, while those of the highest groups will be increased. But the structure will pay attention to the competitiveness of Nigeria relative to countries at similar levels of development with which Nigeria has to compete for foreign direct investment. The tax structure will establish a level playing field, adjusting for the cost of doing business due to poor infrastructure, and stimulate private investment in the real sector.

A major nuisance to businesses operating in Nigeria is the multiplicity of taxes imposed at the federal, state, and local levels. While NEEDS will not encourage the pooling of all taxes in a federal system, it will seek agreement among all tiers of government on which level should collect which taxes and how, in order to avoid too great a multiplicity of taxes and conflicting methods of collection. The Joint Tax Board and the peer review mechanism to be established under this strategy will help achieve a more harmonized tax system and ensure coordination and compliance.

Efforts will also be intensified to increase the contributions to public sector financing of major public enterprises, such as the Nigeria Maritime Authority, the Nigeria Ports Authority, the Federal Airports Authority of Nigeria, the Shippers' Council, the National Civil Aviation Authority, the Securities and Exchange Commission, and NICON Insurance. Over time, these public enterprises have made minimal contributions to development.

\section{The Balance of Payments}

Historically, the Nigerian external sector account could be referred to simply as an oil account. Because of the economy's lack of diversity, swings in OPEC quotas and large changes in the international price of oil have continued to dictate the direction and pace of shifts in the external account. As a result of increases in the OPEC quota, especially since 2000, the country's current account balance and reserves showed remarkable improvements, with reserves reaching a 10-year high of $\$ 10.4$ billion in 2001 . There are few assurances that the government's efforts to secure
Historically, the

Nigerian external

sector account could

be referred to simply

as an oil account 
Nigeria's tariff and

trade policies are out

of tune with trends in

the Economic

Community of West

African States and in

other developing

countries additional increases in the country's OPEC quota will be successful in the short term, however.

The volume of imports in Nigeria is high, and imports are diversified. Imports range from capital goods and machinery to unprocessed food and other primary items. This high propensity to import food items and the associated health hazards they pose has been a source of concern to the government, which has imposed temporary bans on some items.

Nigeria's tariff and trade policy is characterized by uncertainty and highly varying rates of protection, and its customs and ports clearance system is inefficient. Policies are out of tune with trends in the Economic Community of West African States (ECOWAS) and in other developing countries. External reserves are volatile, capital flight persists (albeit at a lower rate than under the military regimes), and inflows of portfolio and foreign direct investment into the nonoil sectors remain weak relative to the size of the economy. The external debt overhang remains ominous, with total debt service payment about equal to the federal government's capital budget (even when the government is not fully servicing all the service payments due).

The balance of payments situation is not sustainable. Oil prices cannot continue to rise indefinitely, and increases in the OPEC quota are not guaranteed. Aggressive export diversification and expansion as well as gradual import liberalization represent the winning strategies for moving forward.

\section{Policy Thrusts}

NEEDS is based on four main policy thrusts:

- Promote exports and diversify exports away from oil.

- Gradually liberalize imports, harmonize tariffs with ECOWAS' common external tariffs, and use special levies and import prohibitions to protect local industries.

- Establish a market-determined nominal exchange rate regime, and avoid overvaluation of the real exchange rate.

- Seek debt reduction to make Nigeria's debt service sustainable.

The trade balance has been in surplus in recent years, as a result of the rise in oil prices. Balance of payments projections assume no change in Nigeria's OPEC quota and stable oil prices of \$22-\$23 a barrel between 2004 and 2007 . This cautious posture is due mainly to the expected re-entry of Iraq into the oil market and the unpredictable behaviour of Russian oil supply. However, negative changes in the international oil market may not be fully reflected in the balance of trade because of expected positive changes in the gas subsector, where production and earnings are expected to rise.

Export earnings should be diversified. In the short run, the emphasis should be on the export of food and other primary products, with value added to exports over time. Incentives will be given to domestic producers in manufacturing and agriculture to exploit opportunities provided by the numerous bilateral and multilateral trade concessions of which Nigeria is a potential beneficiary.

Despite these incentives, only small changes are expected in the volume of imports in the short run. Although Nigeria has banned the importation of some products, the share of these products in total imports is small. Furthermore, the lowering of tariffs in tandem with the rates set by the West African Economic and Monetary Union is likely to increase the import bill, perhaps offsetting the effects of the import bans. Factor payments arising from industrialization programmes and the import of industrial raw materials will continue, at 
least in the short run, to put some pressure on the current account. Thus annual current account deficits of about 0.52 percent of GDP are expected between 2004 and 2007.

With modest deficits, net reserves will grow slowly but steadily, from $\$ 7.7$ billion (about five months' imports cover) in 2004 to $\$ 10.7$ billion (more than six months' import cover) in 2007. This growth is expected to arise from a larger export base and slower growth of imports. The projection for reserves is within the minimum stipulations of the West African Monetary Zone, allowing Nigeria to keep pace with the regional integration process while pursuing its domestic reform programmes.

Assumptions on debt service payment are optimistic. Only 53 percent of the $\$ 12.3$ billion of debt service due between 2004 and 2007 is expected to be paid in full. The states will account for 25 percent of payments, while the federal government will take up the other 75 percent. If the reforms stay on course, with policy consistency and increased prudence in the management of public resources, Nigeria is expected to be able to get debt relief, substantially reducing external debt service payments.

Debt relief would also reduce the debt stock, significantly affecting the overall balance. Additional resources from debt relief are expected to show up in increased spending on the social sectors (health, education, water, and infrastructure). This reallocation would increase the impact of the reform programme on human capital development, a major policy goal of reform. In addition, current efforts by the Debt Management Office to sensitize state governments to the implications of their fiscal actions will be increased. In this regard, civil society has a responsibility to demand accountability from public office holders.
Securitized domestic public debt nearly quadrupled between 1996 and 2003, rising from about $\AA 343$ billion to about $\$ 1.3$ trillion. The domestic debt stock is characterized by a number of deficiencies. One is that the stock is concentrated at the short end of the market. About 60 percent of the stock is made up of 91-day Treasury bills; longer term debt constitutes less than 25 percent. This implies a mismatch between assets and liabilities, as much government expenditure is long term.

Another defect is that nonbank public holdings of government securities represent just 6 percent of all debt; the central bank and deposit banks hold about 94 percent. The large holding of government securities by the banking system has adverse implications for the growth of the money supply and the effectiveness of monetary policy. Although reliable figures on nonsecuritized public debt are not available, indications are that the figures run into the trillions of naira for all tiers of government.

\section{Key Strategies}

During the medium term, policy will focus on:

- Restructuring existing securities into longer term bonds

- Reducing central bank holdings of the government debt so that the Central bank of Nigeria has wider room for efficient and unconstrained monetary policy

- Financing government deficits by floating bonds in the capital market

- Developing an efficient capital market

In August 2003 the government floated A150 billion of federal bonds, with tenors of $3,5,7$, and 10 years - the first bond issue in 17 years. $A$ major goal of domestic debt management during the programme period will be to sustain this effort by lengthening the term structure of debt and
If reforms stay on

course Nigeria is expected to be able to get debt relief, substantially reducing external debt service payments 
increasing nonbank public holding of government debt in order to bring government borrowing under the discipline of the capital market.

In addition, domestic borrowing guidelines will be developed and applied to all tiers of government and their agencies. These guidelines will help ensure that the unsustainable and defective domestic debt portfolio of the federal, state, and local governments does not deteriorate.

The conduct of the monetary, credit, and exchange rate policies

will continue to be

guided by the central

bank's guidelines,

now issued for twoyear periods

\section{Monetary and Exchange Rate Policies}

Historically, monetary policy in Nigeria was mainly short term, but the Central Bank of Nigeria has recently moved to a medium-term framework. Given the fiscal posture for the reform period, monetary policy outcomes will depend largely on the government's fiscal stance. The disparity between monetary targets and outcomes is wide largely because of the statutory financing of budget deficits and the inability of the apex bank to sterilize the liquidity effects of government expenditures. Thus monetary policy intervention has been basically reactionary and short term, leading to missed targets and ineffectiveness in performance. Despite the fact that the basic goal of monetary policy has been price stability, inflation has been relatively high and above the West African Monetary Zone targets.

\section{Policy Thrusts}

NEEDS supports several main policy thrusts:

- Strive to meet the second West African Monetary Zone's convergence criteria.

- Maintain low real lending interest rates.

- Maintain a competitive but stable exchange rate regime.
- Restructure the composition of credit to the private sector to boost production.

- Provide more credit to the private sector, especially long-term credit for real sector development.

- Create effective regulatory and supervisory mechanisms to ensure orderly development of the financial system.

- Continue to use the retail Dutch auction system to determine the nominal exchange rate regime, and adopt a wholesale Dutch auction in the medium to long term.

The conduct of the monetary, credit, and exchange rate policies will continue to be guided by the central bank's monetary, credit, foreign trade, and exchange policy guidelines, which are now issued for two-year periods. The current guideline, Monetary Policy Circular No. 37, covers the policy guidelines for fiscal 2004 and 2005. The overall goal of monetary policy remains price and exchange rate stability; the instruments are those consistent with a deregulated financial system.

Given that the government is committed to a tighter fiscal stance, the inflation rate is expected to drop progressively over the four-year time horizon, reaching 9 percent by 2007. The decline in inflation is expected to improve the macroeconomic environment for planning and to reduce pressure on domestic costs and real interest rates. Interest rates will remain deregulated and market determined, but policy will aim at rates that are above the inflation rate in order to mobilize savings. The reform programme will aim to reduce the spread between lending and deposit rates of interest.

Historically, the structure of credit allocation has been a problem. It is widely believed that public sector demand for credit crowded out the private sector. Credit to the private sector has 
also been affected by the low absorptive capacity of the economy. Monetary projections for the reform period envisage lower public sector deficits, increasing the availability of funds for lending to the private sector. Banks need inducements to lend to the private sector rather than trade in government instruments, conduct foreign exchange transactions, or finance shortterm (commercial) activities.

Providing credit to the private sector will be encouraged through a set of incentives. The central bank has already introduced a credit (risk) guarantee scheme for commercial bank lending to small and medium-size enterprises and the agricultural sector. Other incentives, such as the rediscounting and refinancing schemes of commercial bank debts for small and mediumsize enterprises, will be intensified. The aim is to create incentives that alter the structure of banking from deposit driven to credit giving. Given these incentives, credit to the private sector is projected to grow at least 30 percent a year. The framework also provides for steady but slow average annual changes in broad money over the reform period. With a substantial decline in government borrowing, less financing of government deficits by the central bank, and reduced dependence on oil income for foreign exchange earnings, changes in broad money are expected to be less volatile. 


\section{Part Two}

\section{Empowering People}

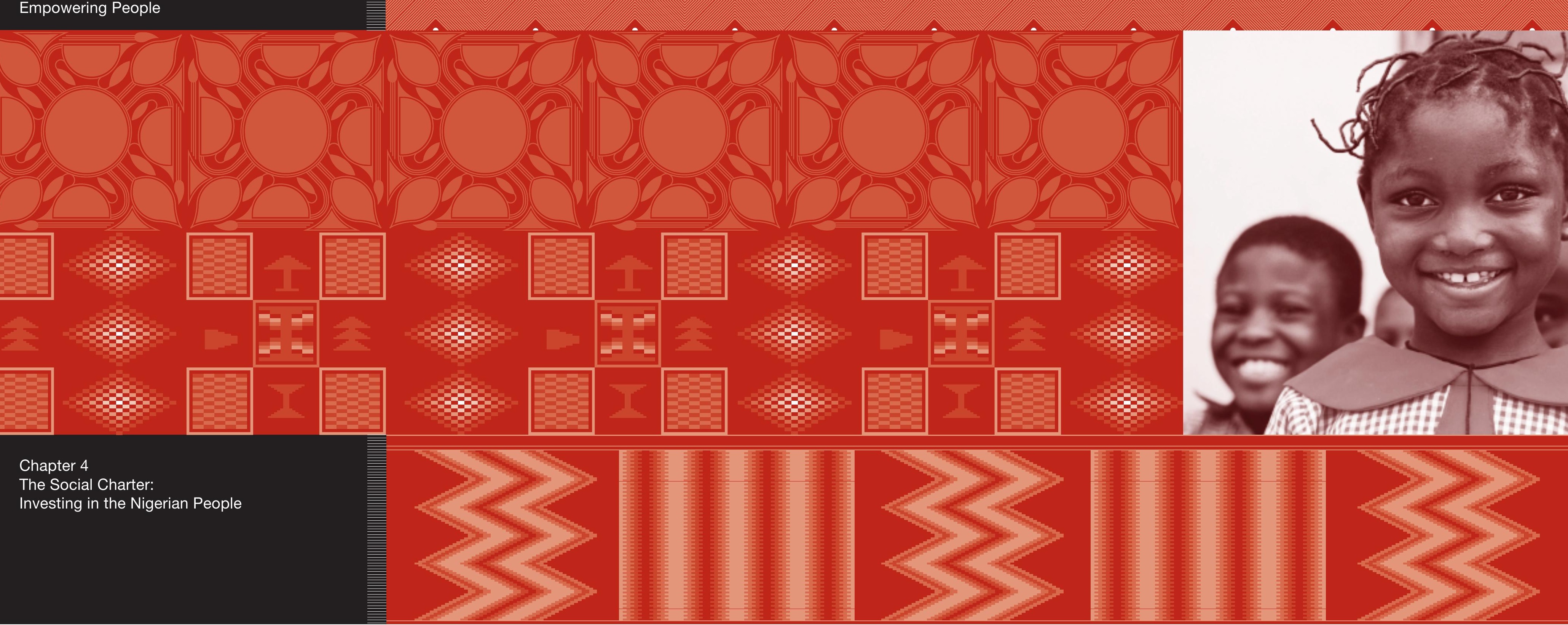




\section{Chapter 14 The Social Charter: Investing in the Nigerian People}

NEEDS is about the Nigerian people- - their health, education, employment, happiness, sense of fullilment, and general well-being (box 4.1). This chapter presents the social agencis

Boosting economic

growth and

empowering people

calls for a human

rights approach to

development planning

that places people at

the centre of

development efforts

\section{Current Challenges}

The social charter refers to the contract between the individual and the government in which the government recognizes the individual's rights and
responsibilities and promises to deliver the basic necessities for a decent human existence. These necessities include potable water, food, clothing shelter, adequate nutrition, basic education, primary health care, productive assets, security, and protection from shocks and risks. Social conditions in Nigeria present a startling paradox: despite a rich endowment of natural and human resources, most of the country is poor. For decades the country has struggled to improve socioeconomic conditions, which have declined despite increasing revenue from crude oll. The growing incidence and the dynamics of poverty in Nigeria have stratified and polarized Nigerian society between the haves and the havenots, between the north and the south, between the educated and the uneducated. Poor parents beget poor children, creating a kind of dynasty of have eroded the fabric that held society together. The challenge is not only to reform the economy in order to boost economic growth but also to empower the people as a means of also to empower the people as a means of revitalizing the weakened social pillar. Doing so ment planning that places people at the centre of denelopment efforts. The added value provided development efforts. The added value provided
by this approach is that the norms and values enshrined in it have the potential to empower the poor. This is important, because it is now widely recognized that effective poverty reduction is not possible without doing so

\section{Poverty Reduction}

Poverty reduction is the most difficult challenge facing Nigeria and its people and the greatest obstacle to pursuit of sustainable socioeconomic growth. The poverty rate in Nigeria increased from 27 percent in 1980 to 66 percent in 1996 (table 4.1); by 1999 it was estimated that more than 70 percent of Nigerians lived in poverty. Life expectancy is a mere 54 years, and infant mortality $(77$ per 1,000$)$ and maternal mortality (704 per 100,000 live births) are among the

Box 4.1 Measuring the Quality of Life: Comments by President Olusegun Obasanjo

Too often we attempt to measure progress by statistical aggregates and technical prowess. We thereby tend to overlook that the main goal of life is to ensure sunvival and to enable everyone to realize his full potential for well-being, fuffilment, and accomplishment in happiness, joy, love, and contentment. National income figures neither reveal the real beneficiaries nor the composition of that income. They do not value the things that human beings consider important for themselves but have ilf or no market value for others or those beholden (latsical aggregats - fredom or choice, better physical violence, better working conditions access to knowledge and information, closeness of family life to community life, satisfying leisure and recreational facilit and time, a sense of participation in the economic, cultural, religious, and political activities of their communities. People also want higher incomes, but income is never the sum total of human life. For most people, heatth, security, freedom, love, recognition, and fulfiment through active participation and accomp

We must not continue to stress the purs growth rate in statistical terms and fail to reduce the and group of our people. We must not absolutely pursue wealth and growth at the expense of inner wetbeing, joy, satisfaction, fulfiment, and contentment of human beings. This, to me, is human development. The human development idea pioneered by Mahbub ul Hag. Pakistan's former Minster of Finance, and under the distinctive from other concepts of growth and development. Economic growth is surely neces not sufficient for human development. For this purpose and to ease the complexity of measurement. UNDP concentrates on only three yardsticks of well-being which are regarded as the essentials of human lifelongevity, knowledge, and a decent standard of living. will add security, participation, and choice.
With relative poverty, a careful judicious and equth no reason why most of the essential goals of human the first decade of the twenty-first century. We have the knowledge and enough resources for this purpose. We only need the political will to break the mould and to remain resolutely consistent and undiverted. Our reform policies, Givin mas be doggedly pusued, are indamental, ifie-

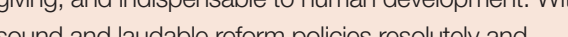
successfully inplemented, ther must, of necesity be mproved incomes. There can be no sustained momentum over the period without a rise in revenue and income at the national, state, community, family, and individual levels. This will entail some element of income redistribution. National economic growth must be pursued relentlessly, but at the same time we must ensure far and reasonable distribution of its fruits. Eradication of comuption will certainly enhance

For vonness or hum an development nationwide, or well and as much as on the reuban population as provision of electricity water roads, health, and sanitation in urban and rural areas must continue to be accelerated. The rural areas, in particular, must be made more livable and worth living in. Along with the physical aspects of viliage and rural renewal and development must be access to education, which will include adu education and distance learning. Human development will be grossly undermined and medium wher

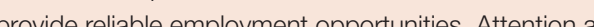
direction must be turned to this. Human development may not necessarily mean uniform human progress, but t must indicate discernible and reasonable progress, fulfiment, and satisfaction for almost all.

Source: Letter from President Olusegun Obasanjo, September 2003. 
Factors that have contributed to poverty

in Nigeria include

problems in the

productive sector

widening income

inequality, weak

governance, socia

conflict, and gender,

intersectoral, and

environmental issues highest in the world. Other social indicators (from 1999) are also weak:

- Only about 10 percent of the population

had access to essential drugs.

- There were fewer than 30 physicians per 100,000 people.

- More than 5 million adults were estimated to be living with HIV/AIDS.

- Among children under five, almost 30

percent were underweight.

- Only 17 percent of children were fully immunized-down from 30 percent in 1990-and almost 40 percent had never been vaccinated.

- Only about half the population had access to safe drinking water (40 percent in rura areas, 80 percent in urban areas).

- Some 29 percent of the total population

lived at risk from annual floods.

- More than 90 percent of the rural population and domestic enesgy for

- Rural households spent an average of 1.5

hours a day collecting water and fuel wood, with household members walking an average of one kilometre a day to collect water and fuel wood.

Qualitatively, poverty in Nigeria has many manifestations and dimensions, including oblessness, over-indebtedness, economic dependence, lack of freedom, inability to provide the basic needs of life for self and family, lack of access to land and credit, and inability to save or own assets. Poor people tend to live in dirty localities that put significant pressure on the physical environment, contributing to environmental degradation. The poor, especially farmers, perceive their economic circumstances to be fraught with uncertainty, affected by events over which they have no control, such as primary commodity prices, the volume of rainfall, pest attacks, fire outbreaks, changes in soil conditions, and social conflicts. Lack of food is the most critic dimension of poverty, reflected in the popular saying that "when hunger is excised from "Wurden of poverty is light."

\section{Causes of Poverty}

nadequate growth is the main cause of poverty in Nigeria. The lack of growth is compounded by the volatility of the oil sector, which affects a range of activities in the economy. High and growing unemployment increases the number of poor people. Other factors that have contributed to the level and evolution of poverty in Nigeria include problems in the productive sector. widening income inequality, weak governance, social conflict, and gender, intersectoral, and environmental issues (table 4.1).

Problems in the productive sector. The limited growth of investment and technological

innovation has constrained the labour absorption capacity of the nonagricultural sector, especially manufacturing. This lack of capacity has exacerbated poverty, especially in urban areas. Two other factors--problems associated with the transition away from high-cost industries that are heavily dependent on imports and the impact of globalization on domestic industries that are unable to compete with imported substitutes-also appear to have contributed to the limited growth of domestic production and employment. International evidence from

countries in roughly comparable circumstances low, providing weak underpinning for the

sustained domestic investment growth needed in the fight against poverty.
Table 4.1 Incidence of Poverty in Nigeria, Selected Years

(percentage of poor people in total population)

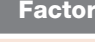

National 1980 1985 1992

Northeast

Northwest

North Central

Southeast

Southwest

Sector

Sector

Urban $-378-375$

$\begin{array}{lllll}\text { Rural } & 17.2 & 37.8 & 37.5 & 58.2 \\ & 28.3 & 51.4 & 46.0 & 69.3\end{array}$

Gender of head of household

Male

Size of household

1 person

-4 people

5-9 people

10-20 people

More than 20 people

$29.2 \quad 47.3$

$47.3 \quad 45.1$

45.1
46.4

ducation of head of household

None

Primary

Secondary
Postsecondary

\begin{tabular}{ll}
2.9 & \\
2.0 & 7.0 \\
8.8 & 193 \\
30.0 & 50.5 \\
51.0 & 713 \\
80.9 & 740 \\
\hline
\end{tabular}

700

Age of head of household

$\begin{array}{lllll}15-24 & 16.2 & 25.3 & 28.7 & 37.4 \\ 25-34 & 17.8 & 33.4 & 28.5 & 52.7 \\ 35-44 & 26.7 & 46.0 & 42.1 & 64.6 \\ 45-54 & 27.1 & 49.7 & 45.7 & 71.3 \\ 55-64 & 39.7 & 55.7 & 48.2 & 69.9 \\ \text { Older than } 65 & 28.8 & 49.1 & 49.5 & 68.0\end{array}$

$\begin{array}{lll}7.0 & 29.0 & 13.1 \\ 19.3 & 19.3 & 59.3 \\ 50.5 & 51.5 & 74.8 \\ 71.3 & 66.1 & 88.5 \\ 74.9 & 93.3 & 93.6\end{array}$

Note: The Federal Office of Statisitics is conducting a new housenold survey. More current data will be avaliable shor

Source: Federal Office of Statistics 
Income distribution. Widening income inequality has contributed significantly to the increase in poverty in Nigeria. Economic growth has tende to benefit people who work in public sector manage decline in the living standards of a grem ing number of pensioners (including retired members of the Nigerian middle class), due to underfunding of the Nigerian mitds (ncluding), due tounderfund and managen mic po

Governance problems are widely thought to have been among the major reasons why

past poverty

programmes have had little effect

Weak governance. Weak governance (including corruption) is believed to have contributed significantly to poverty in Nigeria. Governance the major reasons why past poverty alleviation programmes have had little effect. The capacity of individuals and businesses to exploit the potentia of the Nigerian economy has been hampered by the costs associated with corruption.

Social conflict. The economic and social dislocations caused by internal conflicts have negatively affected the economic well-being of individuals and businesses in various ways. Conflicts often lead to the deaths of principal income earners or the destruction and loss of displaced from conflict areas often face inadequate infrastructure and other facilities needed to earn a decent living. The occurrence-and in several cases reoccurrence - of social conflicts in various localities in Nigeria has increased poverty, not only in areas directly affected by the conflict but also in areas affected by inflows of internally displaced people. The uncertainties associated with actual or potentia conflict situations also tend to discourage domestic and foreign investments.
Gender. As in many developing countries, women They escaping povery. Party due to talition for rights and inheritance practices widows are more vulnerable to poverty than widowers. Partly because they have less formal educetion than their male counterparts, women generally benefit ess from using employment to fight poverty Children's and Women's Rights in Nigeria: A Wake-Up Call a 2001 study published by $A$ Wake-Up Call, a 2001 study published by the provides detailed informition on the proE, progress, and possibilities facing women and children in Nigeria The study is a valuable source of information for developing gender policies as the implementation of NEEDS proceeds.

Intersectoral factors. Some evidence suggests that the rural sector, where about 70 percent of Nigeria's people live, has been facing a more serious poverty situation than the urban sector. The difference is caused by a variety of factors including the following:

- Sharp seasonality in the flow of production, income, and employment opportunities in the rural sector

- Shortage of social and economic

infrastructure compared with urban areas

- Migration of the educated workforce to urban areas and the consequent aging of the rural population

- Low productivity of rural (and especially agricultural) production, due partly to limited access to credit, pesticides, extension services, and modern technology for agricultural production, processing, and preservation

At the same time, increases in population are putting pressure on limited resources in urban areas, which face serious problems of unemployment underemployment, and housing and other environment-related problems.

Environmental factors. Empirical evidence shows that poverty and environmental degradation are inextricably linked in Nigeria, because 75 perce of rural people depend on natural resources for their Iivelinood. Environmental degradation sustainable incomes. Left with no other viable options, they engage in win no other viabse options, hey engage in extractive activities, contibuting to the vicious cycle of poverty and also more vulnerable to environmental disasters and hazards and have few or no strategies for coping with these stresses. In urban areas the poor live in slums, where they are exposed to overcrowded living quarters, unsafe water. improper waste disposal, and other health risks. These conditions reduce savings and investment at the individual, household, and national levels.

Other factors. Other factors affecting poverty in Nigeria include the following:

- Historically, actual and potential participants in economic activity faced an unstable and inconsistent policy environment, which hindered the sustained pursuit of personal or corporate economic improvement plans. Poor maintenance has caused Nigeria's infrastructure to deteriorate, increasing the cost of production and limiting opportunities for employment growth and other means of exit from poverty.

- Nigeria faces significant debt service payments, which eat up resources that could otherwise have been used to expan social services and other antipoverty programmes.
- Nigeria's population is growing at the relatively rapid rate of rate of 2.83 percen a year, making it difficult to increase per capita income.

\section{Weakness of Past Antipoverty Initiatives}

The response of various administrations to the

poverty problem appears to have been largely ad hoc and uncoordinated. A recent survey of policies and interventions chronicles 28 federal projects and programmes with poverty reduction thrusts. Several state governments have also put ion schemes in place.

Programmes such as community banks, family Ppport programmes, the National Directorate of Employment, the Peoples Bank, Better Life for Ru Women, and the Directorate of Food, Roads, and Rural Infrastructure were established by different governments to address various manifestations of poverty, such as unemployment, lack of access to credit, and rural and gender dimensions of poverty. While none of these programmes was completely without merit, none of them had a significant, lasting, or sustainable positive effect.

With the advent of democratic government in 1999, measures were adopted to streamline poverty-related institutions, review past poverty efforts. Several major factors hindering the success of government efforts to reduce the level of poverty were identified. They included:

- Poor coordination

framework

- Excessive political interference

- Ineffective targeting of the poor, leading to

leakage of benefits to unintended beneficiaries - The unwieldy scope of programmes, which caused resources to be thinly spread across too many projects
Empirical evidence shows that poverty and environmental degradation are inextricably linked in Nigeria 
- Overlapping functions, which led to institutional rivalry and conflicts

- The absence of sustainability mechanism in programmes and projects

- Lack of involvement of beneficiaries in project design, implementation, monitoring, and evaluation

\section{Policy Thrust and Targets}

NEEDS seeks to significantly improve the quality of life of Nigerians, create social safety nets for the vulnerable, and meet the needs of people displaced by the reform process. Economic strategy. Given that overall economic growth may not generate poverty reduction at the desired pace, actions to facilitate individual economic empowerment, particularly among the poor and
other vulnerable groups, are imperative. To reduce poverty, NEEDS will seek to meet the following broad targets:

- Increase average per capita consumption by at least 2 percent a year.

- Create about 7 million jobs by 2007.

- Increase immunization coverage to 60

percent by 2007.

- Increase the percentage of the populatio with access to safe drinking water to at least 70 percent by 2007.

- Significantly increase school enrolment rates. especially for girls, and increase the adult. literacy rate to at least 65 percent by 2007

- Significantly improve access to sanitation.

\section{Sectoral Strategies}

Achievement of the social sector targets depends critically on collaboration by all stakeholdersederal, state, and local governments, as well as the private sector, nongovernmental organizaions (NGOs), and the international community. Sector-specific strategies will be developed in 2004 to ensure synergy and complementarity in the intenventions of the various actors in each of the social tons of the various actors in education, helth, environment, and other socia sectors will serve as the fulcrum for the development of such strategies, which wit covelopment of such strategies, which wit objectives of the sector-wide strategies are to eliminate duplication and waste, clearly deline roles and responsibilities, and prioritize and cost sectoral programmes, by creating targets and benchmarks, monitoring mechanisms, and timelines. The strategies will address the effectiveness of senvice delivery in each sector. Increasingly public spending in these sectors rely on key performance benchmarks.

\section{Empowering People through Education}

The Constitution of Nigeria gives all citizens the right to education. But the delivery of education compounded by inadequate attention to policy compounded by inadequate attention to policy
frameworks within the sector. Findings from an ongoing educational sector analysis confirm the poor state of education in Nigeria. The national literacy rate is currently 57 percent. Some 49 percent of the teaching force is unqualified. There are acute shortages of infrastructure and facilities at all levels. Access to basic education is inhibited by gender issues and sociocultural beliefs and practices, among other factors. Wide disparities persist in educational standards and learning achievements. The system emphasizes theoretical knowledge at the expense of technical, vocational, and entrepreneurial education. School curricula need urgent review to make them relevant and practice oriented.
NEEDS recognizes education as the vital transformational tool and a formidable instrument for socioeconomic empowermen The education sector has responsibility for producing and supplying the personnel required to propel and sustain the NEEDS initiative. The goals of wealth creation, employment generation, poverty reduction, and value reorientation can be effectively pursued, attained, and sustained only through an efficient, relevant and function system. Education is critical to meeting the goals set by NEEDS. It is also a sector that the initiative seeks to reform.

Policy thrust. The overall policy thrust of NEEDS in education is to:

- Provide unhindered access to compulson universal basic education to all citizens as a bridge to the future socioeconomic

transformation of Nigerian society.

- Establish and maintain enhanced quality and standards through relevant, competency-based curricula and effective quality control at all levels.

- Enhance the efficiency, resourcefulness, and competence of teachers and other educational personnel through training. capacity building, and motivation.

- Strengthen Nigeria's technological and scientific base by revamping technical, vocational, and entrepreneurial education and making optimal use of information and communication technologies to meet the economy's manpower needs.

- Provide an enabling environment and stimulate the active participation of the private sector, civil society organizations, communities, and development partners in educational development.
Educational goals and key strategies. NEEDS sets six goals for education. The first is to ensure sets six goals for education. The first is to the total development of the individual Targets for achieving the goal include the following:

- Increase the percentage of graduates of - primary schools who acqui function - liter

- Iiteracy and numeracy to 100 percent. secondary school graduates who go on to senior secondary school or senior secondary technical school to 80 percent. - Increase the percentage of senior
secondar secondary school and senior secondan technical school graduates who go on to tertiary institutions to 20 percent.

- Increase the adult literacy rate to

percent.

- Reduce the number of cases of examination malpractice in educational institution by 40 percent.

- Reduce the number of cases of cultism in educational institutions by 90 percent.

- Increase to 90 percent the percentage of primary and secondary schools that physical development.

- Ensure that all tertiary institutions establish sustainable programmes of physical development.

The second goal is to improve the quality of education at all levels. Targets for achieving the goal include the following:

Ensure that 80 percent of primary schoo teachers acquire the minimum teaching qualification (the National Certificate in Education)

- Ensure that 90 percent of secondary school teachers obtain professional qualifications (B.Ed., PGDE). 
- Ensure that 80 percent of teachers in tertiary institutions acquire pedagogical skills.

- Ensure that 80 percent of teachers at all levels are professionals.

- Ensure that 50 percent of primary schoo Ensure that 50 percent of primary scho
have conducive teaching and learning environments.

- Ensure that 60 percent of secondary schools have penducive teachingary schools have conducive
learning environments.

- Ensure that 60 percent of all tertian institutions have conducive teaching and learning environments.

- Ensure that 60 percent of head teachers and assistants undergo training in schoollevel management.

- Establish an efficient institutional framework for monitoring learning and teaching process at all levels.

The third goal is to use education as a tool for improving the quality of life through skill acquisition and job creation for poverty reduction. Targets for achieving the goal include the following:

- Ensure that Nigerians who have completed basic education acquire the literacy, numeracy, and basic life skills needed to live meaningful lives and contribute to

national development.

- Ensure that 50 percent of secondary school students have access to good-quality vocational and entrepreneurial education.

- Ensure that 50 percent of tertiary education graduates acquire sufficient technical skills, entrepreneurial skills, and knowledge to be self-employed and wealth creators

The fourth goal is to ensure periodic review and effective implementation of the curriculum at the secondary level to meet the requirements of higher education and the world of work. Targets

for achieving the goal include the following: to emerging global issues.

- Rehabilitate vocational basic technology

- Ra resource centres nationwide.

- Establish new basic technology an

resource centers nationwide.

- Produce education materials that reflect

the revised curricula.

- Establish libraries and information resource

centers for teachers and students to

complement formal and life-long education

and create awareness of their importance.

- Involve local craftspeople in the delivery of

vocational education in schools.

The fifth goal is to mobilize and develop

partnerships with the private sector and local

communities to support and fund education.

Targets for achieving the goal include the following:

- Improve collaboration among majo stakeholders.

- Achieve 80 percent community involve-

ment in the management of schools.

- Achieve 60 percent private sector

involvement in managing and funding education.

- Retain the 2 percent education tax and enforce 100 percent compliance.

The sixth goal is to promote information and communication technology capabilities at all fevels. Targets for achieving the goal include the ollowing:

Ensure that 10 percent of primary schoo

graduates are computer literate.

Ensure that 80 percent of secondary

school graduates are computer literate.

- Ensure that 80 percent graduates of

tertiary institutions are computer literate.
- Ensure that 50 percent of school managers and proprietors are computer literate. - Ensure that 30 percent of secondary schools have functional information and communication technology facilities.

Ensure that 80 percent of tertiary institutions have functional information and

- Ensure that 50 percent of teachers levels are trained in computer skills. Srategies for achieving the goal include the

following:

- Complete and harmonize all on-going educational planning programmes and initiatives in the Ministry of Education and its agencies.

- Make learning

child and teacher friendly

- Train and retrain teachers, through form and distance learning programmes.

- Review curricula at all levels for relevance. and make them competency based to meet global ch
the job market.

- Provide adult and youth vocational centers with materials and equipment for functiona literacy and the acquisition of occupationa skills.

- Establish effective partnership and collaboration with the organized private sector and the informal sector.

- Produce textbooks and other instructional materials to reflect the curricula.

- Integrate local craftspeople in curricular delivery to accelerate the number of craftspeople and improve access to their products.

- Involve parents and community leaders in the planning and management of schools in their communities.
- Set guidelines on private sector involvement in education and monitor its

mplementation.

corporate computer literacy in primary

ary school curricula.

Develop and produce curricula for teaching

- Provide secondan and tertiany institutions.

with information and communication

echnology equipment and facilities.

Tertiary education. Under NEEDS the government Tertiary education. Under Netas the govern
recognizes the critical importance of tertiary
institutions for developing high-quality human resources, especially in an increasingly technology-driven world economy. The government also recognizes the challenges facing thes institutions, challenges that include inadequate funding and facilities, curricula that are inadequate to meet the challenges of nation building

inadequate and inappropriate staffing (especially among the lecturers), cultism, and low moral and academic standards among students. Higher institutions in Nigeria currently depend almost

exclusively on government subsidies. The bulk of

federal government spending on education goes to tertiary institutions; state governments spend at least 20 percent of their budgets on education, mostly primary and secondary education. Almost total dependence on the government for funding higher education is neither practical nor sustainable. There is therefore a need for fundamental reforms of the higher education system.

The strategy for reform includes the following:

- Diversify funding by attracting private sector funding and considering more appropriate pricing of facilities and services (including hostel accommodation).
NEEDS recognizes the critical importance of tertiary institutions for developing highquality human resources, especially in an increasingly technology-driven world economy 
- Update and restructure curricula to meet the demands of the national econom especially information and communication technology.

- Establish effective monitoring of public and private universities to ensure strict adherence to standards.

- Develop innovative approaches to ensure continuing retooling approaches to ensure of lecturers so that they copacity building of lecturers so that they operate

NEEDS advocates greater involvement and participation by the private sector in

educational

development

- Increasingly move towards a decentralized and competitive wage bargaining system, which promotes a performance-based reward system.

Private sector participation in the education in educational development. An enabling environment will be created to increase private sector participation. Establishment of good-quality privately owned educational institutions at all levels will be encouraged to ensure that gaps in the provision of education are filled. Efforts will be made to achieve 100 percent compliance in paying the 2 percent corporate profit tax that funds education. Linkages between educational institutions and the private sector will be strengthened to ensure the appropriate interface with the world of work.

Improving Health improve the health status of Nigerians in order to reduce poverty. The strategy will continue to emphasize the strengthening of preventive and curative primary health care services. The initiative will involve comprehensive health sector reform, aimed largely at strengthening the national health system and enhancing the delivery of effective, efficient, good quality, and affordable health services.

Policy thrusts. Under NEEDs the government wil: - Improve its stewardship over policy formulation, health legislation, regulation, resource mobilization, coordination,

monitoring, and evaluation.

Strengthen the national health system and improve its management

- Improve the availability and management of health resources (financial, human infrastructure, and so forth).

- Reduce the disease burden attributable to priority diseases and health probutable to including malaria, tuberculosis, HIV/AIDS, and reproductive health-related illnesses. - Improve physical and financial access to good-quality health services.

- Increase consumers' awareness of their health rights and obligations. partnership with all health actors.

Major strategies and interventions. The meet its goals:

the following strategies to

- Redefine the roles and responsibilities of the Ministry of Health and other federal public health structures and institutions in providing and financing good-quality health services. - Reorganize and restructure the Ministry of Health and other public health structures within the context of the redefined roles and responsibilities.

- Review existing health policies and strategies as well as health legislation. Publish a new national health policy and the national health system and the health functions of each of the three levels of government.

- Strengthen the capacity of the Ministry of Health in policy formulation and

mplementation.

- Improve existing or set up new mechanisms to generate and use evidence and information for developing and implementing health policy, programmes, and plans. - Sringry helth care manament.

- Refurbish primary health care facilities and

- make them operational.

- Implement the Vamed Engineering Project standardizing their equipment.

- Establish a national hospital senvices commission to improve management of tertiary health institutions.

- Establish systems for efficient management of health resources, including finance, human resources, and physica infrastructure.

- Construct and institutionalize National

Health Accounts.

- Develop and implement a comprehensive health care financing strategy, including the fast-tracking of the National Health Insurance Scheme.

- Rehabilitate and refurbish the National Drug Production Laboratory.

- Fully operationalize the National Institute for Production of Vaccines and Biologicals. - Establish a national blood transfusion

system.

- Create an enabling environment for local manufacture of about 70 percent of Nigeria's needs for essential drugs and supplies and antiretroviral drugs and reagents.
- Improve data on the burden and socioeconomic impact of diseases in Nigeria. - Develop and implement a well-costed strategic plan for combating malaria

- Develop and implement an approprite

- response to the HIV/AIDS pandopria.

- Create or strengthen mechanisms fo

checking the transmission of polio by the end of 2004: detecting dianosing and responding to epidemics in a timely manner; and rapidly and sustainably

increasing routine immunization covera

- Strengthen existing programmes and initiatives for eliminating or eradicating specific diseases, such as Guinea worm.

- Develop and implement a mechanism for measuring the performance of tertiary health institutions.

- Develop and implement a strategy to improve health workers' attitude, morale, and commitment.

- Establish a reliable system for supplying good-quality drugs and medical materials to health facilities.

- Strengthen the ability of the National Agency for Food and Drug Administration and Control to perform its regulatory functions.

- Develop and implement a strategy to increase consumers' knowledge and awareness of their personal obligations and rights to better health.

- Develop and implement a strategy to enhance community participation in providing and financing health services. - Use the results of the study on the private health sector to formulate policy for promoting public-private partnerships in health care provision and financing. sector. The NEEDS initiative advocates greater involvement and participation by the private sector

The goal of the NEEDS health component is to

- Foster effective collaboration and enact a National Health Act that defines for refurbishing teaching hospitals and

The goal of the

NEEDS health

component is to

improve the health status of Nigerians in order to reduce poverty 
- Develop and implement a framework for enhancing effective coordination of development partners.

- Integrate all tiers of care, as well as traditional medical practitioners. Traditional medical practitioners are included in the referral chains of medica care, as they provide low-cost medica are the first point of contact for rural are the first

Many of the diseases that affect Nigerians are due to unhealthy environmental

Strengthen the ability of the Nigeria Natural Medicine Development Agency and related agencies to develop standards and monitor practitioners to carry out clinical trials to confirm the efficacy and proper dosage of preparations, for example.

\section{Improving Environmental Health}

environments in which people live proms the Many of the diseases that affect Nigerians including malaria, tuberculosis, diarrhea, and dysentery —are due to unhealthy environmenta conditions. Environmental health considerations therefore remain vital to achieving the objectives of NEEDS.

Under the environmental health reform

programme, the government will:

- Articulate a national environmental health policy and national environmental health action plan.

Review and harmonize existing sanitation laws.

Develop environmental health performance indicators.

Develop procedural guidelines for an

environmental health impact assessment.

Develop a national solid waste manage-

ment master plan.
- Assess the environmental health impact of communities in oil-producing and mining areas.

- Promote community-based integrated

Promitation senvices.

food sanitation practices

o ensure food security.

- Promote the safe use of pesticides and

other agro-chemicals.

- Increase antenatal postnatal, and family planning senvices and outlets in order to reduce maternal mortality from the current evel of 704 per 100,000 live births and infant mortality from the current level of 77 per 1,000

- Intensify the campaign to eradicate harmful traditional practices, such as fomal genital mutilation and child marriage Several state governments have already passed the necessary legislation, and many more are

\section{Tackling the HIV/AIDS Challenge}

education health ariculture, defence links to other sectors. The HIV/AIDS epidemic in Nigeria has extended beyond high-risk groups. More tha 2.7 million Nigerians are now infected with the virus. An estimate based on a 2001 sentinel survey conservatively puts prevalence at 5.4 percent of the population. The figure suggests that the nation is in real danger of facing explosive growth in the epidemic, with dire consequences for economic growth, health, and social development.

HIV/AIDS is already having a disastrous impact on social and economic development in Nigeria. If not adequately contained, the epidemic will prove to be the greatest single and other targets for social and economic development. The devastation caused by HIV/AIDS is unique, because it is depriving families, communities, and the entire nation of their young and productive people. The epidemic is deepening poverty, reducing human devepment achievements, increasing gender molities, eroding the ability of government to provide essential services, reducing labour productivity and supply, and putting a brake on economic growth

By 2001 it had become clear that the complexity of the HIV/AIDS epidemic required developmental, holistic, coordinated, and multisectoral approach. The strong politica commitment of the President of Nigeria to fight HIV/AIDS served as a powerful catalyst and motivator for establishing a supraministerial and sectoral body the National Action Committee on AIDS (NACA) under the Presidency. A nationat policy on HIV/AIDS was launched in August 2022 to give policy direction and to make a policy statement on the transformation of NACA from committee to a full-fledged agency that is well positioned and poised to scale up the fight against the epidemic.

The response to HIV/AIDS being coordinated by NACA has focused on the challenges of containing the epidemic and preventing new infections through advocacy, information and education campaigns, behaviour change communication, condom distribution, targeting of groups particularly vulnerable to infection, and other key interventions. It also focuses on treatment and care of people living with HIV/AIDS. Both prevention and treatment are top priorities to NACA, not only because they save lives and reduce human suffering but also because they limit the future impact of the epidemic on human development and poverty reduction efforts.
Through an International Development Association credit, NACA provides funds for NGOs, com contity federal line ministries throughout the country to lichentation of high-priority and demand-driven programmes NACA is also the principal recipient of funding from the Globel Fund to Fight ADS, Tuberculosis, and Malaria Those funds are disbursed to the Ministry of Heath to finance voluntary counseling and testing prevention of mother-to-child transmission of $\mathrm{HIV}$ and antiretrovict treetment for people living with AIDS. The multisectoral response is being implemented in collaboration with developmen partners, including the World Bank, the U.S. Agency for International Development, the Department for International Development, UNAIDS, the Canadian International Development Agency, the World Health Organization, UNICEF, the United Nations Development Progromme the United Nations Population Fund, and other organizations. Positive outcomes of these efforts are the increasing flow of resources for community and sectoral responses, as well as broad ownership of the national response beyond the health sector.

Projected impact of HIV/AIDS on Nigeria's economy and development. HIV/AIDS is projected to affect many sectors of the Nigerian economy.

- Macroeconomic effects. Studies in Africa suggest that the HIV/AIDS epidemic reduces annual GDP growth by about 1-2 percent.

Health sector. The epidemic affects demand for and supply of medical care, staffing levels by function, training and replacement costs, employment terms,
HIV/AIDS is having a disastrous impact on social and economic development in 
The provision of HIV/AIDS-related services adversely affects the provision of other health care services.

- Education. The epidemic affects staffing replacement and training needs, employ ment policies, contracts, employer

- Agriculture and food security HUVADS nas HIV/AIDS has Nerious adveria, potentially affecting subsistence and small-scale commercial agriculture, and small-scale commerclal agriculture, rural Iivelhood strategies, and household and communty support systems. Both result from the epidemic.

- Urban livelihoods. HIV/AIDS has grave implications for urban dwellers. The epidemic will affect employment labour market operation, income inequality, and access to services of people living in urban areas.

- Loss of social reproduction capacity. The impact of HIV/AIDS is not solely, or even mainly, economic. Some of the most

serious costs include loss of social capita and interpersonal and intracommunal trus and support. Such losses-at the individual household, and community levels-will continue for more than a decade.

Policy thrust and targets. The overall goal of the NEEDS HIV/AIDS policy is to control the spread of HIV/AIDS in Nigeria, provide equitable care and support for those infected with HIV/AIDS, and mitigate its impact to the point where it is no longer of public health, social, or economic concern. The policy aims to create an environment in which all Nigerians will be able to live socially and economically productive lives free of the disease and its effects.
The following targets have been set to guide rogramme planning and implementation: Achieve at least a 25 percent reduction the ad

Increase the use of safe-sex behaviou . 50 percent by 2007.

- Reduce the prevalence and incidence of sexually transmitted infections by 50 sexually transmitted
percent by 2007 .

- Ensure that at least 20 percent of all loca government areas offer home-based local to people living with HIV/AIDS by 2007. - Ensure that 30 percent of health institutions will be able to offer effective care for and management of HIV/AIDS by 2007. Ensure that 5 percent of communities affected by HIV/AIDS will have programmes designed to provide social safety nets for people living with HIV/AIDS by 2005, and increase the proportion of communities with such programmes to 15 percent by 2007

Reduce mother-to-child transmission of

HIV by 50 percent by 2007.

- Increase ready access to voluntary

confidential counseling and testing services to at least 50 percent by 2007.

- Ensure access to antiretroviral drugs in all states by 2007 .

Strategies. To achieve the goal of controlling the spread and mitigating the impact of HIV/AIDS, NACA will adopt the following strategies:

Promote a national multisectoral and multidisciplinary response to the epidemic and establish an appropriate legal and institutional framework for its coordination.
- Identify sectoral roles and assign responsibilities for implementing programmes based on sectors' comparative advantages and core competencies.

- Increase awareness of and sensitivity about

HIV/AIDS among the general population.

Foster behaviour change as the main

means of controlling the epidemic.

政 acceptance of the principle that all people must accept responsibility for the prevention of HIV transmission and the provision of care and support for those infected and affected.

- Provide access to cost-effective support and care including antiretroviral drugs, to people with HIV/AIDS.

- Protect the rights of people infected and affected by HIV/AIDS, as guranteed under the Constitution and the laws of Nigeria

Remove all barriers to HIV/AIDS preven and control.

- Empower people infected and affected by HIV/AIDS to cope with their circumstances, through training, counseling, and education. Support research, monitoring, and evaluation of programmes; relevant documentation of activities related to the epidemic; and the dissemination of information to stakeholders and the general population. - Ensure that prevention programmes are developed and targeted at vulnerable groups, such as women and children, adolescents and youth, sex workers, longdistance commercial vehicle drivers, prison inmates, migrant workers, and others.

- Transform NACA into a statutory body, and provide adequate resources for it to meet the goals and targets set for HIV/AIDS prevention and control.

\section{Housing}

The housing strategy is aimed at developing affordable houses for the masses. The Land Use Act will be reviewed with the aim of making the acquisition of land cheaper for developers in order to make houses more affordable. Review of the act will also aim at expediting the acquisition of title by individual land allotees to facilitate access to mortgage finance.

Efforts will be intensified to popularize the use of local raw materials, such os cement-stabilized laterite and burnt bricks, to reduce the cost of housing construction. Faculties of architecture and building at tertian institutions will be encouraged to teach their students to design and build with low-cost, local materials. Public buildings (schools, hospitals, post offices, barracks, markets) will lead in the adoption of these materials. As matter of policy, the production of houses will be the responsibility of the private sector and state and local governments. Except in the federal capital territory, the federal government will assist housing producers only through matching grants for developing sites and providing senices.

\section{Employment Generation}

The rate of urbanization in Nigeria-about 5.3 percent a year-is one of the fastest in the world. Urban unemployment is estimated at about 10.8 percent. If manufacturing and services sectors do not grow sufficiently to absorb the surge of labour to urban areas and if rural areas are not transformed to stem the growth in migration to urban areas, the rate of urban unemployment could become unmanageable. The implications for poverty-and crime, conflict, and the maintenance of democracy—are grave.
If manufacturing and services sectors do not grow sufficiently to absorb the surge of labour to urban areas and if rural areas are not transformed to stem the growth in migration, urban unemployment could become unmanageable 
NEEDS recognizes the urgency of the unemployment situation, but it understands that there will be a lag in the expected job-crea effects of the reform programme. It also recognizes the need for specific steps to facilitate indivalual empowerment, particularly among through the creation of new jobs.

The private sector is expected to generate The private sector is expected to generate most of the new jobs nigeria

- Create an enabling environment by adopting specific sectoral programmes that permit the private sector to prosper. - Empower people by providing for the acquisition of relevant skills to prepare acquisition of relevant skills tor

- Promote integrated rural development in collaboration with the states.

Coordinated implementation of NEEDS at the federal level and State Economic Empowerment and Development Strategies (SEEDS) at the state level is expected to lead to about 7 million new jobs.

\section{Empowering Women}

NEEDS seeks to fully integrate women by enhancing their capacity to participate in the economic, social, political, and cultural life of the
country. To do so, the government will adopt the following measures:

- Ensure equitable representation of women all over the country in all aspects of national life by using affirmative action to ensure that women represent at least 30 percent of the workforce, where feasible. - Implement the provisions of the UN Convention on Elimination of all forms of Discrimination against Women.
Support legislation for the abolition of all forms of harmful traditional practices against women.

- Mainstream women's concerns and

perspectives in all policies and programmes. poverty allevistion strategies, with a view to reducing poverty among women.

- Reduce women's vulnerability to HIV/ADS and other sexually transmitted diseases by empowering them through sustained empowering them through sustained

advocacy, education, and mobilization. secondary and tertiany lemes at the educational opportunities for female students where necessary. Expand adult and vocational education programmes that cater to women beyond formal school that - Increase the access of women, youth, and children to information on key national issues. - Provide social security for unemployed women, youth, and poor children.

\section{Empowering Youth}

Joblessness has resulted in a rising incidence of social ills among young people. Policies will target youth empowerment and development in order to reverse the negative consequences associated with the past pattern of development. Specific interventions include the following:

- Expand opportunities for vocational

- Provide facilities for sports and recreation (public sports facilities and parks).

- Promote the arts and culture.

- Wage a sustained campaign against drug trafficking of women.

42 Projected Sources and Means of Employment Generation under NEEDS

Source of growth

Agriculture and rura

development

Manufacturing and small and

medium-size enterrrises

Solid minerals

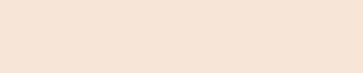

Information and communication

telecommunication

Services (especially tourism)

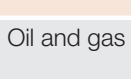

Power

Education

Public works and housing

construction

Intervention schemes

Environment

\section{Means of employment generation}

- Increased productivity of small farmers

- inceased employment from commercial agriculture

- Increased production through coordinated programme by the federal and state

governments

- Federal-state collaboration in the development of industrial clusters and parks

- New investment

- Improved infrastructure al mining sties 500,000 new jobs) Expansion of tellocon

and senvices

Wew

Obudu Cattle Ranch, for example)

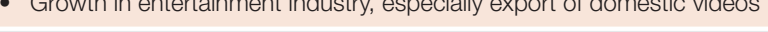

- Enforcement of local content policy

- Growth in gas sector

- Increased participation of independent power providers, which will expand productivity and lead to grog

- Universal basic education and the increasing growth of private provision of education and skill training

- Use of public works in construction of roads and other public utilities, especially by state and local governments

- New and continuing boom in housing construction all over the country

- Microcredit and concessional credit to provide start-up capital for new businesses

- Divestiture of responsibility for waste management to private sector (waste to wealth initiative)

- Forest cottage industries (such as manufacture of cane products) wood and medicinal plants

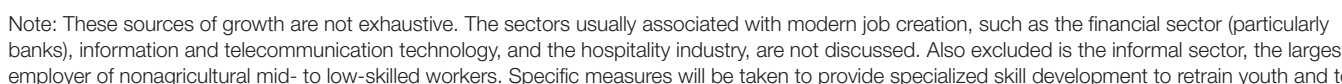

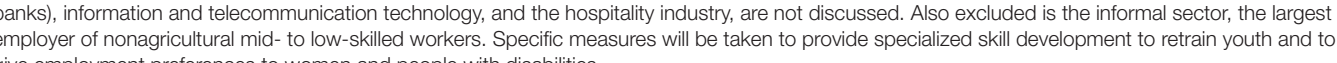


- Increase awareness about the dangers of HIV/AIDS and other sexually transmitted diseases.

- Use public works, such as road maintenance and agriculture-based schemes, to reduce youth unemployment.

- Inculcate in Nigerian youth the virtues of patriotism, discipline, selfess senvice honesty, and integrity through revice, honesty, and integrity through revitalization of organizations such as the Boy Brigade.

Policies will target youth empowerment and development in order to reverse the rising incidence of social ills among

young people

Brigade.

Promote targeted youth employment to Peal with the short-run consequences of the reform process.

- Increase access of women and youths to credit under existing arrangements.

- Increase opportunities for Nigerian youth, especially in the choice of profession, through youth exchange programmes and other avenues that expose them to international best practices.

- Eliminate factors that promote ethnic religious, and social divides among Nigerian youths.

\section{Ensuring the Welfare of Children}

Children's welfare will be protected by strict enforcement of the Child Rights Act of 2003 by child rights implementation committees at the federal, state, and local government levels. These committees will strictly enforce the protection of children from:

All forms of abuse, neglect, and exploitation, including economic exploitation. sexual exploitation, and the use of children in criminal activities or the production and trafficking of narcotics and psychotropic substances

- Child trafficking

All forms of violence

- All forms of hazardous work

- Preciabled disth hunger and mases

It will also:

Recognize children's right to participate in recreation, leisure, association, and matters affecting their lives by promoting eprestation, association, and participation opportunities (through the Children's Parliament, for example).

- Bridge the gender gap in school enrolment

and retention.

\section{Liberalizing Sports Administration}

Worldwide, sporting activities represent a major source of earnings and employment. Huge profits are generated in many countries throug profits are generated in many countries through
ticket sales; sponsorship deals; the sale of advertising, radio, and television rights; product endorsements; and public and movie appearances by sports stars. Athletes' earnings are reinvested in the economy, creating employment Nigeria has not enjoyed the benefits of professional sports, because of the government's domination of sports administration and management and the status given to sports as an extension of social services. The existence of cumbersome laws regulating sports administration has prevented sports from becoming a jobcreating industry.

Under NEEDS the enormous potential of the sports industry would be unleashed by liberalizing the sector. The private sector has demonstrated enormous capacity to invest in the sector and to run many sports profitably. Given the government's lean resources, the private position. Indenent liberalized sports sector could create hund thousands, if not more than 1 million, direct and indirect jobs.

The policy direction in sports management is change the face of sports administration and the incentive structure in favour of a liberalized decentralized, profit-oriented, private sector-led industry. The reform is expected to atract mod resources into the sector, raise the employment athletes and sponsors to reap the fruits of their investment.

The targets of the reform are to liberalize participation and governance of sports associations and to remove all obstacles to entering and participating in sports development, including funding, by private sector organizations.

Under the NEEDS reform programme, the government will adopt the following strategies:

- Review all existing laws (including Decree 101 of 1992) that inhibit effective private sector participation in sports, with a view to creating a new sports governance structure that is consistent with international best practices and incentives for investment in the sector.

- Encourage private sector participation in sports administration by setting up independent sports associations and amending the governance structure of existing ones.

- Encourage private sector partnership in the provision and maintenance of sports infrastructure.
Strengthening Safety Nets

Social protection consists of interventions aimed at safeguarding the poor from becoming poore and the non-poor from becoming poor. NEEDS protect against various risks (table 4.3).

NEEDS will also ensure that the most vulnerable groups in society are protected (table 4.4).

\section{Strengthening Peace and Internal}

\section{Security}

The Institute for Peace and Conflict Resolution, charged with the in-depth study of peace and internal security issues, was established within the Presidency. A conflict assessment carried out by the institute in 2002, in collaboration with civil society, the World Bank, and other developmen partners, reached several conclusions:

- Political corruption stemming srom interethnic rivalry and aimed at the control of the state machinery for private or sectarian interests is at the root of pervasive social conflict in Nigeria.

- Policymakers and other well-meaning stakeholders, even as they nurture the growth of democratic institutions over time, may need to undertake deliberate interventions at times in the interests of peace, security, and poverty alleviation. - Although democracy may make it easier for internal social conflicts to surface, it provides the best long-term mechanism for resolving such conflicts.

The findings led to the development of a national action plan. Elements of the plan include e following:

retraining of personnel in the security
Conflict prevention will be mainstreamed to put in place structures and processes that encourage a culture of peace, in which conflicts are addressed before they degenerate into 


\section{\begin{tabular}{lll} 
Table 4.3 Risks, At-Risk Groups, and Formal Responses \\
\hline
\end{tabular} \\ Risks, At-Risk \\ At-risk groups}

\section{Risks}

Natural. Droughts, lloods, erosion,

pests

ms, and food losses due to men, rural women and young woung

Poor, rural men and young men, rura women and young women

Labour: Loss of job, drop in income

Poor; urban youth

Social: HIV/AIDS, infant and maternal mortality

Well-to-do, poor rural men and young urban men and young men, urban women and young women

\section{Formal response}

\section{Irrigation, agricutural extension senvices} aforestation, agro-forestry, agricultura insurance

Environmental measures to stem poliution, tree-planting campaigns, agro-forestry, incentives to convert to aternalive energy use, enforcement of standard oil field practices Institutionalization of unemployment insurance

Comprehensive heath centers, government immunization and inoculation programme, health insurance scheme, HIV/AIDS programme, universal basic education

Gender: Unwanted pregnancies and Poor, urban and rural women and Sex education at appropriate stage in

Gender: Unwanted pregnancies and
sexually transmitted diseases, job Poor, urban and
young women school, social weffare counseling

discriminin
practices

Life events: Death of spouse, old age

Wellt-to-do, poor, urban men and
young men, urban women, rural wome legislation, advocacy

Pensions and reform of inheritance laws and young women

Conflict: Ethnic conflicts, armed Wellto-do, poor, rural and urban women

robbery, child a buse young women, and girls; urban men and
young men

Police, social weffare counseling National Refugee Commission Crim Justice System Poor urban men, women, and youth

Stable macroeconomic policy, socia

Macroeconomic: Macroeconon

sector, improved logistics, and more effective supervision and control of

personnel

- Vigorous reorientation programmes will be instituted to create a people-friendly police force.

- Early warning and response mechanisms will aim at reinvigorating old structures and creating new ones, from the grassroots to the highest level, to analyze and dissemi- Political reform to create a political process free of the excesses of the past including a review of the conduct of government employees and of imbalances in the allocation of revenues and responsibilities between the federal and state governments.
Table 4.4 Targeted Instruments for Protecting Vulnerable Groups

\section{Group \\ Rural poor}

Urban poor

Women

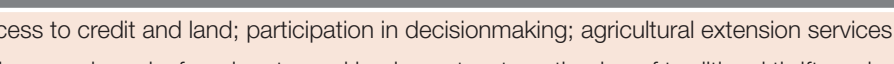
and insurance schemes

Labour-intensive public works schemes; affordable housing, water, and sanitation; skill acquistion and entrepreneurial development; access to credit; scholarships and adur education

Afirmative action (to increase women's representation to at least 30 percent) in all programmes; education, including adult education; scholarships; access to credit and

Youth Education, entrepreneurial development, skill acquisition, access to credit, prevention and control of HIV/AIDS and other sexually transmitted diseases

Children Chidren's Pantiament, ivvenile justice administration, universal basic education, education for girls, care of orphans and vunerable children (children affected by HIV/AIDS),

Rural communities

- Conflict prevention will be mainstreamed to

put in place stru

encourage a culture of peace, in which

conflicts are addressed before they

degenerate into violence, and in which

public officers as well as civil society

public officers as well as civil society

trained in the prevention, management,

and resolution of conflicts. 


\section{Part Three}

\section{Promoting Private Enterprise}
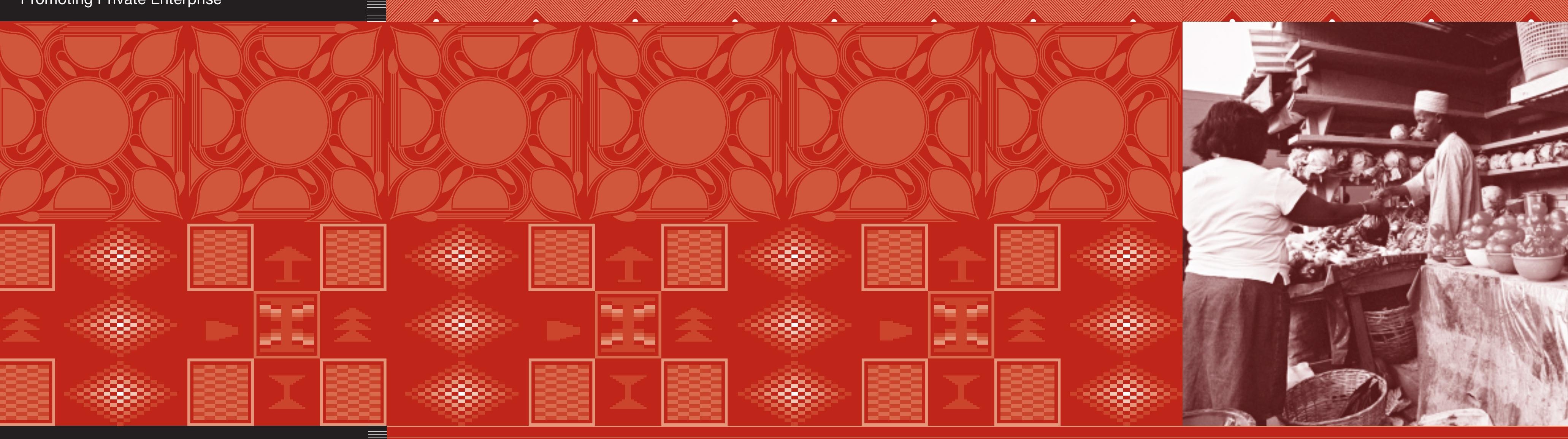

\section{Chapter 5 \\ Creating a Competitive Private Sector}

Chapter 6

Sectoral Strategies

Chapter 7
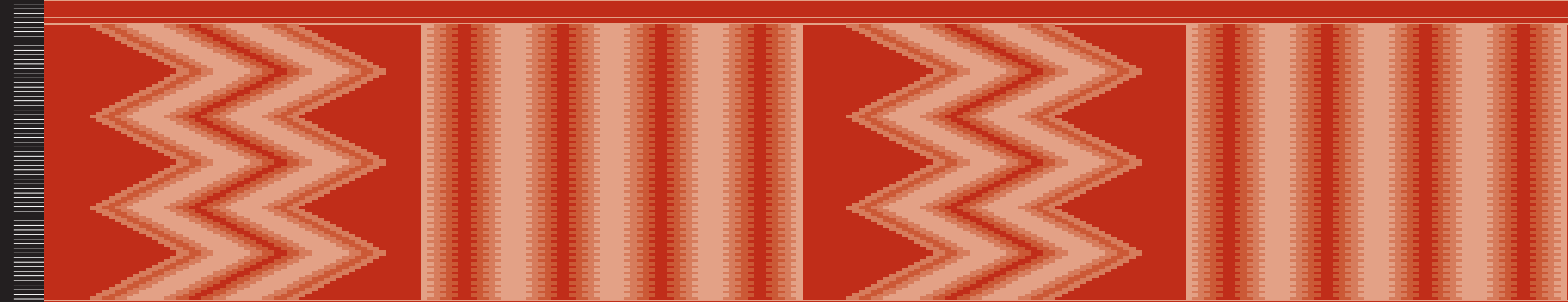


\section{Chapter}

\section{2}

For decades Nigeria's economy was characterized by the growing dominance of the public zed by the gaver do and the pursuit of a highly import-dependent, import-substituting industrial strategy whit these policy thrusts were justified at their inception, experience has shown that growt based on expansionary public expenditure, import-substitution industrialization, and relian import-substitution industrialization, and relian
on the export of a few primary commodities is on the export of a few primary commodities is did not work in Nigeria is evident from several did not work in Nigeria is evident from sever indices of suboptimal performance: low per base with declining industrial output and capacity utilization, large budget deficits and deterioration in the social and infrastructure facilities, low productivity in the real sector, and a high level of unemployment.

The private sector has been dogged by weaknesses inherent in its skewed structure. It is dominated by a few large multinationals that are heavily dependent on imports and operate largely as enclaves and a large segment of small and medium-size enterprises with very little, if any. linkage to the multinationals. A rent-seeking and unproductive culture of overdependence on government patronage and contracts, with very little value-added, governs the sector.
As a result of these factors, Nigeria has become a nation of traders, with a very weak (tequer private sector include the poor state of physical infrastructure; the high cost and limited access to appropriate financing: insufficient domestic demand and the low level of patronage by public sector institutions; the high cost of imported raw materials, equipment, and spare parts: and the lack of skilled labour. Growing the private secto also hinges crucially on domestic policies, environmental factors, and investment flows.

\section{Strategic Thrusts for Growing the} Private Sector

The primary goal of the NEEDS strategy is to build a private sector that can take advantage of the opportunities that abound in the domestic, regional, and global markets. The strategy builds on the achievements of the past few years in transforming the private sector. The main strategic thrusts include the following:

Redefine the role of government as a facilitator and promoter in the economy, recognizing that market failures in developing economies require targeted incentives and interventions in specific areas to $p$ 作 chustios. The government hopes to ment mo usal enabing targeted entrepren

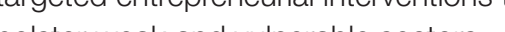

- Consolidate and strenghen an enab.

Consolidate and strengthen an enabling environment for a competitive private

include the following:

- Continue to improve security the rule of law, and the timely enforcement of law, and the
contracts.

interventions in the economy, by adopting the following strategies:

- Nationally coordinated strategies for the key sectors that drive growth-

agriculture, small and medium-size enterprises, manufacturing, oil and gas sector, solid minerals, and services especially information and communication technology and tourism). Explicit strategies and interventions are designed for each of these sectors to harness and maximize their potential for

growth and poverty reduction.

Continue to reduce policy-related costs and risks, such as corruption, red tape and administrative barriers to businesses; a weak legal system. inadequate protection of property rights: inadequate enforcement of tariffs; dumping of fake and substandard products; and policy and other uncertainties associated with exchange rate and other prices.

- Invest heavily in infrastructure,

especially electricity, transport, and water. Studies indicate that about 25 percent of business start-up costs are spent on private power generators, and privately generated electricity costs about two and a half times as much as electricity provided by the National Electric Power Authority. Reforming the power sector could significantly reduce the cost of doing business and improve competitiveness.

- Provide targeted interventions as incentives to grow the private sector. The government aims to play an active developmental role, while avoiding the mistakes of past direct the medium to long run, thinance. In ment plans to drastically reduce the many costs businesses in Nigeria face. In the short to medium term, it will direct low-cost credit to the productive sectors as an incentive to jump-start the private sector.

- Privatization and liberalization.

Privatization of public enterprises is aimed at shrinking the domain of the state and enlarging the size of the private sector. It is also aimed at improving the efficiency and competitiveness of enterprises, leading to their long-term sustainability and contribution to poverty reduction. The liberalization of sectors hitherto monopolized by the government is expected to unleash competition by growth and employment generation.

- Promotion and development of industrial and science and technology parks and industrial clusters. The federal government will work with state governments and the private sector to promote the development of industria the private sector-and hence spur
The goal of the NEEDS strategy is to build a private sector that can take advantage of the opportunities that abound in the domestic, regional, and global markets The strategy redefines the role of government as a facilitator and promoter in the economy 
NEEDS aims to alter

the strategy for

industria

development, to make

it more local

resource-based and

more related to loca

research and

development

strategies

clusters and science and technology parks as pilots for creating industrial growth poles in the country. Export processing zones are also being

developed and strengthened.

- Rationalization of fiscal, monetary, and legal incentives to ensure that firms paradigm that mainstreams ser delivery as the key function of the publc sector aims to provide public senvices to businesses efficiently and effectively.

Imposition of selective import restrictions and agressive export promotion as part of a strategy of industrial development Recent empirical evidence from firm-leve data across developing countries indicates that big bang import liberalzation can hurt industrial development. Under a big bang liberalization, only a small proportion of firms operating at the frontier gain from competitive pressures: the vast majority of firms often risk being wiped out, with dire social and economic consequences. While the government is reducing the cost of doing business in Nigeria, it will use restrictions on imports as part of a strategy to ensure orderly restructuring of the industrial sector. The government will aggressively promote exports and general commercial policy to attract foreign direct investment, and will pursue export orientation as a deliberate policy.

- Create public-private partnerships. For government to be effective in its entrepreneurial or developmental role, it needs to actively interact with the private sector on an ongoing basis to ensure continuing feedback. Government at all wels will maintain structured interactions sector operators to ensure rue partnership in the development

$$
\text { NEFDS sees }
$$

ches resid growth of a resilient and component of to diversify the economic base and reduce the dominance of the oil sector, mainstream the informal sector while strengthening its linkages to the rest of the real sector, increase local value added, increase the share of manufactured goods in total exports, and create incentives for a vibrant private sector that can respond to the rigors of market forces. The government has already taken a number of steps in this direction-by establishing the Nigeria Investment Promotion Commission and technology business incubation centers, for example. These centers provide conducive environments for nurturing the start up and growth of small and medium-size enterprises engaged in value-added and technology-related manufacturing.

NEEDS aims to alter the strategy for industrial development, to make it less import dependent, more local resource-based, and more related to local research and development strategies, particularly those focused on small and mediumsize enterprises. This strategy will lead to the promotion and development of science and technology-based small and medium-size enterprises. It will ensure that process technologies and the design and manufacture of machinery and equipment for small and medium-size enterprises are developed through domestic capacity-building processes. Small and medium-size science and technology-based enterprises will be nurtured in science and technology parks and technology incubation centers. These enterprises, which will be based mainly on national research and development activities and innovations, will generate spin-offs and provide opportuities for creating entroprs and proctivies. They will target the following priority areas: food processing industrial chemicals, information and conmunication technologies, biotechnology electronics and space technology, energy, oil, and gas. NEEDS will also strengthen the rowing partnership between the private and public sectors, while advancing the policy of prive sector-led growth. Enterprising Nigerians, irrespective of their location, will be encourage to participate in the transformation of Nigeria into an economy that is robust, stable, dynamic. competitive, and export-led. The role of government will be redefined as that of facilitator and a catalyst. Where it is in the public interest, deregulation will be vigorously pursued, with the government playing a supervisory and regulatory role. The tremendous achievements in the telecommunications sector, where the National Communications Commission acts as a pivotal agency for regulation and consumer protection, clearly illustrate the possibilities inherent in a successful deregulation programme. In 2004 the National Assembly is expected to enact a law to give effect to the Competition Policy and Anti-Trust legislation, a key component of the private sector growth strategy.

\section{The Role of Government}

These policy thrusts are realistic and realizable. All stakeholders in Nigeria would be better served if the concept of a symbiotic relationship between the public sector as enabler and the private sector as the primary engine of growth of the nation's economy were fully established. In this context of partners in progress, public inestment in economic activities that compete directly with the private sector will be drastically educed. The public sector will emphasize reforms that lay a solid foundation for a prosperous and globally competitive private This includes policy and regulation, public services, and facilitation and intervention to

support other actors by targeting and addressing

key drivers that will improve firm-level efficiency

and reduce the cost of doing business (box 5.1).

Government at all levels (federal, state, and local) commits to systematically:

resources to facilitate the development of strategic economic infrastructure that improves the attractiveness of Nigeria as a preferred investment destination.

- Eliminate bottlenecks and red tape, and improve the social, legal, and regulator regime in order to strengthen security of life and property, governance, the rule of law, and respect for the sanctity of contracts and rights of others.

- Increase opportunities for access to financial resources and strengthen or support other assistance initiatives, such as the Small and Medium Industries Equity Investment Scheme, that aim to improve efficiency and productivity, reduce production costs, nurture entrepreneurship, and enhance the attractiveness of Nigerian products and small and medium-size enterprises in an intensely competitive marketplace. - Adopt and implement a simplified and transparent import tariff regime by common external tariff of the Economic Community of West African States (ECOWAS). Implement fundamental reforms
The public sector will emphasize reforms that lay a solid foundation for a prosperous and globally competitive private sector 
Box 5.1 Institutional and Administrative Reforms to Reduce the Cost of Doing Business

NEEDS proposes reducing the cost of doing business in

Nigeria through the following set of reforms:

Streamline Corporate Affairs Commission

reviewing stamp-duty proced

of name registration with other intellectur

property rights protection procedures. Enhance

staff capabilities through adequate training, and

can be registered within 24

processes and shorten the tim

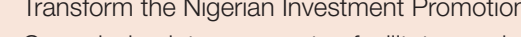
Calvecte by inp a promoter, facilitator, and

provides and elininating the resistationation

lor foreign direct investment.

Streamline Federal Inland Revenue

Service/Ministry of Commerce processes by an automatic declarative process, and reducing

or rationalizing the number of incentive schemes.

Streamline the process for land access and transfir as well as for site development and environmentar

clearance by redcung docum antaron require-

ments, fees, and steps; site visit protocols; and

well as committer.

ing, processing deadlines, and dissemination of

information and gazetted regulations.

Consolidate immigration ma

expatriate positions, work permits, and "permanent until revoked" status. Improve dissemination of information and provide

of the ports and customs clearance procedures to reduce turnaround time and provide Nigerian producers access to

imported inputs at international prices.

- Implement a plan on rapid and focused

commercialization of the results of scientific ordinated, focused training of consular officials

on immigration matters.

- Rallonalize the number of agencies with esponsibility for clearing goods at port facilities, int for Customs Data (ASYCUDA) progrommes, and ensure that the customs senice remains the only ocal point for cargo clearance and that goods clear ports within 48 hours.

- Institute an information clearinghouse at the Nigerian Investment Promotion Council or the Nigerian Export Promotion Councli, rationalize and simpilif the incentives and acquistition schemes, fully open the dissemin specialized areas, broadening the and equiipment in courthouses, creating an alternative dispute resolution system, launching a public awareness campaign, and establishing

Strengthen regulatory institutions and enforce competition policy. As the government withdraw institutions will be strengthened to ensuatory playing field for individual businesses, especially through more effective enforcement of

competition and antitrust laws. The antitust laws will seek to protect consumer rights as well as growth of weaker firms in any industry.

esearch that forges linkages and enhances productivity. direct role in economic and business activities. Vigorously pursue the process of accelerated privatization of major utilities enforcing contracts by training judges and

- Progressively reduce the government's and public enterprises, liberalization, and deregulation of key sectors, accompanied competition and consumer protection policies.

prehensive Tax Reform Bilin order to ensure the elimination of multiple taxation and fiscal harassment. end removichs, improve collections, vibrant private sector.

- Conduct a regular dialogue with private sector operators, and play an active rol economic planning based on market public-private sector dialogue under the auspices of the Better Business Initiative Annual Competitiveness Forum, Nigerian Economic Summit, and other forums. A new annual forum for public-private partnership and peer review mechanism partnership and peer review mechanism SEEDS will be instituted under the auspices of the Nigerian Economic Empowerment and Development Summit. State and local government levels also commit to dialogue periodically with the private sector and the civil society.

- Provide a robust fiscal and monetary policy regime for the smooth functioning of the economy. Adopt financing strategies th do not crowd out the private sector.

- Improve the process of granting land use rights.

- Provide appropriate structures for

regulating and propelling the private sector to develop in a socially and environmentally responsible direction.

- Empower domestic small and medium-size enterprises by purchasing their products and improving tendering and procurement rocesses that stipulate minimum levels of local content

- Encourage the private sector to take advantage of global trade initiatives (such as carbon trading)

- Encourage the private sector to increase its investment profile in research and development activities at Nigerian research institutes and universities.

Seven specialized science and technology parks (One in each geopolitical zone and the Federal Capital Territory) will be established in phased manner, with appropriate government support. Each park will house 300-500

companies aimed at unleashing Nigeria

entrepreneurship. Some companies will have

partnerships with global high-tech enterprises

Support facilities will include venture capital funds, business support services, human resources development facilities, intellectua property rights protection services, global. technological databanks, and market support incentives. The parks, managed essentially by the private sector, will act as pilots. The model could be replicated in many more states based on lessons of experience. Each of the pilots would be located near a commercial center in order to exploit economies of scale. Each park could act as a growth pole in each zone, leading to an integrated national industrial infrastructure. To enhance rapid industrial growth and

efficient exploitation of resources, government will encourage the development of strong linkages between industries in the science and technology parks, research and development institutions, and University researchers. In addition, actions will be taken to promote technology acquisition and

within as well as across national boundaries to ensure global quality standards and competitiveness. Such actions will enhance the encourage the

development of strong

linkages between

industries in the

science and

technology parks and

research and

development

institutions 
successful transition from an import-dependen economy to a knowledge-based, expor-

In supporting private entrepreneurship and the drive for efficiency competitiveness, and private drive for efciency, compeliveness, and private its duty to prowect or govend acent is fully aware of groups to basic social and infrastructur services. groups to basic social and ifrastructure senice exploitation of consumers. Government at all levels exploitation of consumers. Government at all levels will therefore remain committed to its overarching responsibility of ensuring access to basic services for all. It will enact consumer protection laws aim at protecting consumers from monopolistic and unfair trade practices that are direct consequen strategies will be regularly fine-tuned on the basis strategies will be regularly fine-tuned on the basis ers are maximized at all times.

\section{The Role of the Private Sector}

The private sector will be expected to become more proactive in creating productive jobs, enhancing productivity, and improving the quality of life. It is also expected to be socially responsdevelopment of Nigeria and by actively promotin the unity and cultural, educational, moral, and social development of the country. Among other things, the private sector will be expected to:

- Take advantage of opportunities for rapid and sustainable growth of a diversified economy with a modern agricultural sector, an export-led industrial sector, and an efficient and competitive service sector in - Actively work to expand the export base and become internationally competitive by mproving the quality of products and services and using the skills and professionalism of local human resources.

- Transform the structure of the economy, by supporting research and development in focal economic sectors and significantly enhancing the petential of Nigeria to meet the demands for domestic production and consumption; by adapting toduction and consumption, by adapting to changing competition: and by developing strong linkages across the economy- strong

local content policy, especially in the the extractive and construction industries, by forming business partnerships and linkages that engender the processes of learninges technology transfer. According to the National Committee on "the quantum of composite value added to or created in the Nigerian economy through a deliberate utilization of Nigerian human and material resources in the exploration, development, exploitation, transformation and sale of Nigerian crude oil and gas resources without compromising quality health, safety and environmental standards. - Take steps to preserve environmental re-

sources and maintain environmental balance.

\section{Infrastructure Development}

Infrastructure needs cut across sectors and are central to economic development. Nigeria's infrastructure does not meet the needs of the average investor, inhibiting investment and increasing the cost of doing business. Infrastructure development is one of the key areas in which NEEDS intends to make a difference. The government intends to leave routine management of businesses to the private sector and to devote its own efforts to providing adequate infrastructure and a regulatory framework that is conducive to business.

\section{Policy Thrust}

The government's policy thrust is to develop and maintain adequate and appropriate infrastructure that is conducive to private sector-driven economic growth and development, ensuring private sector participation in the process and creation of a competitive business environment. Under NEEDS the government will:

- Rapidly privatize key infrastructure services

to ensure effective service provision.

- Enhance and enforce relevant laws to

improve competition and protect consumer welfare in industries providing infrastructure services.

- Provide targeted interventions in the provision of infrastructure, especially to rural areas and vulnerable groups.

- Encourage private sector initiation and participation in the provision of infrastructure, using such methods as buildoperate-and-transfer (BOT), build-own-operate-and-transfer (BOOT) rehabilitate-operate-and-transfer ( $\mathrm{ROT}$ ), and concessioning.

- Provide counterpart funding for major infrastructure projects for which either the resource involvement is too high or the incentive too low for private sector participation. - Increase the share of renewable energy in the total energy mix.

Transport Secto

Infrastructure reforms in the transport sector will aim to:
Complete ongoing construction of a 3,000-kilometre network of roads, and embark on new construction if fundspecific assistance or finance becomes available. Rehabilitate and maintain the under Operation 500 Roads.

- Strengthen the newly created roads maintenance agency, and involve the private sector in the management of roads. Create a prominent role for Nigerian sea ports within ECOWAS by encouraging private sector participation in coastat

shipping activities.

- Develop a seaport with capacity to handle modern shipping activities, and establish inland dry ports. Provide incentives to use other seaports.

- Make Nigeria's ports more efficient and

competitive, with capacity to handle. modern shipping activities. Implement policies that target local human capital development.

- Rehabilitate and upgrade the railways with a view to restoring their relevance in transporting bulk, haulage, and passengers. - Ensure the achievement and maintenance of world class standards in all aspects of aviation operations, by developing local manpower and maintenance capacity and adopting other measures.

- Achieve total radar coverage of Nigerian airspace, and establish an effective and efficient emergency rescue unit under the Federal Airports Authority.

fllowing:

thegies for the sector include the

Provide, through the draft Public-Private Partnership in Infrastructure Provision Bill, the enabling legal framework for private
The government's policy is to develop infrastructure that is conducive to private sector-driven

economic growth 
sector participation in several infrastructure projects, including roads, railways, and port development.

- Privatize or concession Nigerian Railways to the private sector in order to rehabilitate and modernize it. The government will continue to restructure and strengthen th company to make it functional until it is privatized or concessioned.

- Mainstream the maintenance culture for all infrastructure facilities.

Power is the most

important

infrastructure

requirement for

moving the private

sector forward

- Provide the Road Maintenance Agency

with sufficient capacity to undertake

rehabilitation and maintenance of federa

reads.

- Ensure that infrastructure development is

consistent with environmental regulations.

\section{Power Sector} the most important infrastructure requirement for moving the private sector fonward.

NEEDS envisions reforms that will transform the power sector into one led by the private sector, with the role of government primarily policy formulation and establishment of an appropriate legal and regulatory framework. Fu implementation of the NEEDS reforms would eliminate generation deficits; rehabilitate, reinforce, and expand transmission and distribution networks; impose payment and collection discipline; and increase rural access to electricity, using grid and off-grid approaches. Nigeria's power system is so inadequate that it has held back economic progress and social wellbeing. The system is unreliable and incapable of meeting the demands placed on it. The following facts underscore the neglect of the sector:

$$
1990 \text { and } 1999
$$

No major overhaul of plants was carried out between 1990 and 1999.

- Only 19 out of 79 generating units were in operation in 1999.

- Actual daily generation fell to less than

2000 megawatts (MM) in 1999.

- No transmission lines have been built since

Federal government funding to the sector decreased continually between 1980 and

Some improvement took place between 1999 and 2003, with generation rising to about 4,000 MW a day. Problems of adequacy, transmission, and distribution remain, however. Improvement occurred largely as a result of the President's mandate and the new funds and capacity injected into the National Electric Power Authority (NEPA). Some of the highlights of the mandate include the following:

- Expeditiously implement the electric power sector reform programme.

Generate 10,000 MW a day by 2007, from existing plants, new host generation, and reasonably priced independent power plants.

- Develop the capacity to transmit and distribute the higher level of generation. - Explore alternative energy sources, such as coal, solar power, wind power, and hydropower.

- Renew attention to the question of electricity tariffs.

Deregulate the power sector to allow increased private sector participation These mandates imply increased system capacities (generation, transmission, distribution, marketing) and reform of the electricity industry through deregulation to encourage private sector participation and attract investment. Deregulation and liberalization of the electricity industry will encourage development and use of alternative energy sources. They will also affect electricity tariffs, which will requir regulatory attention.

Policy thrust and targets. NEEDS proposes set of targets for the power sector to meet

- Increase generation capacity from 4,200 MW to 10,000 MW (an increase of 138 percent).

- Increase transmission capacity from 5,838 - megavolt amperes (MVA) to 9,340 MVA, a 60 percent increase.

- Increase distribution capacity from 8,425 MVA to 15,165 MVA an increase of 80 percent).

- Increase tariff collections from 70 percen to 95 percent.

- Reduce transmission and distribution

losses from 45 percent to 15 percent.

- Reduce controllable costs by at least 30

percent.

- Rightsize to reduce staff strength by about 15 percent.

- Create 11 semiautonomous business units (profit centers). (This target was met in January 2004.)

- Make the tran

semiautonomous unit by April 2004 .

Unbundle generation by the fourth quarter of 2004

The electricity supply industry is capital intensive and cannot be funded adequately by the federal government alone. The sector therefore needs to be reformed in order to attract private sector participation.

Key strategies. Necessary reform of the electricity industry cannot take place without enactment of the Electric Power Sector reform bill. Competition (facilitated by unbundling of NEPA and private sector investment) will not take place without an appropriate legal and regulatory premerk, clearly defined market rules and

adequate trading arrangements, tariffs that reflect costs, and improvement in tariff collection.

Reform of the industry is therefore predicated on the federal government's national electric power policy and the enabling legislation. The proposed Electric Power Sector Act will entail

- Unbundling NEPA into distinct business units

- Establishing a regulatory agency for the

electricity industry

Establishing a rural electrification agency

Increasing access to electricity

- Privatizing business units that will emerge

from unbundling NEPA

The unbundled entities can be incorporated into separate legal entities only after the Electric Power Sector reform bill is enacted. Nonetheless, actions are being taken to operationalize the unbundling programme and to carry out other transitional initiatives that are consistent with the overall reform process and have the potential of fast-tracking the restructuring and privatization of the secto

for the power sector: - Revenue enhancement measures. The Commercial Re-Orientation of Electricity Sector Toolkit (CREST) initiative has commenced in some NEPA business units. An extensive metering programme has begun, with a view to metering all customers within the next two to three years. Particular attention will be given to industrial and high-demand customers. Estorts are under way to put all government establishments on prepaid meters by the
The electricity supply industry needs to be reformed in order to attract private sector participation 
end of 2004. Outsourced revenue collection contracts will be strengthened, and measures will be introduced to discourage late payment of bills.

- Distribution and customer service. Some short-term external managerial and technical support will be provided to the unbundled entities. Expansion and reinforcement of the distribution network will be carried out to improve the quantity and quality of supply and to reduce losses. The proposed expansion and reinforcement will be funded largely from internaly generated revenue, since the unbundled distribution companies will be the first to be divested to the private sector.

- Transmission. The government will continue to own most of the major transmission company (TransysCo), but the company could be operated under a management contract. TransysCo will be responsible for electricity transmission and for market and system operations. Meanwhile, projects to close the grid loop and decongest bottlenecks in the network will continue. The ongoing World Bank-assisted transmission development plan project will be concluded. Multilaterals will provide up to $\$ 500$ million to develop the additional transmission capacity required for the enhanced generation.

- Generation. The private sector is already participating in electricity generation. The federal government is funding four new stations, with a total capacity of about 1,400 MW. Most of the anticipated new capacity will come from the private sector. Generation will be unbundled by the fourth quarter of 2004, ahead of its ultimate privatization. Coal-fired generation will be developed as a strategic alternative source of electricity, mainly through private-public partnership, a proven option for this sort of activity. An initial integrated coal utilization project proposed for Enugu will incorporate a 500-1,000 MW power station. Before its implementation, comprehensive studies will be undertaken to ascertain actual levels of coundertaken Other proposed programmes include development of the Mambill and Zunger hydro stations on a private-public partnership basis (with project development studies for Mambilla to be concluded in 2004) and commencement the second phase of major rehabilitation of the second phase of (Jor rehabilitation of to prevent a reduction in capacity. - Gas pricing. The gas and electricity industries in Nigeria are very interdependent. Reform in both sectors is imperative Gas producers will need to make gas-gathering investments, while the Nigeria Gas Company will need to expand or upgrade its transportation infrastructure. The Nigeria Gas portation infrastructure. The Nigeria Gas
Company and NEPA have agreed on gradual adjustments in gas prices compatible with NEEDS economic empowerment and rural development priorities.

- Vandalism. Preventing vandalism of distribution and transmission infrastructure is a major challenge. (The timely completion of the Abuja-Shiroro line was threatened by vandalism.) The high cost of emergency repairs of the power infrastructure as well as lost revenue during periods of repairs are of grave concern and pose threats to the reform process. The government will consider forming a special security unit for policing power installations.

\section{Water Resources}

Nigeria is blessed with abundant water resources. Annual runoff at the Lokoja gauging station on the Niger River has peaked at 165.8 billion cubic metres. There is also a substantia groundwater available in the large sedimentary basins (the Sokoto and the Chad basins) that along Nigeria's borders Surface water potential is estimated at 267.3 billion groundwater potential is estimated at 51.9 billion cubic metres. Irrigation potential for about 3.14 million hectares is only 0.02 percent utilized, milion hectares is only 0.02 percent utilized, and billion cubic metres of water in about 200 dams nationwide is effectively used. The Federal Office of Statistics' 1999 Multi-Indicator Cluster Survey ost Statistics thated that 52 percent of urban dwellers (48 percent including semi-urban dwellers) and 39 percent of rural dwellers have access to potable water. Water shortages are increasing in
the North, major pollution is growing in the Delta area, and gully erosion is occurring in the southeast.

\section{Policy Thrust}

The government's policy direction commits to eradicating water-borne diseases and to improving water supply and management for other productive economic activities. NEEDS particularly recognizes the importance of managing water resources in an integrated and sustainable manner. The policy thrust of the government therefore will build on the Nationa Water Resources Management Strategy (WRMS), which involves all stakeholders to ensure integrated management and development of water resources in the country. The thrust is on more on integrated and sustainable water resources management to meet the nations present and future water resources needs in all demand sectors-including human consumption

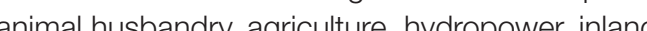
waterways, environmental protection, and industry. The key objectives of the water esources policy include:

- Ensuring the development and management of water resources in an integrated

manner and as a national strategic resource Protecting water resources and the economic development

- Involving all stakeholders-particularly the private sector-in the sustainable development of water resources through coordinated management and holistic utilization

- Optimizing the use of water resources at all times for present generations to sunvive al without compromising water supplies for future generations

\section{Strategies}

- Develop and implement a system of quality assurance consistent with WHO standards -with hydrogeological mapping and water quality laboratories

- Reactivate the River Basin Development Authority and other existing urban water

- Protect watersheds to enhance underground water supply for sustainable aquifer

Establish a legal and regulatory framework to promote rational use and protect water resources

- Create an institutional framework and participatory approach encompassing all
stakeholders in a public-private partnership in the sustainable development of the nation's water resources
The government's

policy direction

commits to

eradicating waterborne diseases and to improving water

supply and

management 
- Build an information and water resources database to coordinate management and utilization of water resources in an integrated and holistic way

- Uphold the principles of water resources Uphold the principles of water reso
economics and financing to ensure adequate funding and economic viability in water resources management

- Maintain high standards in water resources infrastructure and assets management at all times

Because water supply and sanitation are

central to

improvements in so

many aspects of

human development

they will remain a

primary focus under

NEEDS

- Uphold Riparian principles and the

philosophy of sharing of benefits in matters

of international waters

\section{The National Water Supply and Sanitation}

\section{Strategy}

Because water supply and sanitation are central to improvements in so many aspects of human development, health, education, urban and rut development, development of industry, and general economic development-and thus centra to the Government's primary mission of poverty reduction-water supply and sanitation will remain a primany focus of the government under NEEDS. The National Water Supply and Sanitation Programme proposes an intervention strategy for the water supply and sanitation sector in four subsectors: urban areas, small towns, rural areas and water resources management and sanitation. For urban areas, federal and state governments have agreed to cooperate in financing capital investment. State governments that are directly responsible for operational service will also need fundamentally reorientation their provision of services. Reform will require basing institutional and regulatory frameworks on the concept of water supply as a service industry. Despite the public monopoly characteristics of water supply, separating infrastructure investment and ownership from service operation creates competition with significant efficiency gains. Allowing state water agencies more autonomy and firms could increase efficiency- Detailed lival institutional, and financial preparations are needed or water uilities to be efficiently maned and adequately regulated and for state water agencies to become asset owners or regulators. For small towns, government policy is to decentralize ownership and management of water decentralize ownership and management of water community involvement and support from the private sector-including operating under contract - and regularizing the senvices of independent providers or franchisers. In small towns the focus is on community ownership coupled with local private sector contracting for operations. For rural areas, government focus is on ncreasing the water supply to attain 60 percent rural coverage by 2007 with a three-pronged approach of water rehabilitation, expansion, and construction of low-cost rural water schemes. This strategy includes sharing ownership and management by communities and local governments, with communities taking charge of operations and maintenance. In small towns and rural areas, the fiscal focus must be on phasing out subsidies for maintenance altogether and restricting such subsidies to partial capital costs to engender greater community ownership.

\section{Environmental Management}

The environment provides the foundation for all development efforts in Nigeria. Its close linkage to other major sectors of the economy is exemplified by the fact that agricultural productivity-and therefore food security — cannot be guaranteed in a degraded environment. Environmental degradation is caused by declining soil fertility, unsustainable land use practices, lack of land for farming, harsh climatic conditions for crop growth and animal rearing, and other factors.

The environment provides numerous opportunities for wealth creation and employment generaties for wealth creation and employment generaprovides a plethora of income opportunities for the provides a plethora of income opportunities for extraction of nontimber forest products, such chewing sticks, ogbono, and a variety of healthfut condiments. The majority of the ruraly of health relies on medicinal plants for their health care needs, indicating another important source of income from forests. The coastal environment provides seafood, including fish, sea turtles, and provides seafood, including fish, sea turtles, and foreign exchange earners. The potential to develop ecotourism and to generate income by converting waste to wealth are also worth noting

High levels of air, land, and water pollution and unsanitary environmental conditions predispose Nigerians, particularly the poor, to disease. The result is an unhealthy workforce and the reduction of the potential for productive activities. A degraded environment also forces people to use resources to treat diseases that could have been prevented by maintaining a healthful environment. It is a glaring paradox that despite the contribution of the environment to the national economy, environmental considerations are rarely mainstreamed into national development planning in Nigeria. The lapse probably reflects the fact that the contribution of the environment to the

economy is not readily captured by traditional.

measures of growth, such as GDP.

Critical issues in this sector include the following: - Rapidly increasing production of waste
Uncontrolled development, without regard for waste management or pollution control, and the lack of proper management of waste

- Low level of sanitation, especially in city

centers and peri-urban slums

- Absence of significant private sector

involvement in waste management

Environmental degradation, including

deforestation, erosion, desertification, and

pollution of the air, water, and land

- The impact of oil and gas development on

the environment and unsustainable land use

- Weak enforcement of environmenta laws

- Loss of biodiversity

- Extreme climatic events, such as droughts,

floods, and climate change

- Inadequate environmental data

environment and public health

- Absence of a system of national accounting that captures the contribution of the

environment to development indices

\section{Policy thrust}

NEEDS focuses on ensuring a safe and healthful environment that secures the economic and social well-being of Nigerians on a sustainable basis. The specifics of the agenda are enunciated in the Environmental Renewal and

Development Initiative, the primary objectives of which are "to take full inventory of Nigeria's natural resources, assess the level of environmental damage, as well as design and implement restoration and rejuvenation measures aimed at

Targets

The reform programme includes several targets:

- Control environmental degradation

processes.
The environment provides numerous opportunities for wealth creation and employment

generation 
- Bring environment and waste pollution in cities and urban centers under control.

- Foster private sector participa
environmental protection.

- Comply with international standards Comply with international standards in

controlling and monitoring the environ-
ment.

Promote local manufacture of equipmen and the use of raw materials for environ-

- Standardize the use of equervation.

environmental senvices.

- Comply with international safety, health, and environmental standards as they relate to specific industries and sectors of the

economy.

- Reverse the loss of biodiversity.

- Phase out persistent organic pollutants.

- Phase out ozone-depleting substances.

conomic and socia

well-being of

Nigerians

\section{Key strategies}

The government's strategic intent is defined by the following:

- Establish a central self-sustaining regulatory agency responsible for environmental enforcement, compliance monitoring, environmental auditing, impac assessment, and standards setting.

- Strengthen the machinery for desertifica-

tion, erosion, and flood control.

Promote synergy in implementing

environmental conventions.

Use space-based research and information technology for environmental management. Develop a private-public partnership scheme to address the increasing urgency of waste management.

- Promote a programme for private sector investment in waste-to-wealth management in cities and urban centers.
Evolve proactive management of extreme climatic conditions.

Reduce deforestation, especially in

gically fragile areas,

(a)p community-driven developmen management.

- Promote community-based sanitation

senices.

Install, calibrate, and standardize

relevant early warning systems for

monitoring the onset of environmental

hazards.

Promote the safe use of pesticides and

environment and public prealth.

- Ensure food security by engaging in sound

food sanitation practices.

- Promote sustainable measures for

reforestation and afforestation that foster community-based industries and improve food security.

- Promote agro-forestry.

Monitor and evaluate environmental

management plans.

- Implement a strategic environmental

assessment.

- Review the environmental impact of

Decree 86 of 1992.

- Promote wildlife farming, sericulture, apiculture, and the marketing of nontimber forest products.

- Develop and adopt a system of national accounting that captures the economic contribution of the environment sector. Encourage the growth and adoption of aromatic and herbal plants for primary health care.

- Implement the National Biodiversity Strategy and Action Plan.

\section{Chapter Sectoral Strategies}

Federal government ministries, their state counterparts, and private sector stakeholders strategies will be nationally coordinated, with clearly delineated roles and responsibilities for each level of government, the private sector, other stakeholders.

The overall strategy is to diversify the productive base of the economy away from o and to foster market-oriented, private sector-driven economic development with strong local participation. The goal is to develop an indigenous entrepreneurial class capable of competing in a global market in which technoogy and skills play dominant roles. As the government continues to redefine its role, resources will be freed up, allowing the government to focus on its primary role of providing basic infrastructure, security, defence, and the social services that are necessary to create a competitive environment that enables the development of sustainable private sector-driven wealth and employment. For its part, the private sector will be encouraged to commit to genuine and responsible investment, good corporate governance and citizenship, and internationally acceptable practices. It must also commit to transparent partnership with the public sector, especially in promoting and developing small and medium size enterprises.

is in this context that the various sector strategies are couched. Given the interdependent nature of the different sectors of the economy several cross-cutting issues will need to be addressed. These include:

- Inadequate infrastructure

- The finance and funding gap

- Inappropriate and inadequate technology

- Unfair competition

- Inadequate institutional and legal framework, including bureaucratic

- Policy inconsistency and lack of commitment and political

- Inadequate human capital development

- Lack of security, law and order, and

respect for contracts

The government will encourage organizations (public and private) to modernize by adopting information and communications technology. The Raw Materials Information System (RMIS) of the Raw Materials Research and Development Council will be updated to will routinely provide the following information
The goal is to develop

an indigenous

entrepreneurial class capable of competing in a global market in which skills play a

dominant role 
investors, industrialists, researchers, policymakers, and other stakeholders:

- Raw materials available by sector

- Location and estimates of reserves

mand for raw materials

- Industrial uses

- Processing equipment fabricators in Nigeria

- Science and technology experts in Nigeria

- Quantities and prices of important

commodities

Agriculture remains To promote harmonized and integrated

science and technology-diven socioeconom

the mainstay of national Research and Development

Coordinating Council, chaired by the President,

with all core science and technology-based

ministries as members. Other members

include the Minister of Finance and representa-

tives of the Office of the Economic Adviser to the

President; umbrella science, engineering and

economics associations, research institutes, and

associations of Nigerian academies, universities

and polytechnic schools; the Nigerian Investment

Promotion Council; and small and medium-size

enterprises, among others.

\section{Agriculture and Food Security}

Despite the dominant role of the petroleum sector as the major foreign exchange earner, agriculture remains the mainstay of Nigeria's economy. In addition to contributing the largest share of GDP, it is the largest nonoil export earner, the largest employer of labour, and a key contributor to wealth creation and poverty alleviation, as a large percentage of the population derives its income from agriculture and related activities.

Over the years the rate of growth in agricul-

tural production has stagnated and failed to keep pace with the needs of a rapidly growing population, resulting in a progressive increase in mport bills for food and industrial raw materials. major employer of the growing labour force and an earner of foreign exchange has also been undermined. As a result, the large majority of Nigeria's population, many of whom lise in rura areas, remain poor , mander the NEEDS programme, agricultura development will be vigorously pursued, with the aim of achieving food security and reducing poverty.

Major constraints inhibiting private sector erticipation in the transformation of agricultura production include the following

- The rapid shift of the population from rura to urban areas and the shift in consumption patterns from local to imported food items

- Lack of funds, inadequate processing and storage facilities, and inefficiencies in input supply and distribution

- The oil boom, policy inconsistency, and the decline in political commitment to agricultural and rural development

- An inadequate incentive framework and

pervasive distortions in the macroeconomy

- Absence of a price support mechanism

and pervasive distortions in macroeconomic and sectoral policies, including misaligned exchange rates and heavy taxation of agricultural exports

- Continued dependence on rain-fed

agriculture and the absence of economies of scale

- A land tenure system that inhibits the acquisition of land for mechanized farming - Inadequate agricultural extension services and the lack of indigenous capacity or technologies responsive to local conditions
- A degraded environment that has reduced agricultural yields

\section{Policy Thrust} economy, prospects for food security, the supply growth are critically dependent on what happens in this sector. Accordingly the government is committed to increasing investment in food and griculural production. Its main policy thrusts include the following:

- Provide the right policy environment and torict the sector. Implement a new agricultural and rural development policy aimed at addressing the constraints in the secto.

- Foster effective linkages with industry to achieve maximum value-added and processing for export.

- Modernize production and create an agricultural sector that is responsive to the demands and realities of the Nigerian economy in order to create more agricultural and rural employment opportunities, which will increase the income of farmers and rural dwellers.

- Reverse the trend in the import of food (which stood at 14.5 percent of total imports at the end of 2001), through a progressive programme for agricultural expansion. The government is committed to reducing the growing food import bill to stem the rising trade imbalance as well as diversify the foreign exchange earning base.

- Strive towards food security and a food surplus that could be exported.

- Invest in improving the quality of the environment in order to increase crop vields.
Targets

To restore agriculture to its former status as a eading sector in the economy, NEEDS sets the following targets:

Achieve minimum annual growth rate of 6 percent in agriculture.

Raise agiculural exports to $\$ 3$ billion by 2007. A major component of these exports will be cassava

cally reduce food imports, from 14.5 2007.

Develop and implement a scheme of land preparation senvices to increase cultivable arable land by 10 percent a year and foster private sector participation through

incentive schemes.

- Promote the adoption of environment-

friendly farming practices.

- Protect all prime agricultural lands for

continued agricultural production.

\section{Strategies}

To achieve these targets, the following strategies will be employed:

Vigorously implement presidential initiatives on cassava, rice, vegetable oil, sugar. ivestock, tree crops, and cereals. Under this initiative, Nigeria hopes to generate as much as A3 billion a year from agricultural exports. Take advantage of the various concessional arrangements provided by the World Trade Organization (WTO), the European Union's African, Caribbean, and Pacific states agreement, the U.S. African Growth and Opportunity Act, and the National Partnership for African Development, as well as the huge West African market. agricultural training, and streamline the
The government is

committed to

increasing investment

in food and

agricultural

production 
extension delivery system. Involve NGOs and opinion leaders in extension delivery by building capacity and promoting improved - technologies that meet farmers' needs.

- Review the agricultural input supply and distribution system with a view to developing an effective and sustainable private sector-led input supply and distribution system.

- Promote integrated rural development involving agricultural and nonagricultura activities, including through the provision physical infrastructure such as feeder roads, rural water supply, and rural

roads, rural water
communications.

- Encourage states to develop model rura

communities and fo develop model

providing them with feeder roads,

boreholes, vocational training, simple farm

tools and equipment alternative energy

sources, and communications centers to

provide a wholesome rural life and reduce the incentives to migrate to urban areas.

- Adequately capitalize the Nigerian

Agricultural, Cooperative and Rura

Development Bank (NACRDB) to provide

soft agricultural credit and rural finance.

(NACRDB has been restructured and its

mandate expanded to include full financial intermediation.)

- Refurbish the eight functional silo

complexes and phase completion of the remaining ones to improve and increase the capacity of the food reserve programme as a step towards achieving food security. These facilities would be leased to farmers on an individual or group basis.

- Promote joint venture, private sectormanaged, multicommodity developmen and marketing companies to guarantee emunerative prices for farmers, stabilize consumer prices, and provide alternative markets for farm produce through a buyesort mechanism.

Support all-season farming by promoting ain-fed and irrigated farming, with an

- Implement the programme for the ma

prosive

environment

management.

\section{Manufacturing}

Although the manufacturing sector (including micro-, small, and medium-size onterprises) has the potential to create wealth and employment, the sector has stagnated in Nigeria, and its contributions to GDP and employment remain small. The activity mix in the sector is also limited, dominated by import-dependent processes and factors. Although reliable data are unavailable, rough indicators show that capacity utilization in the sector has improved perceptibly since 1999 but that the sector still faces a number of constraints, including the following:

- Lack of demand for the products and services of small and medium-size enterprises, and ineffective linkages between industry and research institutes and universities

- Lack of political will to implement local content and technical know-how policies - Lack of engineering capacity to translate scientific research results into finished goods and maintain existing machinery; low level of entrepreneurial capacity, complete lack of institutional mentoring and technological support, and paucity of trained artisanal skills

- Unfair competition from dumped

secondhand, counterfeit, smuggled, and substandard products

- A weak legal framework; weak business, financial, and information management systems and practices; an underdeveloped payment system

- Systemic and operational constraints that impede the competitive capacilies of lar manufacturing companies mentes

The the following additiona constraints:

- Low market access

- Poor access to credit

- Poor information flow

- Poor access to land

- Weak linkage among different segments of operations in the sector

- Lack of infrastructure for microenterprises

- Weak safeguards against occupational and

other health hazards

\section{Policy Thrust}

The overriding objective of industrial policy is to accelerate the pace of industrial development by radically increasing value-added at every stage of the value chain. Under NEEDS, for the most part Nigeria's resources will no longer be traded in their primary state. The government will emphasize increases in total factor productivity by pursuing knowledge- and skill-intensive production on the basis of best practices. Nigeria's industrial development strategy will encourage forward and backward linkages in a few niches. The government will continue to provide the enabling environment for private sector leadership, facilitate renewal for sunset industries, and encourage innovators. Specific policy thrusts include the following:

- Establish a structured and efficient micro-, small, and medium-size enterprise sector onstainable economic

development, generate employment, and

- Facilitate the development of an industria sector that is internationally competitive and can take advantage of existing preferential arrangements as well as give priority to the processing of Nigeria's abundant resource endowments into intermediate raw materials or finished goods for local consumption and export.

- Develop science and engineering

infrastructure-well-trained technical and managerial personnel, physical plants, tools, spare parts, materials, and other inputs needed to operate efficiently and profitably.

\section{Targets and Strategies}

Targets for the manufacturing sector include the following:

- Increase capacity

(n) 2007

- Increase the private sector's share of

To reverse the dwindling fortunes of the manufacturing sector, the government is committed to the following strategies:

Remove infrastructure constraints on small and medium-size enterprises, and expedite action on establishing clusters and industrial parks. These critical ingredients
The objective of

industrial policy is to

increase value-added

at every stage of the

value chain 
for increasing the participation of the private sector will be targeted at growth poles. by unpropriate institutional support, by undertaking studies aimed at attracting foreign investors and by scanning overseas markets and montoring developments that Small and Medium Enterprise

Development Agency of Nigeria will be Development Agency of Nigeria will be and executive capacity. In collaboration

The service sector

has witnessed a

boom in recent years

with the relevant agencies at the state and local government levels, it will play the role al politer, faclintor, and coordinator of supports an export-oriented manufacturing sector and encourages large businesses to foster the growth of small and medium size enterprises in their value and supply chain. - Provide targeted incentives (such as tax - deductibility) for scientes (such as tax research and develo

- In collaboration with relevant agencies

the state and local government leves, coordinate and faciltate the implementation of an effective competitive industrialization strategy. all policies affecting small and medium-size
enterprises. Strengthen the Bank of Industry and oth special-purpose finance institutions (the Nigerian Export Import Bank, the Nigerian
Agricultural, Rural, and Cooperative Bank) Agricultural, Rural, and Cooperative Bank to perform their statutory roles (especially
the provision of concessional loans and credit guarantee schemes) and enlarge their scope to include large manufacturing companies.

- Strengthen the legal and institutional framework for the operation of micro finance institutions by streamlining the operational guidelines and tax incentives for small and medium-size enterprises and adopting other measures. Explicitly recognize the informal sector, remove constraints to implementation of the Small and Medium Enterprise Investment Equity Scheme (SMEIES), and design incentives targeted at investors who would specialize exclusively in exporting.

- Review and implement a codified tax and incentive structure reform (including providing for necessary tradeoffs) that
Promote joint venty

incentives ventures and provide existing small and medium-size enterp

- Implement a government procurement policy that supports locally produced goods and senices, especially of smal and medium-size enterprises.

Promote the production of good-quality goods and senvices in Nigeria to facilitate competitive export-oriented manufacturing sector.

- Strengthen the Loan Guarantee Scheme, which will enable banks to make loans to small and medium-size enterprises.

\section{Services}

The service sector has witnessed a boom in recent years. Liberalization led to a substantial increase in the volume of activities in the banking and other financial services industries. The recent to huge increases in telephone service per capita and created many new job opportunities. Improvements in the service sector are expected to strengthen performance of the real sector. direct investment in pe thew of foreign liberalization of the communications industry led
Information and Communication

\section{Technology a}

The following issues represent challenges to

. - High cost of private provision of power - Lack of local manufacture or maintenance of information and telecommunication equipment and the lack of local software development capacity

- Absence of effective and efficient postal communication

- Inadequate human capacity and indigenous technical know-how

Policy thrust. Under NEEDS the government is committed to the following policy thrusts:

- Develop and sustain a modern information

and communication technology to suapor private sector-driven growth and economic development and to improve the quality of life and reduce the level of poverty significently.

- Improve access to Internet connectivity,

and raise the level of computer usage and literacy.

- Facilitate the development of a national multimedia supercorridor, including provision of appropriate incentives for private sector involvement.

- Aggressively promote information and communications technology as an instrument of mass education, growth, and development.

Targets targes:

- Increase telephone density to one

telephone per 25 people.

Make telecommunications accessible to a wider range of Nigerians, regardless of where they live.
- Develop a national communications and telecommunications backbone, including a national multimedia supercorridor.

NEEDS adopts the following strategies: Use a combination of fiscal and financia investment in senvice provision in the industry.

Enforce intellectual property rights, and promote entrepreneurship, training, and partnerships.

- Pursue a local content policy in the manufacture of electrical and electronic equipment and communications and telecommunications equipment, including

- Facilitate access to special financial

support (through NEXIM, the Bank of Industry, SMEIES, and other institutions) for private sector-driven wireless telephony and Internet connectivity development in rural areas.

- Foster an enabling environment for

developing software capacity.

- Provide incentives to develop industrial

parks in information and communications technology.

Nigeria's tourism industry has great potential for attracting foreign investment, which would generate employment and foreign exchange. The industry is constrained by several factors,

- Inadequate facilities at established touris centers

- Low level of global awareness of tourist attractions in Nigeria

Undeveloped tourist infrastructure

- Lack of security
Improvements in the service sector are expected to

strengthen performance of the

real sector 
The focus of NEEDS in the tourism sector is to make Nigeria the preferred touris destination in West
- Low level of investment - Poor attitude and disposition towards recreation and vacation by Nigerians

Target. The primary focus of NEEDS in the tourism sector is to make Nigeria the preferred lourist destination in West Africa. The key targe arivals into the country by 10 percent a year.

Strategies. To achieve this target, the govern-

Low level of technological input in the

industry

- Uncertain intellectual and proprietary rights

Underdeveloped distribution structure

- Lack of access to adequate financing

human capacity

- Human capacity of informality

Policy thrust. The government's policy thrust is to facilitate the development of a technologically competitive, private sector-led film industry in ment will:

- Concession existing tourist attractions and provide support infrastructure for tourism. - Encourage private sector investment in the tourism sector, and participation in the

management of national parks.

- Improve security to encourage foreign

tourists to visit Nigeria

- Launch an awareness campaign within and outside the country on the benefits and potentials in the secto

- Reorient visa officials to a pro-tourism

approach.

- Establish a tourism database.

- Establish a private sector-oriented institute for hospitality and tourism, regulated by

the government.

- Pursue an aggressive environment policy that supports and encourages the tourism industry.

\section{Film Industry}

The Nigerian film industry has significant foreign exchange-earning capacity. Recent reports indicate that some 2,000 Nigerian videos were rented or sold in a single month in a single outlet in the United States. The potential market for Nigerian films is large, but the industry is held back by several constraints:
Nigeria that will create employment, wealth, and net foreign exchange earnings.

Targets and strategies. NEEDS has established the following targets:

- Facilitate technological input into the

production process.

- Foster development of a Nigerian version

of Hollywood for film production.

Encourage the local manufacture of film

production inputs, and support senvices clusters.

- Generate \$200 million in foreign exchange earnings by 2007 from the export of videos.

- Develop standards and provide incentives for private sector investment in the industry.

To achieve these targets, the government will: - Strengthen the regulatory agency for the industry to facilitate healthy competition, upgrade quality, ensure appropriate controls, monitor standards, and promote standardization.

- Strengthen the capacity of regulatory and promotional agencies to promote the industry, enforce standards, and ensure compliance with copyrights laws. These agencies include the Ministry of Information and National Orientation, the National Film Corporation, the National Film Institute, the geria Copyrights Commission, and the Nigeria Film and Video Censor's Board. - Encourage tha development of a window of special funding for

- the banking industry. fast-track export scheme to bring export fast-track export scheme to bring expor

Provide incentives for further private sector investment in the sector.

\section{Financial Services}

Over the past decade and a half, the financial sector has experienced substantial fluctuations in fortunes. These developments have highlighted their strategic role in Nigeria's development process. Apart from their importance in mobilizing and efficiently allocating resources, they also play a key role in pricing and trading risks and
implementing monetary and fiscal policies. The shift in emphasis to a private sector-led economy deepens the significance of the financial sector in Nigeria's overall development. There is a strong case for ensuring the efficiency of the financial system and for dealing with the contradiction inherent in the fact that despite high profit levels the sector does not appear to be playing a catalytic role in the real sector. Other concerns include the following:

- The capital market remains shallow. - The banking system is dependent on public sector funds as a significant source of deposits and foreign exchange trading.

- Some of the information submitted to the

monetary authorities is not accurate.

- Fiscal and mon
- Bank loans and advances are not repaid promptly.

Policy thrust. To build and foster a competitive and healthy financial system to support

development and to avoid systemic distress, the thrust of policy under NEEDS is to:

- Deepen the financial system in terms of

Dsset volume and instrument diversity.

Drastically reduce and ultimately eliminate banking system in order to free up resources for lending to the private sector.

- Review capitalization of financial institu-

tions in the system.

- Develop a structure of incentives to enable the financial system to play a developmental role by financing the real sector of the economy.

Strategies. Given that the success of NEEDS will depend, in part, on the ability of financial intermediaries to play their roles, the financia regulatory authorities and monetary policy framework will adopt the following strategies:

- Embark on a comprehensive reform process aimed at substantially improving the financial infrastructure (legal codes, information systems).

- Restructure, strengthen, and rationalize the regulatory and supervisory framework in the financial sector.

- Address low capitalization, the poor governance practices of financial intermedaries that submit inaccurate information to the regulatory authorities, and the consequent costs to the financial system

- In collaboration with banks and other financial institutions, work out a structured financing plan that ensures less expensive
The shift to a private sector-led economy deepens the significance of the financial sector 
and more accessible credit to the real sector. Direct government policy towards financia deepening (establishing links between rura forman, banking and nonbanking, and financial product diversification (filling the missing midule for commercil fing the senices for small and medium-size enterprises with new senices based on enterprises wh new services based on financing, leasing, and so forth).

The oil and gas sector is seen as an external sector, because it has no links to the other

\section{Oil and Gas}

The oil and gas sector is seen as an external sector, because there is no link between it and the other sectors of the economy. The key issues requiring attention include the following:

- Low local content level and community
unrest in locations of proven reserves

- Absence of indigenous technical know-how

and a deficient capacity-building programme

- Multiplicity of legislation governing

operations in the sector

- Absence of a national gas infrastructure

(national gas grid system)

- Price and quota volatility

- Absence of an independent industry

regulator for the various subsectors

- Inefficiency and widespread fraud

- Poor safety and regulatory systems

Inadequate financing arrangement for

operations, including cash-call obligations

- Petroleum product supply constraints,

including inadequate local refining and distribution capacity

- Lack of value-adding activities and processes (integrated petrochemicals capacity)

\section{Policy Thrust}

The government's policy thrust is defined by the

- Increase the level of crude oil reserves. - Ensure regular supply and distribution of petroleum products through a liberalized and deregulated supply, distribution, and refining system.

- Increase the drive for investments to

establish integrated petrochemicals based on gas stream, with a majority private

sector interest.

- Increase local content improving linkages

to the rest of the economy.

- Sustain the focus on the terminal date for

ending gas flaring.

- Hedge the national economy against volatility

in the crude oil market and OPEC quota.

- Harness and exploit the country's huge

gas reserves to increase the use of gas in power generation and boost foreign

exchange earnings from gas.

- Foster healthy, orderly, and competitive

development of oil and gas subsectors

through effective and efficient regulation,

standards, and quality control agencies.

\section{Targets and Strategies}

NEEDS has established the following targets in the sector:

- Achieve an OPEC quota increase of 7-10 percent in 2004 and a reserve level of 40 billion barrels by 2007 .

- Design and facilitate the implementation of a national gas grid by 2007.

- Completely deregulate and liberalize the downstream petroleum sector, including the distribution network.

- Unbundle the Nigerian National Petroleum Corporation (NNPC) and privatize its downstream subsidiaries, and enable the Nigerian petroleum Development

Company and a professionalized NNPC to compete as Other oil companies around the world do.

- Increase local content in the oil and gas senice sector to attent in the oil and gas service
2007.

- Review and codfy and gas industry

To achieve the targets,

dopt the following strategies:

In collaboration with the private sector ensure the effective implementation of a national oil and gas policy and a nationa gas grid system.

- Explore the use of alternative funding schemes in the sector. Set up long term financing arrangements in support of local content.

- Develop a database in Nigeria on the country's oil and gas deposits, facilities, and professionals.

- Review, streamline, and codify existing

incentives in the sector.

- Facilitate projects that transfer technology and generate employment in the nonoil

sector, especially the petrochemical industry.

- Complete deregulation of the downstream sector by privatizing the refineries, product haulage facilities, and distribution network.

- Improve security (against vandalism at facilities), and strengthen the Department of Petroleum Resources and the Ministry of Environment to allow them to perform their regulatory functions properly.

- Encourage transparency in the management of oil revenue by implementing the principles of the Extractive Industries Transparency Initiative.
Facilitate private sector investment in the development of support industries that use petrochemical products as primary raw

Encourage oil companies to proactively werward especially in downstream activities, and pertner with or involve local companies in jint ventures. Where capacity exists, resenve specific jobs for domestic value adding industry, strengthening the domestic base of the sector. Make companies' track records in promoting domestic value-added a consideration in determining the allocation of future oil and gas blocks.

- Implement the National Oil Spill Contingency Plan.

\section{Solid Minerals}

Nigeria has abundant solid mineral deposits. Some independent estimates indicate that the country's solid mineral deposits could provide more revenue, foreign exchange, and employment than the oil and gas sector do. Exploitation of these resources could provide a major impetus for growth and development.

But several factors constrain development of the sector. A comprehensive geological survey of all solid mineral deposits has yet to be undertaken. Other constraints include the lack of adequate proven deposits, the lack of adequate capacities in mining and processing, the lack of infrastructural facilities, an unfavourable fiscal regime, and an uncompetitive legal and regulatory framework. A short-term programme especially for minerals that are vital for local
Independent

estimates indicate that solid mineral deposits could provide more revenue and employment than the oil and gas sector 
industries, such as barytes, limestone, gypsum, exploitation of solid minerals to provide inputs for pal industries as well as for exports.

A serious problem is informal and illeg mining of mineral deposits. Such activitios have - Environmental degradation, inclualing pits, pollution of river systems, river silting. and high exposure to radioactive and and high exposure

NEEDS will support exploration for base

metals and

gemstones,

encourage sustainable production, and create

self-employment

Social problems, including child labour and

ational security risk, due to the migration of foreign nationals from one site to another, working on sites with both vigorously promote the exp the govern

led to:

overnment, reduce environmental degradation, ish social and health problems, such as child labour and the spead the of HIVAADS.

\section{Policy Thrust}

The goal of government policy in the sector is to provide incentives and an enabling environment for private sector investment The major policy thrust is to ensure the vigorous and orderly explotation of solid mineral resources in order to genter exports, and provide inputs for local industries. The NEEDS action plan will vigorously support exploration for base metals and precious and semiprecious stones. Informal sector mining activities will be formalized and supported to encourage sustainable production and create self-employment.

registered and unregistered titles

Low productivity and waste of minerals, during mining as well as inefficient production and processing techniques

Lack of regard for health and safety

- Haphazard sale of mineral products and attendant loss of revenue to government - High level of smuggling

In many countries informal mining operations have been formalized into economically viable and environment-friendly ventures. These programmes are often used to reduce poverty as they provide massive employment in rural areas. In addition to making the mine fields attractive to investors, informal and artisana mining activities contribute to exports. Formalizing these operations could create sustainable self-employment for at least 500,000 Nigerians, increase revenue payments to the

\section{trategies and Specific Measures}

\section{The government will adopt the following}

strategies:

Implement the existing legal framework for small and artisan operators in the sector.

- Complete the upgrading of the sector,

empower the Geological Survey Agency to become the industry regulator, and provide a comprehensive database of the locations and estimated reserves of all known solid minerals in Nigeria that could be mined. orderly allocation of bitumen and tar sand blocks in the vast Nigerian bitumen belt, which stretches from Edo State to Lagos State.

- Compile a cadastral register of all available mining rights, licences, and leases of known minerals.

- Codify a system of incentives to attract private sector investment in the sector.
- Simplify the process of issuing licences. - Review the Land Use Act to facilitate entry into the sector

several specific measures for

the sector:

inmediate first step, conduct a geological survey of the entire country in 2004, using remote sensing

(Landsat/Radarsat). That survey will be complemented by aeromagnetic,

electromagnetic, and radiometric surveys.

The government will conduct ground-

truthing surveys using the remote sensing

results in the hope of attracting private

investment. It will also immediately begin

digitalizing existing maps.

- Establish licenced buying centers as the cooperative and licenced miners on one side and local users and export markets on the other. Buying centers can ease the problems associated with marketing problems associated with marketing
products and enable miners to earn premiums on sales of products near operational sites. The centers will also help the government reduce smuggling and collect revenues.

- Create extension services. Technical assistance and support services in prospecting and exploration will be provided to artisanal and small-scale miners in order to enhance and sustain their operations

- Review current legislation through a consultative process with mining

communities, ensuring that public interests (social, economic, and environmental) and community interests (cultural, social, conomic) are considered.

- Inventory the number of miners, the environmental status, the market structure, licensing, and other features of artisanal small-scale mining in Nigeria.

control and assistance (financial and technicall) and guarantee the sustainabilty of mining in active collaboration with community leaders and state and loca governments.

- Promote the establishment of central processing units in order to enhance the value of the minerals. environmental rehabilitation of sites after mining.

- Promote training in environmentally acceptable mining and processing methods in order to improve skills and competence and reduce health risks of miners and their dependents.

- Develop basic infrastructure senvices in mining communities.

- Stimulate and enhance access to financia assistance for artisanal and small-scale miners.

- Promote transparency and participation at all levels of government and management of small-scale mining activity.

- Promote interaction and consultation between different agencies exploiting natural resources (land, forest, minerals). - Establish and enforce environmental standards for mining activities. 


\section{Chapter}

NEEDS seeks to deepen Nigeria's integration with the rest of the world and

to maximize the benefits of strategic

integration
As a small, open economy, Nigeria depends on the global economy for inflows of human and financial capital, technology, imports of inputs into production and for consumption, and as a market for its output and investment.

NEEDS seeks to deepen Nigeria's integration with the rest of the world and to maximize the with the rest of the world and to maximize
benefits of strategic integration. Regional benefits of strategic integration. Regional maximizing the benefits of globalization.

\section{Regional Integration}

With globalization has come the emergence of multinational firms with strong presences in strategically located markets and a convergence of consumer tastes for the most competitive products, irrespective of where they are made. Regional integration represents an effective means of improving the level of participation of countries in the West African subregion in world trade and integrating them into the borderless and interlinked global economy.

Nigeria is committed to the full and complete implementation of the free trade zone agreements of the Economic Community of West African States (ECOWAS), the creation of a single monetary zone, and the unification of West Africa into a common customs territory. Government policy will be aligned towards realization of the following objectives:

- Adopt a common trade and competition policy in West Africa as a buiding block towards full integration of African

economies.

- Adopt a common currency in West Africa under the West African Monetary Zone Protocol.

- Remove all nontariff barriers to trade and introduce a common external tariff regime in West Africa.

\section{Policy Thrust}

The thrusts of the NEEDS trade policy include the following:

- Continue to work towards the macroeconomic convergence criteria as well as the harmonization of financial and economic policies that are expected to lead to monetary integration within ECOWAS.

- Strengthen infrastructure, particularly infrastructure that plays a key role in building regional markets (roads, electricity, telecommunications), and reinvigorate intra-African trade.

- Continue to cooperate with other West African countries in addressing common in order to increase market integration within the subregion. The government w governance issues.

- Fully implement the New Partnership for African Development (NEPAD), especially as it pertains to the AfricPAD), especially mechanism, the promotion peer review governance, intra-African trade, invest-

governance, intra-African trade, invest-
ment, and infrastructure development.

Monitoring Group) to provide security and facilitate business linkages.

- Continue to encourage the learning of a second language (French) by all Nigerians to enhance the integration of the people of West Africa.

- Stipulate minimum domestic value added for commodities and manufactures to be raded within ECOWAS under existing protocols, and strictly enforce the rules of origin clauses in intraregional trade.

Nigeria has the

Strategies

The government's strategies include the

- Harmonize trade and investment codes as well as port and customs clearance procedures across West African countries work with the ECOWAS Secretariat and other West African countries to ensure effective implementation of all protocols designed to advance economic integration of the subregion.

- Facilitate the establishment of a regional, private sector-driven stock exchange. Through ECOWAS, the government will encourage harmonization of the operation of the financial and payment systems within the region.

- Promote regional trade associations, such as the Federation of West African Manufacturers Association

- Encourage the private sector to build refineries and distribute refined petroleum products in West Africa as part of the deregulation of the downstream sector.

- Promote the concept of regional security integration (as distinct from the regular

\section{Trade Policy and Development}

Nigeria is a coastal African country with the potential to become the gateway to much of West and Central Africa. Much of this potentia has not been realized, because of a number of constraints, including:

- The high cost of doing business in Nigeria which has constrained investment and production

- Sometimes poorly implemented incentives, especially fiscal and tariff regimes

Massive smuggling, counterfeiting and dumping of products

- Lack of standardization, required for products to compete internationally - Unfavourable international trade rules Another constraint has been Nigeria's trade policy stance. Although significant improvements have occurred in trade policy since the late 1980s (with large reductions in tariff rates and especially in the application of tariffs and exemptions, transactions costs at ports, customs clearance procedures, and the use of import bans. Nigeria's tariff and nontariff barriers 
have on average exceeded those of the other ECOWAS countries.

\section{Policy Thrust}

The thrust of policy is to drastically reduce the uncertainty and unpredictability of the trade policy regime, harmonize trade practices with facilitate the Free Trade Area within the region respect Nigeria's obligations under the multilateral and regional trading system, and create conducive and competitive environment in which conducive and competitive environment in whic Nigerian businesses can flourish and compete in policy is to lay a solid foundation for fully exploiting Nigeria's potential in international trade and helping it become the gateway to West and Central Africa.

\section{Strategy and Instruments}

exports and gradu to aggressively promote liberalization. NEEDS aims to promott led growth strategy that will take advantage of globalization and the external trade opportunities that regional and international trade and economic integration arrangements offer. The strategy will encourage the growth of industries that have been hampered by narrow domestic market opportunities, promote technological innovation, and diversify foreign exchange earnings. The elimination of exemptions and adoption of a tariff structure that is harmonized with that of other ECOWAS countries will give investors and producers access to capital goods and raw materials at very low duty rates. Selective import restrictions are used as safeguards against unfair trade practices and the dumping of counterfeit and substandard goods, as well as for health and cultural reasons. Some restrictions are warranted to provide temporary protection to firms and industries that need to upgrade their technobgies and pperations in the light of global trends or to alow the government to address the high cost of doing business (especially Nigeria's high infrastructure costs). This strategy is expected to creaste jobs, timu. tion, and earn significant foreign exchange Through trade policy - a key component of the strategy for economic diversification-nonoil exports are expected to increase significantly over (ime, and dependence on imported finicantly over consumer goods (especially food products) is expected to decline significantly.

The key instruments and strategies employed o achieve the objectives of policy include the following:

- Drastically reduce the domestic cost structure - especially infrastructure costs to provide a competitive investment climate as a necessary foundation for production and exporting.

- Aggressively promote exports and economic diplomacy. It is the responsibility of all Nigerians, the private sector, and government agencies and missions abroad to promote Nigeria's commercial interests. abroad.

- Harmonize tariffs with the Economic and Monetary Union of West Africa (UEMOA) and other countries to create a common ECOWAS external tariff. The common tariff is expected to come into effect no later than 2005. Already the government, in consultation with stakeholders, has decided to harmonize Nigeria's tariffs with tariffs imposed in UEMOA countries. When the new tariff book comes into effect (after legislation is passed by the National
Assembly), Nigeria will have reduced the number of tariff bands from 19 to 4 (0, 5 , 10 , and 20 percent). About 65 percent of Nigeria's total imports (an 65 percent of materials, and essential goods, such medicine and books) a subject to as medicine and books) are subject to dutes percent of Nigerie's tiff line were high than the Nerig with the UEMOA rates, Nigeria's average tariff rate is expected to decline more than tariff rate is

Continue to use special levies and import - Contrine to use special restrictons in particula ciranstances to sectors against unfair competition; to protect the health, culture, and environprotect the health, culture, and environsecurity. Import restrictions also give the government time to address the domestic cost structure. But for the high cost. structure in Nigeria, domestic firms could be competitive in some industries in which Nigeria has a comparative advantage. The temporary protection will be reduced in step-wise manner as costs are reduced, in order to expose the firms to international competition, thereby encouraging innovation and growth.

- Rationalize and strengthen institutions responsible for promoting and facilitating trade. Task forces will ensure that Nigeria fully harnesses the potential benefits of concessionary trade arrangements, such as the U.S. Africa Growth and Opportunity Act and the EU Cotonou Agreement.
- Cooperate and collaborate with other African and developing countries to ensure that the WTO trade negotiations address Africa. Provide leadership in the of the Economic Partip in Agregmation with Europe, as required under the Cotonou Agreement, to ensure that i promotes rapid economic development in Nigeria and West Africa.
Colcelopment

Nigerians and other Africans in the diaspora to deepen technical and busin ties with the rest of the world, and improve export market penetration, especially in textiles, food, and cultural artifacts.

- Reform customs and ports to drastically

reduce turnaround time in the ports. Reduce transactions costs at the ports, enhance prompt and effective collection of government revenues, and ensure customs clearance within 48 hours.

- Develop a deep-sea port, inland container depots, free trade zones, and a shipbuilding facility to enhance coastal shipping, international trade, and regional integration. Nigeria is well positioned geographically to serve as a major hub for regional trade and distribution network in a rapidly expanding global market. To take advantage of these opportunities, the private sector will be encouraged to develop new and creative production arrangements with foreign partners, develop entrepreneurial skills, and significantly increase local capacity in shipbuilding and maritime services. 


\section{Part Four}

Changing the Way the Government Does Its Work

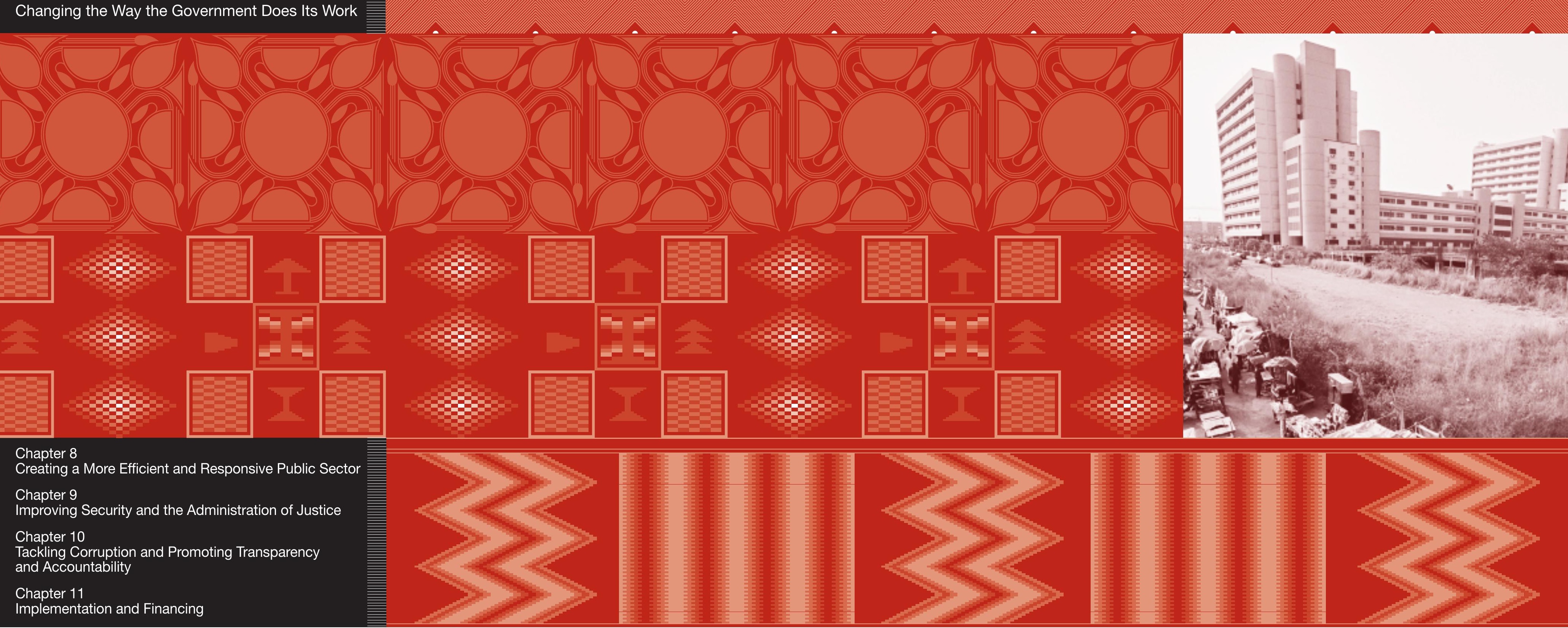




\section{Chapter Creating a More Efficient and Responsive Public Sector}

Nigeria's public sector has grown tremendously over the years. Among the contributing factors have been inappropriate responses to increased oil revenues: domination of the economy by government in the 1970s and 1980s; rapid expansion of development programmes response to bureaucratic, political, and international pressures; movement towards a unitary type of government, with the federa unevernment attempting to cover all areas, often resulting in duplication of effort; the large apparatus associated with democratic governance at the federal, state, and local government levels; and the 1988 civil service reforms, which expanded the number of departments in many ministries and created several new ministries. The share of government in Nigeria's economy is large and has grown significantly in recent years, with consolidated government expenditures rising from 29 percent of GDP in 1997 to 50 percent in 2001. The government is still involved in many production and service delivery activities that it cannot perform well, and the activities that should be at the core of its mandate suffer as a result. Compounding this is the fact that in Nigeria's decentralized governance structure the three tiers of government often step on one another's toes in some areas of economic activity and basic service provision.
The government is perceived as a provider of contracts and a major employer, even though the civil senice has been largely deprofessionalized. The result of developments in the past decade has been a weakened public service: persistent deficits financed by domestic and external borrowing creating a high debt senvice burden; the breakdown of the traditional instruments of control, leading to corruption and misappropriation of funds; the high incidence of ghost workers: poor costing of programmes and projects; a large portfolio of abandoned and ongoing projects; and the mushrooming of institutions, especially inefficient and wastefu public enterprises. The system has accumulated pension arrears, and some states and federal government agencies are beginning to accumulate salary arrears and arrears to contractors and suppliers. A country that used to have an adequate civil service, a well-functioning judiciary and rule of law has seen these institutions severely undermined. An important aspect of the reform programme therefore focuses on restoring the professionalism of the civil service.

The rolling plan hardly informed the preparation of the budget-or indeed major policies. Resource scarcity and political intervention in priority setting rendered impotent comprehensive planning that detailed every public sector project and programme. Annual budget expenditure priorities and fund releases failed to respect the provisions of the approved bud to respect provisise and private sectorpose challenges for planning NEEDS secks refocus the traditional planning process and refocus the the budget process process and strengthen the budget process as instrumer developme 1999 corruption was proctically institutionalized as the foundation of governance in instulionalized as the foundation of govenn Nigeria. Societal institutions decayed to an unprecedented extent, as opportunities were colonized by the powerful. As could be expected, this process was accompanied by the intimidation manipulation of existing laws and regulations, the suffocation of civil society, and the containment of democratic values and institutions. Power became nothing but a means of accumulation and subversion, as productive initiatives were abandoned for purely administrative and transactional activities. The legitimacy and stability of the state became compromised as citizens began to devise extralegal and informal ways to sunvive. The corruption quagmire in Nigeria was rooted in the failure and virtual collapse of governance, the contamination of democratic values, the erosion of procedures for accountability, and the prevalence of bad leadership. Waning public confidence in the country's political and economic institutions promoted a culture of contempt for the rule of law and ultimately a societal tolerance for behaviour previously considered abominable.

Neither today nor in the future can Nigeria afford the social, political, or economic costs that systemic corruption has imposed. Reforms aimed at increasing the transparency and accountability of public institutions and government operations are still urgently needed to redress our circumstances.

\section{Policy Thrust: The Reform Agenda}

The NEEDS reform agenda for the civil senvice of seven main goals:

Right-size the sector and eliminate ghos

workers.

- Restore the professionalism of the civil service.

Rationalize, restructure, and strengthen institutions.

- Privatize and liberalize the sector. - Tackle corruption and improve transparency in government accounts, accounts of government agencies, and joint venture oil companies.

- Reduce waste and improve efficiency of

government expenditures.

- Enhance economic coordination.

Since coming into office, the administration has established a number of institutional and structural measures aimed at redressing the situation. These measures include:

- Open and competitive tender arrangements for government contracts

- Establishment of a due process mechanism to vet and eliminate fat from government contracts

- Massive anticorruption campaigns involving all public officials, including the President - Public sector reforms to reduce, if not completely eliminate, opportunities for corruption, especially through the comprehensive monetization of benefits to public officers - A committed focus on privatization and auctions for government licences (leading for example, to the liberalization of the telecommunications sector)

- Establishment of an independent anticorruption agency and an economic and financial crimes commission
Nigeria cannot afford the social, political, or economic costs that systemic corruption

has imposed 
- Establishment in the President's office of a policy and programme monitoring unit to build a comprehensive policy database to follow up on all decisions of the President public enterprises

\section{Enforcing Anticorruption Laws} To enforce existing anticorruption laws, the Corrupt Practices and Other Related Crimes Commission (ICPC) and the Economic and Commission (ICPC) and the Economic an
Financial Crimes Commission (EFCC). The leadership of the commissions has deme strated strong commitment to tackling financia crime, money laundering, and other economic crime, money laun has created difficulties for Nigeria with the OECD Financial Action Task Force. In view of the pervasiveness of corruption in Nigeria, early in the NEEDS period the government will set up task forces to help fo institutions attack selected aspects of the problem, including corrupt practices in schoos and sales outlets, money laundering, and corruption at the local level. The work of the ICPC and EFCC is fully complemented by ongoing reforms of justice administration and the police. These efforts include an anticorruption campaign, recruitment and training of personnel, provision of equipment, increased wages and allowances, and general improvement in conditions of service.

\section{Reforming and Strengthening Public}

Procurement

Historically, the award of contracts in Nigeria has been perceived as lacking transparency. Inflated contract costs and processes that were closed, discretionary, and well-designed conduits for abuse of public power were systemic.
The administration recognized that a piecemeal approach to remedying the process of competition for government contracts would

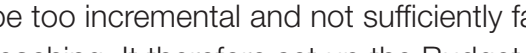
Moning. It therefore set up the Budget begaring and Price Intelligence Unit, which oversight, and certification, commonly referred oversight, and certification, commonly referred certifies for public funding only proiects that have passed the test of proper project implementation packaging. Through certification, value for money is returning as the fundamentat premise for public expenditure.

In the two years since implementation of the due process mechanism, progress has been made in introducing competition into the process of bidding for federal government contracts. By reviewing contracts, the Budget Monitoring and Price Intelligence Unit has saved the government huge sums, estimated at hundreds of millions of dollars. Several contracts awarded by spending units that failed to comply with open, competitive bid parameters have also been cancelled.

While the government has expressed concerns about the timeframe for contract review, oversight, and certification, the success of the due process mechanism has strengthened the government's resolve to create a Public Procurement Commission with a broader mandate of oversight over all federal procurements. The executive recently withdrew a bill for the establishment of the commission from the National Assembly for comprehensive review through broader stakeholders' consultation. The revised bill should be approved by the Federal Executive Council and resubmitted to the National Assembly by the end of June 2004
Reforming the Bureaucracy

The government has begun implementing a range of administrative reforms that reduce the wive for corrupt behaviour through strategies (cilties, moung benefits (cars, housing, uthles, doming assistance, drivers); redefining rotating officers; and increasing supenision. Reducing the size of the bureaucracy will free up resources, which will be directed towards reducing incentives for corruption by giving civ reducing incer for forruption by giving aiv favourable working conditions.

\section{Increasing Information and Transparency} A committee has been set up to implement the Extractive Industny Transparency Initiative. The privatization and liberalization of key economic sectors has been a deliberate action to entrench transparency and accountability and to build consensus in support of reforms.

The administration has also embarked on a number of initiatives designed to complement its anticorruption drive. Its emphasis on efficiency, civil service reform, and service delivery and the campaigns for quality leadership at the local level, democratization of political parties, empowerment of civil society, and the transformation of institutions have unleashed new enthusiasm for building accountability throughout Nigeria. The local government reform initiated by the government is designed to check waste, disorganization, inefficiency, and corruption.

Successfully weaning some sections of the private sector from the old guarantees of profit through distortions in public sector operations and policies is a Herculean task. In the short to medium term, it will result in social dislocations, but these dislocations are the price that may have to be paid to create a more durable, productive, and sustainable system.

Other reforms involve properly redefining and (the role or form of planning, bringing the capital and recurrent budgets together in a mann med Budget Office will collaborate effectively with the National Planning Commission and the Ministry of Finance to ensure proper synergy between capital programmes and recurrent expenditures.

The administration will encourage private sector and civil society checks on the exercise of government power by providing information about government actions. It will publish budgets, records of revenue collection, statutes, and rules and encourage the Nigerian National Petroleum Corporation (NNPC) and the oil companies to fully disclose their revenues and cost of operation. Both the Offices of the Accountant General of the Federation and Auditor General of the Federation will be strengthened to perform their statutory functions as effectively as possible to improve transparency and reduce corruption.

\section{Increasing Transparency in Privatization}

\section{and Market Liberalization Processes}

Privatization and liberalization of key economic sectors have been deliberate and timely, seeking to entrench transparency and accountability and build consensus in support of reforms. The sale of government-held equity stakes in cement, petroleum marketing, and banking companies in 2000 and 2001 was by open, competitive bidding-the first time this level of transparency The televised auction of digital mobile

cences, carried out with the technical assistance and support of British consultants in 2001, was 
hailed as one of the most transparent licence 2001 the second and third phases of the privatization and market with the same degree of transparency. All advisory services being procured and assets and shares being sold have been advertised, and the auctions for all divestiture transactions have be broadcast live on national television.

The televised auction of digital mobile licences in 2001 was hailed as one of the most transparent in

\section{Improving Economic Coordination and} Implementing Institutional Reforms NEEDS will provide a strong economic coordination platform for federal, state, and local government programmes. The budget p all levels and tiers of government will be strengthened and made more transparent and
cohesive. Efforts will be made to establish an annual budget framework and guidelines that wil be followed by all tiers of government A Fiscal Responsibility Bill will be enacted into law early on as an essential component of the reform programme. The Peer Review Mechanism to be established under the strategy will enable heads of government agencies to exchange views on how well counterparts are performing and who is violating the agreed principles and guidelines. These principles and guidelines will encourage the government and its agencies to adopt a balanced budget stabilization strategy to encourage "saving for a rainy day," generate revenue internally, implement agreed upon prio programmes, impose budget discipline, reduce the incidence of arbitrariness in the selection of projects and use of public funds, and apply costeffective methods in implementing projects. The codified guidelines will be discussed with all levels and tiers of government and democratically agreed on. The Joint Planning Board, the Joint Tax Board, and the National Economic Counci will work to achieve a more effective and cohesive Anomic management system.

At the federal level, ongoing studies to strengthen economic coordination will be completed ealy in 2004. The roles of valious arms of the Presidency the National Planning Commission, the Ministry of Finance, and other institutions will be redefined to promote hamo and establish an effective framework for economic coordination.

The role of the legislature in the budget process will be addressed to reduce or eliminate conflicts and delays in enacting appropriation bills into law. Release of the annual budget bills into law. Release of the annual budget
should become more timely under NEEDS. Regular press releases and special reports will be published and widely disseminated to keep stakeholders abreast of the performance of the budget. Room for discretionary application of funds will be discouraged: only the process of virement will be permitted under appropriate circumstance.

\section{Redefining the Role of Government}

Promoting Public-Private Partnerships barrier to growth in Nigeria. Not only has it promoted inefficient use of resources, it has also distorted market signals and stifled private investment through its impact on inflation, interest rates, the exchange rate, and the pattern of credit expansion. Right-sizing government, reducing budget deficits, and properly structuring the entry of all governments (especially the federal and state governments) into the capital stimulate private investment.

The government has begun to withdraw from the dominant role it played in the economy, by privatizing, liberalizing, and deregulating. That process will be accelerated under NEEDS. The government will withdraw from direct production of goods, except in the oil and gas sectors. Senice provision will be in the key areas of Service provision will be in the key areas of technology, and capacity building. The public and private sectors, the donor community and and private sectors, the donor community, and senvices. The adoption of build-operte-transfer, build-own-operate-transfer rehabilitate-operatebuild-own-opere transfer, and other innovative schemes to at generation and distribution, roads, railways water supply, ports, prison infrastructure the courts, and other areas. The administration has already started the process in the power sector (in Sapele and Afam) and the Niger Bridge. More concerted efforts will be made in this direction. The role of government will become that of facilitator providing the enabling environment for the private sector to invest and operate in a free market system. For the government to play this role effectively, a significant paradigm shift is needed in the public service, from the old orientation of control and checkmating, risk avoidance, personalizing of governance, patronage, and so forth to the new orientation of efficient and timely delivery of services. The senvice delivery framework and guidelines will be set up by 2004/05, with implementation commencing immediately thereafter. Efforts will be made to streamline role definition of differen agencies and tiers of government to avoid duplication of efforts. E-governance and subscription to International Standards Organization (ISO) standards will be pursued as part of the reform. A productive partnership must be forged between the public and private sector, with the public sector facilitating and the private sector committing to playing by the rules and delivering good-quality and competitively priced goods and services. Less bureaucracy, less paper work, and fewer hurdles will open the way to increased private investment.

\section{Improving Regulation}

The free enterprise, market-driven, private strategy does not imply the absence of regulation. Regulation will, howeve, be aimed at enhancing competition, breakn up monopolies improving the functioning of the market, protecting weak and vulnerable groups, and stimulating industries and activities in which Nigeria has a medium- to long-term comparative advantage. NEEDS will attempt to explore these areas under special incentive schemes and measures that will not jeopardize investment flows. The economy will brace for globalization armed with the appropriate tools and responses. The competition law will be enacted in 2004, supported by antitrust and consumer protection laws.

\section{mproving Service Delivery}

form a major thrust of the efforts to reposition government to better serve the people of Nigeria A service delivery charter will be developed, the monitoring of inputs and outputs and processes of government agencies will be increased, and regular bulletins and publications will be provided to inform the public on the activities and benchmarks of each government agency. Efforts will be increased to refocus government policies and programmes on improving the provision of basic social services and supporting the sources of growth in the economy, such as agriculture, small and medium-size enterprises, oil and gas, solid minerals, and manufacturing.
The government has begun to withdraw from its dominant role in the economy by privatizing, liberalizing, and deregulating 
They will also seek to improve debt management and develop proposals for debt relief and debt reduction.

These reforms will be accompanied by a modest rudimentary programme of measureme and monitoring of inputs, outputs, processes, and outcomes. The idea is to make policymakers, ministers, and programme managers more used and results obtained. The government used and results obtaned. The government will communications programme that reaches out to the legislature and to the grassroots to explain the rationale for the reforms the rakeholders abreast of proget inputs, and keep

As part of a policy to improve service quality, every government agency will be encouraged to implement a service delivery charter that inclu checklists, processing deadines, and other charter will mainstream service delivery at the national, state, and local

\section{Monetizing Fringe Benefits in the Federa}

\section{Public Service}

Over the years the cost of governance has continued to rise, partly because of the in-kind benefits the government provides public servants. These benefits, largely a carryover from the colonial era, include highly subsidized accommodation, transport facilities, chauffeur-driven vehicles (for the senior echelon of the service), free medical services, and highly subsidized electricity, water, these amenities has become so large that little is left for funding capital projects. The problem is compounded by the fact that these benefits are not provided in the most cost-effective manner. To check the spiraling cost of providing these benefits, the federal government monetized fringe benefits for all categories of public servants. The new policy is designed to stem the ever-rising annual outlay on benefits.

These benefits did not help public servants prepare adequately for life after retirement. On the contrary, for many of them it created a dependency . senvants for life after retirement and prevent them from suffering a sharp drop in their standard of living It should also encourage public senants to mats esoures. The policy is likely to affect the reat estate market in the larger cities, especially Abuja, the seat of the federal government, where the rent on leased properties is expected to fall once the government stops leasing houses for its workers. In addition, the government will release a number of publicly owned houses into the market, putting a downward pressure on housing prices, if not in the short term, at least in the medium to long term. The monetization policy was given legal teet with the passage and coming into effect of the Certain Political, Public and Judicial Office Holders Act, 2002, which was extended by circular to cover all federal civil servants. The law took effect July 1, 2003, and was extended, with somewhat modified rates of benefits, to federal civil servants October 1,2003 . The monetized fringe benefits and allowances for federal civil servants are shown in table 8.1 .

\section{Challenges and Implementation}

Implementation of the policy faces severa challenges, including the following:

- Mobilization of the sizable resources required to fund the terminal benefits and entitlements of the staff who will be phased

Table 8.1 Monetized Fringe Benefits for Federal Givil Servants

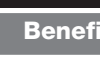

\begin{tabular}{|c|c|c|}
\hline Benefit & Pay grade level & Amount \\
\hline \multirow[t]{3}{*}{ Accommodation subsidy } & $01-06$ & 50 percent \\
\hline & 07-14 & 60 percent \\
\hline & 15 and above & 75 percent \\
\hline Transport subsidy & $01-17$ & 25 percent \\
\hline \multirow[t]{5}{*}{ Meal subsidy } & $01-06$ & $A 6,000$ \\
\hline & 07-10 & स8,400 \\
\hline & $12-14$ & $A 9,600$ \\
\hline & $15-17$ & $A 10,800$ \\
\hline & Permanent Secretary and above & स16,200 \\
\hline \multirow[t]{2}{*}{ Utility subsidy } & 01-16 & 15 percent \\
\hline & 17 and above & 20 percent \\
\hline \multirow[t]{3}{*}{ Domestic servant } & 15 & 1 GL 3 Step 8 \\
\hline & $16-17$ & 2 GL 3 Step 8 \\
\hline & Permanent Secretary and above & 3 GL 3 Step 8 \\
\hline Leave grant & 01 and above & 10 percent \\
\hline Medical care & 01 and above & 10 percent t to be paid to National \\
\hline \multirow{2}{*}{ Furniture allowance } & & Health Insurance Scheme) \\
\hline & 年 & 0 \\
\hline \multirow{3}{*}{ Vehicle loan a } & $01-05$ & 40 percent tor 5 years \\
\hline & $06-07$ & 150 percent \\
\hline & 08 and above & 200 percent \\
\hline Driver & 17 and above & 1 GL 3 Step 8 \\
\hline
\end{tabular}

out of the civil service as a result of the

monetization policy.

- Development of equitable criteria that balance the requirement to obtain marke value for the government assets sold with the need to allow public servants, whose emoluments were not always market driven, the opportunity to successfully bid for those assets.

- Challenge of convincing public officers that it is no longer business as usual as far as the enjoyment of the in-kind benefits they

The monetization policy is being undertaken in phases. At the federal level, the President has designated the State House as the pilot in a show of his personal commitment to the scheme. Accordingly, the State House has implemented monetization in full. Throughout the public sector, government-owned vehicles paid into the Treasury. 
Passage and implementation of the fisca 2004 budget is expected to give additional impetus to monetization by all arms and

agencies of the federal government, especially

within the civil service. Monetization will gradually

be extended to all aspects of the federal public

service. It is expected to reduce expenditure engender a new orientation and attitude towards public resources and public service. The best practices that are bound to emerge as a result expected to have a positive demonstration effect, thereby encouraging state and local governments to adopt their own versions of the policy
Chapter er

Security of life and property is a fundamenta human right guaranteed under Nundam

constitution. Successive governments have

to ensure securty, especially since 1999.

security in parts of the country has fallen, driven

by growing poverty, wide income disparities,

high unemployment, social dislocation caused

by massive rural-urban migration, and the

breakdown of societal values, leading to fraud

and community unrest. The institutions

established to guarantee security are incapaci-

tated by limited personnel and skills, inadequate

funding, poor equipment, and lack of proper

orientation and commitment by some. A weak

economy can only exacerbate the situation.

The government has taken several measures

to deal with the problem. It established the

Independent Corrupt Practices Commission and

the Economic and Financial Crimes Commission,

implemented the recommendations of the Justice

Kayode Esho Commission of Inquiry, strength-

ened institutions for enforcing standards, such

the National Agency for Food and Drug

Administration and Control, and substantially

improved the personnel strength, equipment, and

mobility of the police. Much remains to be don

administration of justice that Nigerians deserve.

\section{Overall Policy Thrust}

NEEDS seeks to increase the level of security of life and property, reduce uncertainty, and improve the confidence in Nigeria by both Nigerians and investors. The strategy recognizes the role society must play in enhancing security by imbuing the light values and attitudes towards safeguard life and property. It focuses on growing the safety nets for vulnerable groups, including children; and fighting corruption and drug abuse. It pays attention to training and equipping security institutions and agencies (judiciary, police, prisons, immigration, customs, and other organs) charged with guaranteeing internal security. An important dimension of the NEEDS policy is achieving a paradigm shift and change of attitude of some of those involved in security matters to see themselves as public servants who should deliver high-quality services to their customers. Corrupt practices among security operatives will be vigorously fought; corrupt officials will not only be weeded out but severely punished. The quality of services delivered will be closely monitored as ongoing reforms.

ols, religious institutions, an disciplined and law-abiding citizenry with the rig
NEEDS seeks to

increase the level of security of life and

property and improve confidence in Nigeria 
values. Teachers, parents, and people in positions of authority must recognize that children and youths see them as role models. They must provide young people with the right orientation and advice, especially with respect to using vionce, especialy wh ristrespect to using

\section{Increasing National Security}

NEEDS plans to increase national security by increasing police effectiveness,

reforming prisons, improving the judicia

system, and

protecting human

NEEDS plans to increase national security by increasing the effectiveness of the police, reforming the nation's prisons, improving the judicial system, promoting and protecting human the rights of people living withts, and ensuring

\section{Increasing the Effectiveness of the Police} The number of police in Nigeria tripled between 1999 and 2003, rising from 110,000 to about 310,000 . The challenge now is to make the police effective. To enable the police to meet the challenges of modern policing and crowd contro and to eliminate corruption, NEEDS will build capacity by training police personnel, pursue a paradigm shift in the orientation of the police force, and better equip the force to improve its image and its responsiveness to distress calls and to adopt a more proactive approach to crime prevention and detection. Specific policies include the following:

- Change the orientation of the police to improve the quality of service.

- Increase the use of scientific methods in policing (forensic science, lie detectors, psychologists, computerization of vital information) to enhance the quality of

evidence and investigation.

- Introduce appropriate equipment (such as custom-built vehicles suitable for sandy or marshy areas) and develop an exclusive communication system to improve police effectiveness

- Build capacity, train, and retrain the police, and involve communities in policing

- Use lethal weapons less often to control crowds.

- Pay all entitlements, especially call and duty allowances, in a timely manne.

guipped to enhance their effectiveness in combating crime. In hiring new police ifficers, attention will be paid to applicants' education qualifications and capacity for training and retraining. Particular attention will be paid to attracting more personnel with higher national diplomas and university degrees. GSM elephony, sophisticated equipment, and improved vehicles should improve police performance. The overall goal is to effect a paradigm shift towards friendly, fairer, and firmer interactions between police and the public and to create a police force of dedicated people who shun corruption

\section{Reforming the Nation's Prisons}

The prison system faces great challenges,

Congestion and a high p

Decaying infrastructure

The burden of imprisonment on prisoners and their families (disease exposure, social ostracism, loss of means of livelihood)

- The cost to society of keeping a large number of people in jail

- The poor quality of prison personnel The prison system will be reformed to emphasize rehabilitation rather than punishment. The number of inmates per square metre will be reduced. A parole system and system of house arrest will be introduced for offenders who show remorse and display good conduct.

the fogncies and other stakeholders, he federal government wil immediete step, the government is committed to taking the following steps:

with the root causes of the problem, such with the root causes of lack of sureties, abuse of escort due process, lack of functional escort vehictes, and so forth.

- Strengthen the capacity of the Legal Aid

Council to provide legal senvices to the poor

Encourage and recognize private practitioners involved in pro bono work. Attorneys wishing to qualify as Senior Advocates of Nigeria may be required to show evidence of having rendered free legal service to poor people.

- Encourage NGOs and other groups

working on prison reforms.

- Conduct an up-to-date audit and develop a database on inmates awaiting trial in all prisons.

The welfare of inmates will be improved by providing better medical care, meals, and access to athletic activities. Prisoners will be given greater access to training and skill acquisition opportunities and encouraged to engage in productive activities, such as agriculture, arts and crafts, and small-scale industries to enable them to run small businesses on discharge. Such activities should also assist in providing food and clothing to inmates. Prisoners with appropriate skills acquired under the skill acquisition scheme will be considered for access to cheap credit (microcredit schemes) for starting their own businesses upon release from prison.
Prison wardens will be trained, equipped, and oriented to handle prisoners evenhandedly. The (1) infrastructure for lease to the government.

Voluntany organizations and religious institutions will also be given the opportunity to provide assistance to prisoners and improve their living environment.

\section{Improving the Judicial System}

Julds civilized sociely ustice is a threat to the corporate existence of the society. The essence of democracy is justice. Every democracy ought therefore to strive to provide access to justice for all and protect the rights of the citizenry. The destiny of the country lies in making the system of justice work smoothly and efficiently

The congestion in Nigeria's prisons is due partly to the judicial system, which is characterized by an enormous load of pending cases, frequent adjournments, ineffective dispensation of justice, and in some instances pure perversion of justice. An uniust judicial system cannot instil confidence, and it often promotes self-defence aggressiveness, and abandonment of the rule of law. NEEDS provides for the strengthening of the judicial process.

Partnering with the private sector. The government will initiate a sustained dialogue with the private sector on designing and implementing reform measures. A Law and Economy Group will be set up to articulate necessary reforms in the commercial laws, with a view to promoting economic development. A key component will be creating a legal environment that is conducive to the inflow of capital, that encourages competition, and that improves the level of trust and confidence.
Justice is the ligament that holds civilized society

together 
Increasing access to justice. As a democratic country, Nigeria has a duty to ensure that people, rich or poor, can easily use the ins of law to resolve the the law and the courts with or withou be able intervention of lauyers for simple matters. Efforts will be made to simplify proceedings and the law itself and to encourage the use of alternative dispute resolution mechanisms that are closer to the African method of resolving disutes. To widen access to justice NEEDS will encourage the provision of greater state and privaurage the provision of

pocedures of Nigeria's civil courts will be reviewed to:

- Lower the cost of litigation and broaden

access to justice.

- Reduce delays so that cases can be

decided speedily.

- Ensure that litigants have an equal opportunity, regardless of their resources,

- Make the legal system understandable to those who use it.

Creating a more effective criminal justice system. During the NEEDS period, vigorous efforts will be made to improve the efficiency of criminal justice administration. Part of this process will be the elimination of excessive delays in disposing of criminal cases. The government will explore the possibility of stipulating a reasonable duration as well as processes and procedures for hearing and determining criminal cases. The review will also consider options for empowering judicial officers to curtail irrelevant or unduly protracted crossexamination and testimony and amending the rights to interlocutory appeal in criminal matters.
The judiciary is already getting rid of corrupt or neffective officers. Also important is the commitment to train and upgrade judicial support staff, equip judicial libraries, and introduce computers for storing and retrieving data and writing judgments. Attention will be given to upgrading the infrastructure of the court system.

\section{Promoting and Protecting Human Rights} One of the dividends of democracy in the past four years has been the prevailing atmosphere of freedom. Human rights, especially civil and political rights guaranteed by the Nigerian The bread pursuit of accorded due resp The broad pursuit of human rights has democracies. The National Action Plan on Human Rights is the government's response to the violations of human rights that characterized the military regimes of the past. The Ministry of the military regimes of the past. The Ministry of the National Action Plan on Human Rights, so that agencies can begin implementing it. The ministry is also seeking amendments to the ministry is also seeking amendments to the
constitutive instrument of the National Human Rights Commission. Those amendments will enhance the work of the commission while strengthening its capacity to play its envisaged role in implementing the National Action Plan on Human Rights.

Ensuring fairness in dealing with citizens and other residents will boost the confidence of investors and contractual partners. The principle of the sanctity of contracts will continue to be upheld and enforced. A juvenile justice system in line with the provision of the Child Rights Act of 2003 will be instituted. The judiciary will constantly be reviewed to eliminate corrupt personnel and reward uprightness, efficiency, fairness, and the impartial delivery of justice. The courts will be better equipped with needed personnel and equipment to enable them to function effectively. The use of arbitration and other alternative dispute resolution mechanisms will be encouraged and strengthened to provide speedy resolution of disputes. A strategy for computerizing cour Pending cases will be reviewed reguled. pat prisoners do not serve time in excess of that to which they would have been their cases been heard expeditiously. Abuse of the court process, including the unwarranted adjournment of cases, will not be condoned. The fue on offences for which bai can be posted will be rigorously applied Innovative processe mechanisms for dispute resolution will be developed or strengthened by establishing sm claims courts and mobile courts for traffic offences and by expanding the multidoor cout system. The number of commercial courts will be increased, and civil society will be encouraged to set up mechanisms for counseling and the peaceful resolution of disputes, in an effort to create a more harmonious society State and local governments will be encouraged to facilitate the process and establish such mechanisms. Access to justice will be widened by increasing state-funded legal assistance to the poor and involving nonstate legal aid providers.

\section{Increasing Women's Rights}

The Women Affairs Ministry will identify and review and procedural laws that affect and Productivity and other ministries that work in areas in which women have traditionally been neglected Relevant committees of the Nationa Assembly and civil society groups and organizations will also participate in the discussions.

\section{Ensuring the Rights of People Living with}

\section{HIV/AIDS}

In line with the recently launched national policy on HIV/AIDS, the Ministry of Justice will produce a clear statement on the rights of people with HIV/AIDS. The ministry will work with the relevant agencies to create awareness among lawyers and judges about the appropriate legal responses to HIV/AIDS-related issues. Ministries charged with enforcing and protecting the rights of Nigeria's citizens (such as the Ministry of Labour and Productivity, which has responsibility for protecting the rights of people in the workplace) will be strengthened. 
- Commitment to the welfare of vulnerable groups

- Pride in the spirit of Nigeria

\section{Strategies and Interventions}

\section{Chapter 0 Tackling Corruption and Promoting \\ Transparency and Accountability}

Our goal is to fight corruption to a standstill.

-Olusegun Obasanjo

A strong and effective anti-corruption policy

is a priority of the

government privileges have long been features of Nigeria's economic and political landscape. Systemic corruption and low levels of transparency and accountability have been major sources of development failure. Illegal activities such as the advance-fee fraud (known as 419) and money laundering have torn the fabric of Nigerian socie Forms of corruption include, but are not limited to, unconventional and fraudulent trade practices, misappropriation or diversion of funds, kickbacks, under- and overinvoicing, bribery, false declarations, abuse of office, and collection of illegal tolls. Indeed, Nigeria is rated as one of the most corrupt countries in the world. Given the adverse implications of the negative values of a small number of people on the nation's image, growth, and development, the government cannot ignore them, particularly as experience has shown that the successful pursuit of a national vision has often been nurtured and advanced by the inculcation of good moral and ethical values in the citizenry.

\section{Policy Thrust}

A strong and effective anti-corruption policy is a priority of the government, which hopes to crea a transparent and accountable Nigeria in which the incidence of corruption is low. NEEDS envisions a prosperous country that is not ony developed economically but infused with strong moral and ethical values. Without these values it would be difficult if not impossible, to achieve the desired level of growth and development.

Moreover, even if Nigeria were able to break out of the vicious cycle of poverty and underdevelopment, it would be a developed society without moral character.

Some of the values on which attention must

be focused include the following

- Integrity and good citizenship at the

individual and corporate level

- Discipline and a strong work ethic

- Excellence, competitiveness, creativity, and innovation in service delivery

- Perseverance and longer term thinking as

opposed to short-term expediency

Enterprise, thrift and savings, and curbing

of waste

- Thirst for knowledge, information, and

know-how
- It sold government licences at transport auctions and established due process. - It pushed forward a Public Procurement Commission Bill, which will soon be

- It established the Economic and Financi

vigorous campaign to arrest people suspected of fraud The leadership of the commission has shown strong commitment to tackling financial crimes, money laundering, and other economic crimes that had created difficulties for Nigeria with the Financial Action Task Force of the Organisation for Economic Co-operation and Development.

- It established the Extractive Industries Transparency Initiative, aimed at encouraging the Nigerian National Petroleum Corporation and other oil companies to fully disclose revenue and cost of operations. To curb corruption, reduce waste and

inefficiency, establish the right set of values, and discourage rent-seeking and other unproductive values, NEEDS supports the following measures: - Reform, strengthen, and modernize institutions whose duty it is to foster and enforce compliance. These institutions include the Independent Corrupt Practices Commission, the Economic and Financial Crimes Commission, the National Orientation Agency, the National Agency for Food and Drug Administration and Control, the police, customs, the judiciary prisons, and immigration. Laws aimed at combating corruption and promoting law and order will be strengthened.

Step up measures to check economic and financial crimes, including the legal
The President is personally committed to tackling corruption and increasing

transparency 
provisions for the exposure and punishment of unethical

- Adopt a formal code of ethics for al organizations and sectors, publish a code of thics to engender transparency in the onduct of government affairs, and requ the disclosure of information by companies.

- Instivtionalize the process of tor in ethical behavior, and launch a programme to foster leadership by example.

- Fast-track the process of reform in governance codes at the corporate level and at all tiers of government,

subscribe to international standards in civi meausres to curb corruption, reduce waste, and establish the right set of values
To improve transparency and accountability in government fiscal operations and check unproductive public expenditures by all tiers of information bills will be enscted in 2004 . The Fiscal Responsibility Act will require publication of and agencies and public enterprises within six months of the end of their financial year. It w months of the publc of their financial year. It will which windfall revenues will be transferred. The Right to Information Act will fostansferred. The Right to kn by reedback by streamlining and rationalizing the storage, and dissemination on a timely basis.

\section{Chapter Implementation and Financing}

Effective implementation of policies and programmes is key to the success of NEEDS Implementation defines the process, institution framework, and instruments for translating an:rations, goals, and programmes into action and concrete results.

Nigeria's experience has been one of formulating good plans, policies, programmes, and projects and then failing to achieve

objectives because of ineffective

implementation-or no implementation. Because Nigerians have now reached consensus on the problems facing the country and the urgent need to turn things around, prospects are much more positive for NEEDS than they were for earlier initiatives.

Implementing NEEDS calls for commitment discipline, and a strong will to stay the course of reforms-at all levels, from the President and federal executive branch down to the grassro Implementation will be holistic, consistent, and persistent, as half measures yield not half results but often failure.

Critical to the success of NEEDS is an effective institutional framework, particularly a public service dedicated to excellence and efficiency and supportive of reforms. Equally important is adequate infrastructure and an enabling environment in which private investment has been put in place. can thrive. Other critical success factors are education, health care, and abiding faith and commitment to change.

The government is aware of the skepticism of the Nigerian people, following years of failed promises. It also recognizes that it has limited time to show results in many areas. Consequently, implementation of the NEEDS agenda has begun in earnest. Almost every aspect of the strategy is either already being implemented or awaiting enabling legislation. Real results are already being achieved. To sustain momentum, a clear framework for monitoring and evaluation

As a necessary complement to NEEDS, state governments are developing State Economic Empowerment and Development Strategies (SEEDS). Within the states, local governments will be encouraged to develop medium-term grammes, benchmarks and targets, deliverables, timelines, and implementation guides. These plans, called Local Economic Empowerment and Development Strategies (LEEDS), will complement SEEDS and NEEDS. NEEDS recognizes that effective planning at the local level is critica to reduce or eliminate waste and inefficient resource allocation and to ensure integrated rura development and poverty reduction. Local
The government is

aware of the

skepticism of the

Nigerian people,

following years of

failed promises 
The institutional

framework for

implementing NEEDS

recognizes the

importance of

coordination among

the federal

government, the

states, and local

governments governments and state governments are much closer to the people and are better positioned to deliver many social services.

Institutional Framework

The institutional framework for implementing NEEDS recognizes the importance of coordination among the federal government (NEEDS), the achieving the national development gous (figure 11.1). For this reason, statopment goals (forr (through the National Economic Council and National Council on Development Planning) constitute an integral part of the implementation, monitoring, and evaluation framework. The system is cohesive and provides for interactior with all stakeholders. At the apex are the President, the Vice-President, and the Nation Assembly. The federal Executive Council and National Economic Council consider all matters pertaining to implementing NEEDS and SEEDS, presenting periodic reports to the President and the National Assembly

A key institution is the Independent Monitoring Committee. The committee - chaired by the Secretary to the Government of the Federation and composed of government officials, representatives of the private sector, the press, and civil society—-periodically monitors and evaluates implementation of NEEDS and SEEDS programmes and projects. It informs the Nationa Assembly of its findings and reports to the President and the National Economic Council for appropriate action. The committee is expected to present quarterly reports on pertormance, which will be posted on the Nigerian economy Web site (www.Nigerianeconomy.com). A summary of the findings will also be disseminated to the Nigerian people, through print and electronic media. Members of the National Economic Council will use the results of the monitoring and evalution to fine-tune implementation in the soltes. The eports of the National Economic Council review will also be forwarded to the National Assembly and the President.

The Secretariat of NEEDS is located at the National Planning Commission, which will

coordinate the implementation framework. Other agencies critical to the effective coordination and implementation of NEEDS and SEEDS are the Joint Planning Board, the National Council on Development Planning and the National Economic Council. As the Secretariat for these statutory bodies, the National Planning Commission is being restructured and stren ened to perform its statutory mandate of coordinating plan development and implementa tion across the tiers of government Membership of the National Council on Development Planning will be enlarged to include other stakeholders. and the Senvice Delivery Unit will play an

important role in setting performance targets on service delivery.

Each state government is expected to set up an independent committee to monitor its SEEDS The ministry responsible for the planning functioning will serve as the Secretariat, and the Secretary to Government will serve as chair. States are also encouraged to undertake quarterly reviews of progress based on clearly articulated benchmarks and targets, timelines, activities, and officials responsible for implementation. The results of such exercises could be posted on the state Web site and disseminated o state residents.

The National Council on Development

Planning and Joint Planning Board (composed of all Commissioners of Planning and Permanent

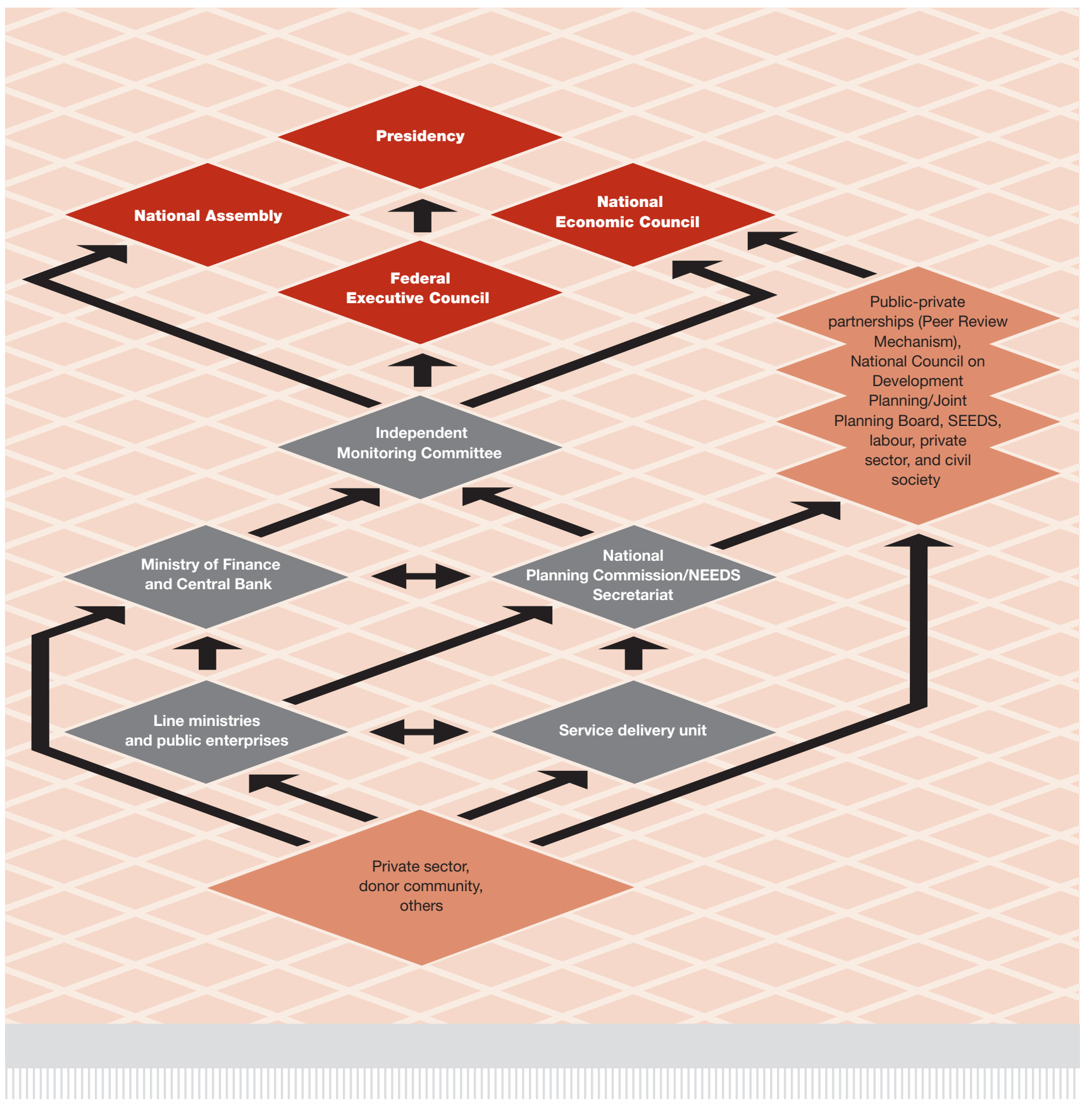


Secretaries of Planning in the states, together with their federal counterparts and other officers agreed to set up a National Joint Monitoring committee will also include representatives of th private sector, civil society, international organizations, and labour. The results of these monitoring exercises will increasingly be used international donor organizations to align their international strated commitment to reforms and performance. The matching grants scheme and location of certain projects by the fecra government will also be directed increasingly to support states that are frontrunners in reform performance. A set of performance in indorators be developed before August 2004 to guide the joint monitoring exercises.

\section{Instruments}

The Independent Monitoring Committee (together with the NEEDS Secretariat, the Economic Management Team, and relevan ministries and implementing agencies) will complete development of the detailed Implementation Guide for NEEDS before the end of the third quarter of 2004. These guides, containing specific benchmarks, targets, activities, timelines, and responsible officials and agencies, will form annexes to the NEEDS document. They will be posted on the Nigerian economy Web site (www.Nigerianeconomy.com). Guides have already been developed for most aspects of the NEEDS agenda. They will be periodically revised in the light of changing circumstances and new legislation, budgetary changes, or changes in operating rules and directives.
With the guides in place, each ministry and mplementing agency is expected to send a quarterly report on its implementation to the 作 and gummize the reports for evaluation by the Indepummanze the reports for evaluation by the Monitoring Committee could ask ind ministries and agencies to provide further explanations, or it could independently visit a monitor projects or programmes. Conclusions of the coordination meetings of the Economic Management Team will also form part of the quarterly evaluation reports. The strengthened national statistical system will be actively involved national statistical system will be actively involved of the impact assessments of specific projects and programmes. The Federal Office of Statistics will provide timely and reliable surveys of the basic social and economic conditions of Nigerians to provide policymakers with Nigerians to provide policymakers with an Quarterly reports of the Monitoring Committee will be presented to the federal Executive Council, the President and Vice President, and the National Assembly.

The reforms hinge on changes occurring at the administrative and legal levels. Legislative action will be needed to reform some laws and enact new ones to support the strategy. Some of these actions are reflected in the relevant sections of the strategy document and listed later in this section. Others will be identified as implementation progresses.

Under NEEDS, areas of responsibility are specified, with appropriate devolution of responsibility across the three tiers of government, consistent with the Constitution, the revenue allocation formula, and the principles of a federal system of government. The target areas are agriculture, primary and secondary education, potable water supply, primary health care, intrastate roads, and housing.

New Forms of Coordination and Partnership to Eliminate Waste and Duplication

NEEDS envisions several new forms of coordination and partnership, from matching grants to a peer review mechanism and publicprivate partnerships.

\section{Matching Grants Schem}

An ad hoc committee will be set up to take a census of federal government projects in the states and determine which can be passed on
communities, local governments, or states or sold outright. This committee will also identify the areas for direct intervention by the federat areas for direct intervention by the federa coordination and application of matching grants. Coordination among the tiers of government is important to avoid duplication and wament is delivery of services. Given that most social services are included in the concurrent list of Constitution, it is important for the federal government to coordinate with state and loca governments to determine the scope and limitations of federal interventions. The system of execution of programmes at the federal, state, and local governments in areas of concurrent jurisdiction is duplicative, inefficient, and wasteful. Programmes on potable water supply, primary health, primary education, and agriculture are replete with duplication. NEEDS seeks to drastically reduce duplication and waste. One possible way to do so is through a the federal government would provide matching grants to states and local governments for priorities but whose implementation is best handled at the state or local level In 2004 committee will work out the modalities and incentive structure for implementing the schem as well as the projects and programmes for which the scheme will be applicable. The scheme will be based partly on need and partly on performance by state and local governments. To enhance synergy, harmonization, and complementarity, NEEDS enhances coordination, based on a recognition that a developing country such as Nigeria requires more active coordination than industrial economies do. The goal is to design strategies, policy guidelines, and

programmes that avoid duplication of effort and waste of scarce resources.

The Fiscal Responsibility Pact will be enacted into law early in the life of NEEDS as an essential component of the reform. The pact will provide the legal basis for coordinated fiscal behavior of all three tiers of government, promote greater transparency and accountability, ensure predictability and sustainability of public finance and ensure that national fiscal behavior is consistent with Nigeria's macroeconomic objectives

\section{Peer Review Mechanism and Public-}

A peer review mechanism is a key element of the implementation process. The mechanism will be used at all levels of implementation-within ministries and agencies; among ministries and agencies at the federal and state levels; at the federal, state, and local government levels; the private sector and civil society organizations 
on the other; and within the framework of aid coordination. The Independent Monitoring Committee (together with the NEEDS Secretari the Economic Management Team, and the (a) the federal level.

Mnnisters and implementing agencies will at regular internal reviews. These reviews will provide opportunities for sharing experiences on implementation, learning, and group brainstorm implementation, learning, and group brainsto ing on solutions to implementation prob
Public reviews will involve ministries and implementing agencies appearing in front of the private sector and civil society, the press, and other stakeholders to account for their sources and uses of funds, innovations introduced results achieved, and challenges ahead. The mechanism allows the people to hold individual implementing officers and agencies accountable thereby promoting effective senvice delivery. It is proposed that a peer review meeting/public-private partnership summit be held at least once a year, to bring together federal, state, and local governments to accoun to the Nigerian people. The meeting would be organized in partnership with the private sector academia, nongovernmental organizations (NGOs) and civil society organizations, the international community, and other stakeholde in the Nigerian economy. In addition to the federal government, state governors would be offered the opportunity to address all Nigerian on prime time television and radio about the most innovative approaches they are adopting to reduce poverty, create wealth, and generate employment. The private sector and civil society groups would also be offered the opportunity to discuss their contributions to the economy and (n) their activites in Nigeria. The goal is to provide least one national forum for evaluating performance, sharing experiences, and learning, and providing feedback from stakeholders. States are also encouraged to undertake Priodic peer reviews of their SEEDS, in collaboration with relevant stakeholders. The National Council on Development Planning the Joint Planning Board agreed to set up a joint monitoring committee to evaluete implem a joint of SEEDS. In addition to representatives of government agencies, the joint monitoring team would include representatives of the private sector, NGOs and civil society, and the international community. Guides and benchmarks for the joint monitoring exercise will be developed. Part of the donor coordination effort in Nigeria would entail the alignment of donor assistance with SEEDS. Selection of a state for donor assistance would depend on the coherence of its SEEDS, its woldementation record, and the basic needs of the state. States that are in need and have demonstrated capacity to provide value-formoney would be given priority.

At the local government level, planning and public accountability mechanisms should be institutionalized. State governments are expected to work with local government councils to develop medium-term plans. Such plans should be prepared with the participation of all relevant stakeholders. Periodically (say, every quarter) the local council should convene town hall meeting of all relevant stakeholders-traditional rulers, community heads, ward councilors, and representatives of the private sector, labour, NGOs, and civil society - to discuss the sources and uses of funds, results achieved, challenges, and a road map for the future. Town meetings should help promote good governance, transparency and accountabilty at the government level and greatly improve senice delivery and poverty reduction.

NEEDS intends to mainstream public-private partnership at all levels of government. Sectora mirnistries are encouraged to continuously interact with private sector associations, NGOS, and civil society organizations. Partnership between the public and private sectors is for effective implementation of NEEDS.
Government agencies are encouraged to maintain an open door policy with regard to idea
and suggestions from the private sector. The formal organs for coordinating plan implementation, especially the National Council on Development Planning and the Joint Planning Board, will have private sector representation. Donor coordination is an important element implementing NEEDS. Without effective donor coordination, resources are wasted through duplication of effort. An ongoing effort at the National Planning Commission to articulate a strategic framework for borrowing policy and donor coordination will be completed in 2004 , collaboration with the Ministry of Finance. The goal is to move away from the current system of uncoordinated (largely project based) assistance towards a coordinated system aligned to nationa priorities, sector-wide approaches, and budget support.

Restructur

\section{System}

NEEDS recognizes that Nigeria's statistical system is weak. The cuationa governed by the 1957 Statistics Act, which is obsolete. Of about 4,700 staff of the Federal O of Statistics, only 5 percent belong to the professional cadre. In the 57 years of its existence, the office has never had a building of its own, and it has been grossly underfunded. The conse-

quence has been a largely ineffective institution.

Timely and reliable statistics are critical to

(ective planning, monitoring, and evaluation of conernment the statistical system a ven important priority. With the help of international and national consultants, a new master plan (with a new draf statistics bill) was produced. Stakeholders were consulted and the final master plan was approved for implementation. The government has already sent a strong signal regarding its seriousness about reform by purchasing a new building for the Federal Office of Statistics. Development partners are providing assistance to ensure state-of-the-art furnishing and equipment of the building, as well as institutional capacity building. The government has also significantly increased the budgetary allocation to the Federal Office of Statistics to enable it to collect timely statistics. Effective implementation of the master plan will ensure timely, robust, and reliable statistics.

\section{toring Service Delivery}

The quality of services delivered by ministries and government agencies will be monitored. Heads monitor that all correspond public enterprises within 72 hours. All ministries and state enterprises will subscribe to ISO standards. The Service Delivery Unit

A complaints point will be established in each ministry and state enterprise as well as the Planning Commission, where citizens who receive
poor service or are rudely treated in government 
offices will be able to register their complaints. Services covered include investment-promotion activities, data and information dissemination (other than personal or security information), and police, prisons, ports, customs, immigration, and
other institutions that deal with the public. The monitoring by the Senvice Delivery Unit will be done in collaboration with the relevant supenvisory done in collaboration with the relevant supervison authorties and the Public Complaints

NEEDS targets minimum annt commission. Over time governance will be depersonalized as much as possible, so that the
bulk of communication will be through the Intern rather than by mail or by que through the Inter ment offices. E-governance is the ultimate goal.

growth rates of

5 percent in 2004,

\section{6 percent in 2005 The Role of the National Assembly}

The National Assembly is expected to be critical to implementing NEEDS. In addition to contributing to the content of NEEDS, members of the

National Assembly will play three key roles:

- Enacting the relevant laws needed to

implement NEEDS and ensuring that with the thrusts of NEEDS

- Overseeing the relevant agencies to ensure

that NEEDS is implemented

- Educating the people about NEEDS and

mobilizing their support

Laws that inhibit free enterprise need to be reviewed and changed, and new legislation

needs to be enacted. Table 11.1 gives examples of some of the bills that are urgently needed to jump-start implementation of NEEDS.

\section{Financing the Plan}

NEEDS targets minimum annual GDP growth rates of 5 percent in 2004, 6 percent in 2005 and
2006, and 7 percent in 2007. Relative to recent history, the investment called for is ambitious, yet it capita incom neded to increase adequate per box 11.1). To finance the programme, the

gox 11.1). To inance the programme, the government will increase the efficiency of resource all bak in w whlic expenditure and sources of revenue and reoming institutions), selling assets, reforming the tax system, increasing the efficiency of resource use mobilizing domestic savings, and trying to attract foreign direct investment and overseas development assistance. It will also seek debt relief from creditors.

\section{Reducing or Eliminating Wasteful}

\section{Spending}

Several reforms will be implemented to reduce or eliminate wasteful spending.

Expenditure-reduction imperatives. The federal government's share of the federation account has decreased from about 60 percent to 46 percent but the change does not yet reflect the devolution of responsibilities to state and local governments. The rationalization envisaged in this strategy will involve clearer delineation of roles among the federal, state, and local governments in line with the changes in the revenue allocation formula. The federal government will withdraw from programmes and projects best left to state and local governments, not only to avoid duplication but also to enhance efficiency in implementing and monitoring programmes and projects. A federal matching grant scheme will be established to promote national programmes and projects.

Fiscal regime. Payroll and overhead expenditures currently consume about two-thirds of govern-
ment revenues, excluding the cost of running
Table 11.1 New Legislation Needed to Implement NEFPS

\section{Bills about to be initiated}

\section{Fiscal Responsibility Bil}

Competition and Antitrust Bil

Finance Bill

Pension Reforms Bill

Tax reform bills

Revision of corporate tax

- Personal Income and

Local government reform

Local government reform

\section{Bills being reviewed by the House}

HB 4 Corrupt Practices and Other Related Offences Bill

(amendment), 2003

HB 7 National Institute of Tourism and Hospitality Bill, 2003

HB 6 Right to Information Bill, 2003

HB 16 Niger-Detta Commission Bill (amendment), 2003

HB 10 Protocol to Prevent, Suppress and Punish Trafficking in

Persons, Especially Women and Children, Supplementing the

UN Convention against Transnational Organized Crimes Bill

(ratification and enforcement), 2003

HB 11 Convention against Torture and Other Cruel, Inhuman, or

Degrading Treatment or Punishment Bill (ratification and

enforcement), 2003

HB 15 Convention of the Arrican Telecommunications Union Bill

(ratification and enforcement), 2003

HB 21 Agriculture Input Bill (provision of subsidy), 2003

HB 22 Shelter Belt Project Bill, 2003

HB 24 Guaranteed Minimum Price for Farmers Authority Bill, 2003

HB 30 Palm Oil Development Fund Bill, 2003

HB 37 Allocation of Revenue Bill (federation account), 2003

HB 25 Agriculture Bill (provision of budget allocation). 2003

HB 40 Pension Reform Bill, 2003
Thsuitution or sector

Reform component

All government agencies Fiscal disciline

Minisity of Commerce Domestic trade and production

National Electricity Power Authority Power pry

Head of Service $\quad$ Pension

Individual and corporate taxpayers Tax policy

All local governments

Als

All government agencies

Tourism subsector

Presidential hitititive on tourism development Transparency in government business Infrastructure development

Women and youth

Women and youth development

Judicial system

Social charter

Ministry of Communications

Ministry of Agriculture

Housing and Urban Development

Ministry of Agriculture

Ministry of Agriculture

Ministry of Agriculture

Pension Board
Infrastructure development

Agricultural development and food security Housing development Agricultural development and food security Agricultural development and food security Budgetary and fiscal reform Agricultural development and food securtity Presidential initiative on pension reforms 
Table 11.1 New Legislation Needed to Implement NEEDS (continued) Thent NEEDS (continued)
HB 41 Nigerian National Volunter Service Bill, 2003 Ministry of Agriculture

\section{Reform component}

Reorientation of social service Presidential initiative on food securty

BB 31 Handicicapped P P

HB 32 National Social Security Board Bill, 2003 Ministry of Sports and Social Development

HB 42 Nigerian Solid Minerals Development Bill, 2003

Ministry of Solid Minerals Development

Social charter

Presidential initiative on the development of solid mineral sector

HB 49 Economic and Financial Crimes Commission Bill, 2003

HB 50 Money Laundering (Prohibition) Bill, 2003

National Forestry Bil

Ministry of the Environment

\section{Anticorrution}

Anticorruption

Sustainable management of forest resources tition of benefits with loc communities

National Drought Bill

National Oil Spill Contingency Bill

Ministry of the Environment

Ministry of the Environmen

Revision of Environmental Impact Assessment Decree Ministry of the Environment

National Environmental Management Bill

Ministry of the Environment

Equity issue sand oil spill management

ncreased responsiveness to contemporary

issues in environmental management

Updating of existing laws
Table 11.2 Aggregate Investment Projections, 2003-07

\section{(billions of naira)}

\section{Investment}

Gross investment

Private fixed investment

Government fixed investmen

Federa

\begin{tabular}{rr|}
\hline 003 & 2004 \\
155.0 & $2,071.2$ \\
76.7 & $1,497.3$ \\
378.3 & 5549 \\
188.0 & 3490 \\
190.3 & 2249
\end{tabular}

government hidden in the capital budget. This high level of spending makes it difficult for the government to service its debts and pay for the capital programme required for growth. The reform strategy addresses the problem by drastically reducing payroll and overhead expenditures and proscribing extrabudgetary expenditures. To eliminate ghost workers, the

\begin{tabular}{lrrr}
$\mathbf{2 0 0 4}$ & $\mathbf{2 0 0 5}$ & $\mathbf{2 0 0 6}$ & $\mathbf{2 0 0 7}$ \\
\hline $2,071.2$ & $2,672.0$ & $3,456.4$ & $4,663.7$ \\
$1,497.3$ & $1,814.4$ & $2,454.9$ & $3,272.3$ \\
5544.9 & 857.6 & $1,001.5$ & $1,391.4$ \\
349.0 & 433.0 & 511.0 & 634.0 \\
224.9 & 424.6 & 490.5 & 757.4
\end{tabular}

policy also ensures that only personnel who are working and on the payroll are paid. The target is to ultimately ensure that the cost of running the government does not exceed 40 percent of total government revenues. The capital budget will also be rationalized to eliminate projects that cannot be funded to completion. Uncompleted projects will be privatized through "sale as is" o
Box 11.1 Allocation of the Federal Government Gapital Budget to Priority Sectors

NEEDS will require a heavy investment programme to jump-start the economy in a way that is pro-poor important in their strategic roles in delivering long-term development, and a sector's importance is not necessanily equivalent to the size or its sectoral buaget. Development of some sectors will be driven largely by states and mostly one of coordination and faclitation. In the move towards a private sector-led economy the importance of some sectors would be expressed through the provision of a sound regulatory framework rather than through direct intervention. The sectors listed in the table below (aside from security) are ones in which the direct and heavy government investment will be

required over the reform period.

Lecritical chertion, and puployment poveny reduction, weall assist the ministries and stakeholders to design and mplement medium-term sector-wide strategies. The table excludes spending by state and local

governments and recurrent expenditures. For most sectors, especially health and education, the recurren budget often makes up a larger share of total

handed over to states, local governments, or communities in order to reduce the federal government's capital budget.

Civil service reforms. When completed, the civil service reforms envisaged under NEEDS will lead to more openness, transparency, and accountability in the operation of government. The changes will release or generate resources and lead to more efficient use of funds collected.

Monetization of fringe benefits. In the short run monetization of benefits is not likely to substan- expenditures. For example, since almost all state pudget on education, total government spenaing on a

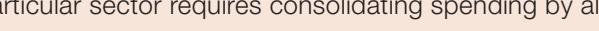

Poposed Allocation of Central Government Capita Budget, 2004-07 (percent)

\begin{tabular}{|c|c|c|c|c|}
\hline \multirow{2}{*}{$\begin{array}{l}\text { Sector } \\
\text { Agriculture and rural } \\
\text { development }\end{array}$} & 2004 & 2005 & 2006 & 2007 \\
\hline & 3 & 4 & 4 & 4 \\
\hline $\begin{array}{l}\text { Roads (maintenance, } \\
\text { rehabilitation, and } \\
\text { construction) }\end{array}$ & 12 & 15 & 15 & 14 \\
\hline Education & 8 & 8 & 9 & 10 \\
\hline Health & 8 & 8 & 9 & 10 \\
\hline Water resources & 10 & 10 & 10 & 10 \\
\hline Power & 16 & 15 & 13 & 12 \\
\hline Security & 5 & 5 & 5 & 5 \\
\hline $\begin{array}{l}\text { Share of allocation for } \\
\text { priority sectors in total } \\
\text { allocation }\end{array}$ & 62 & 65 & 65 & 65 \\
\hline $\begin{array}{l}\text { Share of allocation for } \\
\text { nonpriority sectors in } \\
\text { total allocation }\end{array}$ & 38 & 35 & 35 & 35 \\
\hline
\end{tabular}

tially reduce the cost of running government. In the long run, however, it will reduce costs.

Management of Treasury accounts. The government will maintain a single account, with the Central Bank of Nigeria, in order to avoid cash management problems, especially situations in which the government maintains balances in ministries' accounts but borrows from the central bank.

Procurement. A bill proposing the establishment of a Public Procurement Commission has been sent to the National Assembly. This bill and the 
reform of the Accountant General's office will generate savings.

University autonomy. Universities will be granted autonomy. The government will continue to eave it to them to find additional funds. Universities will be free to charge fees and generate income from research and semicommercial ventures, reducing the funding needed from the government. move in the direct

of a low, stable,

simplified tax and

tariff regime

\section{Implementing Institutional Reforms} A variety of institutional reforms will increase government revenues.

Fiscal Responsibility Pact. A Fiscal Responsibility Pact or similar initiative is expected to be passed into law in 2004. The reform will lead to increased transparency and accou ty and better management and efficiency in the use of public resources.

Banking and financial sector reforms. The machinery for tracking and monitoring the collection of government revenues will be strengthened. The Presidential Committee on Revenue Monitoring and Reconciliation will monitor payment of taxes and duties collected through the banks. The financial senvices regulatory framework will be reformed to improve supenvision of the activities of banks and financial institutions that abuse the system for revenue collection and remittance. The number of banks approved to receive government deposits will be rationalized, and banks that default will be delisted.

Solid minerals. With growing investment in solid minerals, the government expects increased revenue from rents and royalties. Substantial revenues are already being earned from gem stones and bitumen.

Long-term funds. The government will promote deepening of the capital market by encouraging investment in insurance and pension schem exchange will also be encouries on the public educetion programme will broaden a public the opportunities offered by the capital market. To increase the pool of investible funds, the banking sector will be expected to encourage small savers by making the process of opening accounts more customer friendly and interest rates more appealing. A national savings certificate scheme has been launched as an attractive alternative to small savings in commercial banks. The scheme will be structured and incentivized to encourage small savers to participate.

\section{Selling Assets}

Substantial revenue is expected to be generated by privatization of refineries and steel mills, the sale of shares in the automotive industries, the unbundling of the National Electric Power Authority and the expected initial public offering of shares of Nigerian Telecommunications, Ltd. Proceeds of these sales can be used to finance infrastructure development under NEEDS. The law setting up the National Council on Privatization stipulates that all. proceeds from privatization be placed in the privatization proceeds account, which is automatically transferable into the consolidated revenue fund. The privatization programme is expected to attract private capital to increase working capital, replace equipment, and rehabilitate plants. With the monetization of fringe benefits, the government will dispose of some of its assets, especially buildings and cars. Proceeds from these sales will augment the budget.
Implementing Tax Reforms

There is scope to increase revenue yield by aggressively pursuing tax collection in all sectors of economy. Target areas include the oil and gas sector, personal and property taxes, and indirect taxes. The praclice whreby most revenuecollected on behalf of the central governmes breach of financial regulation, will be checked. NEEDS will generally mowe in the direction of a low, stable, simplified tax and tariff regime. Bu existing ones increased slightly to raise revenue.

To increase revenues, the government will

- Return to the use of market-based development stocks, with appropriate tenures, to meet medium- to long-term financing needs. The change will check sector by borrowing from the banking system.

- Review and strengthen the enabling laws to ensure that institutions such as the Nigerian Social Insurance Trust Fund, pension funds, and life insurance companies adhere to guidelines that require them to use most of their funds to finance real sector activities.

- Support programmes, such as the comprehensive review of public sector pension schemes, that mobilize and effectively manage long-term funds.

- Adopt appropriate regulatory and enforcement machinery to ensure that development finance institutions are well funded and that their funds reach intended beneficiaries, especially those operating in the priority sectors.

- Mainstream micro-, small, and mediumsize enterprises, especially those operating in the priority sectors, to broaden the real sector and enhance their access to funds available in the banking industry.

Reducing Costs and Increasing Tax Collection in the Oil and Gas Sector

reducing the cost of operations in the upstream il and gas sector. Several taxes are probably not being collected due to the special nature of the industry and the lack of capacity to capture all potential sources of revenues. The government has subscribed to the Extractive Industries Transparency Initiative and will explore ways of reducing its contribution to joint venture cash calls in order to free resources to finance the programme. It will also engage the services of world class oil and gas industry tax consultants, giving them a mandate to design a framework for capturing and monitoring costs of joint venture operations and collecting taxes due from the oil sector generally. Revenue targets will be set using benchmarks being developed for the purpose.

\section{Improving External Financing}

The macro framework for NEEDS points to the need for a financing facility that bridges the financing gap and supports the balance of payments position. External financing for the programme is derived from the balance of payments accounts. Under NEEDS, Nigeria's main nonoil exports would rise an average of 10 percent a year over the next four years, while nonoil imports would rise by 4.5 percent. OII exports would decline in 2004 and 2005 and remain at that level in 2006 and 2007. The trade account would decline from a positive balance of 2007. 5 million in 2004 to $\$ 305.1$ million in million in 2004 and $\$ 2,341.6$ million in 2007 . The 
current account deficit would be $\$ 2,173.7$ million, or 2.89 percent of GDP, by the end of the programme. The average financing requirement

Foreign direct investment. With better management of the economy and the restoration of investor confidence, a higher level of investment inflow is expected, especially in view of the h. About $\$ 1.5$ billion a year is expected to be attracted into manuffecturing construction, solid minerals, and large-scale farming over the period. Efforts will be made to attract investment from wealthy Nigerians home and abroad, and strategies will be developed for inducing other Africans in the diaspora to invest in Nigeria.

Official development assistance. NEEDS is Nigeria's poverty reduction measure. The international community has expressed suppo for Nigeria's home-grown programme Consequently, it is expected that donor agencies will significantly increase their aid budget to Nigeria. Better coordination of aid and an emphasis on value for money should amplify the impact of assistance to Nigeria. Nigeria may also be able to access international credit on concessional terms (IDA terms or better) provided that the projects for which loans are sought are bankable projects that will generate sufficient returns to pay back the credit.

\section{Obtaining Debt Relief}

Nigeria's debt service is high and unsustainable. Annual debt service due averages more than $\$ 2.5$ billion a year. Including arrears of about $\$ 3.47$ billion incurred as of the end of 2003 annual debt service is about $\$ 3$ billion a year.
Beyond the direct cash flow impact, debt relief would facilitate the restoration of insurance cover on exports to Nigeria (including foreign direct investment) by helping (lear current the country's debt status. Debt relief che which would form part of the financing required over the programme period.

Debt senvice payments have come at great pportunity cost in terms of social senices. External debt service payments made between 2001 and 2003 were five times as high as the recurrent federal government budgetary

allocation to education and about six times as

high as the recurrent budgetary all ximes as high as the recurrent budgetary allocation to Nigeria to pursue a meaningful devell programme. This conclusion is corroborated by a 2002 study by the International Monetary Fund that revealed that even with a good policy environment, resolving Nigeria's debt problem would require a 67 percent net present value flow rescheduling followed by a concessional stockof-debt reduction of up to 67 percent of the net present value of the debt.

With the recent change in posture by the G-8, which has expressed a willingness to be more flexible and pragmatic about granting debt relief to countries other than those eligible for the Highly Indebted Poor Countries Debt Initiative, it is hoped that donors will grant Nigeria debt relief once they see convincing progress in implementing the reform programme. Resources generated from such relief would be used to fund poverty alleviation and employment generation programmes, especially in education, health care (HIV/AIDS), and other social infrastructure. Nigeria would also assess the opportunities provided under the global Debt for Nature Swap Initiative.
Generating Revenue from Other Sources

\section{Other sources of revenues include:} penalty interest on payments that are not nts and its agencies. The tissue of delayed payments by the government to its contro suppliers will be studied after settling existing arrears and "cleaning the budget."

existing arrears and "cleaning the budget. - Recovery of looted and misappropriated $\$ 600$ million) will be used to aument $\$ 600$ million) will be used to augment revenue item, however, these funds canno be relied on to cushion the budget beyond fiscal 2005. Efforts will continue to be made to track all misappropriated funds, including payments made to contractors who failed to perform.

- Partnership with the private sector. NEEDS is about partnering for accelerated growth and development. Its success - or failuredepends critically on private investment. Under the programme, the private sector is expected to invest three times as much as all the governments of the federation together. This is a great challenge. The government is committed to providing an enabling environment to promote private investment, even in areas traditionally reserved for government.

- Private sector investment in infrastructure. In the spirit of partnership, the private sector will be granted incentives to invest in infrastructure, especially in power generation and supply, telecommunications, and roads, railways, and ports. Accordingly, new strategies for increasing private sector participation such as bulld-operale-and-transfer (BOT), rehabilitate-operate-and-transfer (ROT),

schemes, will be pursued.

- Small and Medium-Size Enterprise

Investment Equity Scheme The fund accrued under the Small and Medium Enterprise Investment Equity Scheme be expeditiously but efficiently disbursed during the NEFDS period. Disbursement of the funds, which are expected to increase the funds, which are expected to increase tion of bankable projects. The Central Bank of Nigeria will facilitate the process by creating a Web site providing information on potentially profitable investments.

- Worker remittances. Remittances have increased in recent years, and they are expected to continue to do so during the period of NEEDS. They have become an increasingly important source of capital. 


\section{Abbreviations}

\begin{tabular}{|c|c|c|c|}
\hline ECOWAS & $\begin{array}{l}\text { Economic Community of West African } \\
\text { States }\end{array}$ & NERC & $\begin{array}{l}\text { Nigerian Electricity Regulatory } \\
\text { Commission }\end{array}$ \\
\hline \multirow[t]{2}{*}{ EFCC } & \multirow{2}{*}{$\begin{array}{l}\text { Economic and Financial Crimes } \\
\text { Commission }\end{array}$} & NEXIM & Nigerian Export Import Bank \\
\hline & & NGO & nongovernmental organization \\
\hline & $\begin{array}{l}\text { Group of Eight Countries } \\
\text { gross domestic product }\end{array}$ & NNPC & $\begin{array}{l}\text { Nigerian National Petroleum } \\
\text { Corporation }\end{array}$ \\
\hline GSM & $\begin{array}{l}\text { Global System for Mobile } \\
\text { Communication }\end{array}$ & OECD & $\begin{array}{l}\text { Organisation for Economic Co-operation } \\
\text { and Development }\end{array}$ \\
\hline HIPC & Heavily Indebted Poor Countries & OPEC & Organization of Petroleum Exporting \\
\hline \multirow[t]{2}{*}{ ICPC } & \multirow{2}{*}{$\begin{array}{l}\text { Independent Corrupt Practices and } \\
\text { Other Related Crimes Commission }\end{array}$} & & \\
\hline & & PRSP & Poverty Reduction Strategy Paper \\
\hline IDA & International Development Association & RMIS & Raw Materials Information System \\
\hline ISO & International Standards Organization & SEEDS & State Economic Empowerment and \\
\hline \multirow[t]{2}{*}{ LEEDS } & \multirow{2}{*}{$\begin{array}{l}\text { Local Economic Empowerment and } \\
\text { Development Strategies }\end{array}$} & \multirow{2}{*}{ SMEDAN } & \\
\hline & & & $\begin{array}{l}\text { Small and Medium Enterprise } \\
\text { Development Agency of Nigeria }\end{array}$ \\
\hline \multirow{2}{*}{$\begin{array}{l}\text { NACA } \\
\text { NACRDB }\end{array}$} & National Action Committee on AIDS & \multirow[t]{2}{*}{ SMEIES } & \multirow{2}{*}{$\begin{array}{l}\text { Small and Medium Enterprise } \\
\text { Investment Equity Scheme }\end{array}$} \\
\hline & $\begin{array}{l}\text { Nigerian Agricultural, Cooperative and } \\
\text { Rural Development Bank }\end{array}$ & & \\
\hline NEEDS & $\begin{array}{l}\text { National Economic Empowerment and } \\
\text { Development Strategy }\end{array}$ & UEMOA & $\begin{array}{l}\text { Union Économique et Monétaire de } \\
\text { l'Ouest Afrique }\end{array}$ \\
\hline NEPA & National Electric Power Authority & UNAIDS & $\begin{array}{l}\text { Joint United Nations Programme on } \\
\text { HIV/AIDS }\end{array}$ \\
\hline NEPAD & $\begin{array}{l}\text { New Partnership for African } \\
\text { Development }\end{array}$ & UNICEF & United Nations Children's Fund \\
\hline
\end{tabular}

